Appendix B

Geologic, Geomorphic and Chemical Characteristics of Wetlands Selected for Use in Biocriteria Development by the Montana Department of Environmental Quality

\author{
by \\ Mark D. Shapley \\ Montana Natural Heritage Program \\ 1515 East 6th Avenue \\ Helena, MT 59620 \\ for the \\ Montana Department of Environmental Quality \\ Water Quality Division \\ December, 1995
}

STATE DOCUMENTS COLLECTION

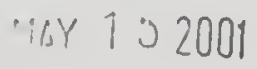

MONTANA STATE LIBRARY

1515 E. 6th AVE.

HELENA, MONTANA 59520 
Geologic, Geomorphic and Chemical Characteristics of Wetlands Selected for Use in Biocriteria Development by the Montana Department of Environmental Quality

\author{
by \\ Mark D. Shapley \\ Montana Natural Heritage Program \\ 1515 East 6th Avenue \\ Helena, MT 59620 \\ for the \\ Montana Department of Environmental Quality \\ Water Quality Division \\ December, 1995 \\ STATE DOCUMENTS COLLECTION

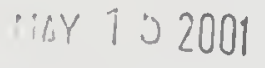 \\ MONTANA STATE LIBRARY \\ 1515 E. 6th AVE. \\ HELENA, MONTANA 59320
}


maR 62003 
Appendix B.

Narrative Summaries of the Physical Setting and Chemical Characteristics of the DEQ Wetland Characterization Sites 


\section{Alkali Lake}

climatic setting. The net annual precipitation balance for Alkali Lake (from the MAPS database) is approximately -13 inches. This places the site toward the less evaporative end of the climatic spectrum for closed basin sites, but near the more evaporative extreme for Rocky Mountain sample sites. Monthly average precipitation for the Fortine climatic station shows relatively even distribution throughout the year, with a moderate peak in May and June. Annual records from the Fortine station show the 3-year running average precipitation has been below the long-term mean during most of the last 30 years. Annual precipitation during the sample year of 1993 exceeded the average for the period of record by approximately 5 inches.

Geologic setting. The Alkali Lake basin is underlain by calcareous till and possibly other glacial sediment types of late(?) Wisconsin age. Shorelines are composed of coarse-grained sediments in high energy areas, marly mud in deeper water and sheltered littoral areas. Bedrock geologic units are of the Proterozoic Belt Series, probably including the calcareous and dolomitic Helena Formation.

Hydrologic type. Alkali Lake is a glacial depression lacking surface drainage at current water levels. Strandlines represented by tree kills indicate historic water levels within the past few decades which would have allowed surface discharge. Groundwater outflow is inferred from moderate salinity of this topographically closed basin.

Basin characteristics. Alkali Lake has a small surface catchment with respect to lake area and volume. The basin is linear and shallow at both ends, with a maximum measured depth in mid-basin of 37 feet. The cluster of lakes in the vicinity display disjunct water quality; Thirsty Lake, nearby and at a lower elevation, exceeds Alkali Lake in specific conductance by more than an order of magnitude. Road construction has partially isolated the eastern arm of the lake during high-water conditions.

Water chemistry. Alkali Lake is proportionately high in magnesium and is almost completely depleted in calcium; low calcium concentrations appear to be maintained by solubility controls, evidenced by deposition of authigenic carbonate minerals. High relative magnesium concentrations are typical of hydrologically similar sample sites. Equilibrium calculations indicate supersaturation with calcium and magnesium carbonate species.

In comparison to hydrologically similar sample sites, Alkali Lake exhibits relatively low water-column concentrations of trace elements. Total organic carbon concentrations are at the high end for the region and for hydrologically similar sites.

Chemical history. Specific conductance measurements from 1968 were 

approximately $25 \%$ lower than 1993 and 1994 measurements. Seasonal measurements in 1993 and 1994 show approximately 10\% difference in salinity. Vegetation indicators show considerably higher lake volume within the past few decades, implying significantly more dilute water chemistry. The measured salinity range within the lake basin was minor, amounting to approximately 5\% in specific conductance.

Sediments. Sediment trace element concentrations are generally low with respect to regionally and hydrologically similar sample sites. Trace elements found above detection limits (arsenic, boron, copper and $z$ inc) occurred at concentrations below the regional mean soil concentrations for these parameters (Shacklette and Boerngen, 1984 ). 


\section{Bandy Reservoir}

climatic setting. The net annual precipitation balance for the Bandy Reservoir site (from the MAPS database) is -15 inches, placing the site toward the more humid end of the range for hydrologically and regionally similar sites. Monthly average precipitation for the ovando 9 SSE climatic station shows a bimodal distribution, with a primary June peak and a secondary January peak. The 3-year moving average of total annual precipitation remained below (often considerably below) the long-term average from the mid-1970s through 1993. The total precipitation for 1993 (the year prior to sampling) was very near the long-term average.

Geologic setting. Bandy Reservoir is underlain by calcareous late pleistocene till deposited by ice advancing down Monture creek from sources in the Swan Range. Bandy Reservoir lies along the kettlepocked lateral moraine marking the westward extent of the Monture advance. The till is described as variable in texture and may overlie glacial deposits (including outwash) deposited by the slightly earlier clearwater glacial advance. Fine-grained Tertiary aged valley fill deposits underlie glacial deposits at unknown (but probably shallow) depths.

Bedrock geologic units in the source area for sediments deposited by the Monture advance include several distinct formations of the Proterozoic-aged Belt series; large areas are underlain by the calcareous and dolomitic Helena Formation.

Hydrologic type. Bandy Reservoir is an artificial impoundment of a natural basin that probably had a prior history as a smaller natural water body. Presently it provides off-stream storage of water diverted from Shanley Creek. Discharge is back to Shanley creek (and to local irrigated areas?). Water levels are manipulated for irrigation storage purposes, and probably do not reflect natural water level fluctuations of unmanipulated nearby lakes.

Basin characteristics. The natural (closed) catchment of Bandy Reservoir is small and probably supported only a minor (perhaps seasonal) pond or wetland similar to many others along the Monture moraine. As a reservoir, it receives inflow from a large catchment and has a relatively high catchment to wetland area ratio. Diversion rates and lake volume are unknown, but the flux of water through the reservoir is probably relatively rapid.

Water chemistry. At the time of sampling, Bandy Reservoir contained dilute ("fresh") but highly alkaline calciummagnesium/carbonate water. Equilibrium calculations indicate oversaturation with carbonate species at the sampled $\mathrm{pH}$. Phosphorous, nitrogen and total organic carbon concentrations were near the low end of the ranges for hydrologically and regionally similar sites. Most trace element concentrations were below detection limits. Arsenic and copper were found at concentrations 

near the low end of ranges for similar sites.

Chemical history. No chemical data other than those from the DHES sampling are known for Bandy Reservoir. It is reasonable to infer that flushing with dilute, high-quality water from Shanley creek maintains dissolved constituents within a relatively narrow range. Prior to hydrologic manipulation, the basin may have developed somewhat more saline water similar to nearby closed ponds and wetlands.

Sediments. Arsenic, boron, copper and zinc were found at low to mid-range concentrations in comparison to hydrologically similar sites. Selenium and mercury were reported at their respective detection limits; values for both elements approximate mean concentrations in soil and other surficial material of the western U.S. . 

climatic setting. The net annual precipitation balance for the Beaver Creek site (from the MAPS database) is -6 inches, placing the site near mid-range in evaporative intensity for Rocky Mountain sample sites. [At absolute values in this range, the "annual precipitation balance" should definitely be considered only a relative scaler of evaporative intensity, not an indicator of the true sign of the site's moisture balance.] Mean monthly precipitation for the Seeley Lake Ranger station climatic station shows a bimodal distribution with the primary peak in January and a secondary June maximum. The 3-year running average at seeley Lake shows an apparent periodicity in annual precipitation, with a period of five to six years. Since the early 1970 's, the threeyear average has been mainly below the average for the period of record. Total precipitation in 1993 (the year prior to sampling) was about 3 inches below average.

Geologic setting. The Beaver creek site is underlain by till (and other glacial sediments?) deposited by the late Pleistocene advance of glacial ice down Placid Creek. The texture of the till in the general area is described as sandy; soil drainage, however, is described as poor. Bedrock formations underlying the area inferred to have contributed glacial sediments to the site include mainly noncalcareous formations of the late Proterozoic Belt series.

Hydrologic type. The Beaver creek wetland is an apparent kettle lacking discrete surface water inflow or outflow. Mineral equilibria (see below) may reflect either a ground-water recharge position for this site, or a lack of carbonate lithologies in local geologic materials.

Basin characteristics. The WET03 site is one of a cluster of poorly integrated depressions forming a stepwise profile across an interfluvial plateau. Ground-water flow between depressions is inferred from the lack of surface drainage and dilute water quality of the sample site. The calculated ratio of catchment to wetland area is toward the higher end for sites included in this type; the surface catchment used, however, does not discriminate small internally drained areas and so may not be meaningful to the hydrology of the wetland site. Road construction may have altered drainage from this wetland.

Water chemistry. The Beaver Creek wetland displays very dilute calcium bicarbonate chemistry. The measured total dissolved solids concentration was among the lowest in the sample set. Mineral equilibria indicate substantial undersaturation with carbonate species. Phosphorous concentrations were near the low end of the range for all sample sites, nitrate was below detection limits, and the ammonium concentration was mid-range for hydrologically similar sites. The total organic carbon concentration was among the upper $50 \%$ of hydrologically similar sample sites. 

Most trace elements were below detection limits; the copper concentration was mid-range among hydrologically similar sample sites.

Chemical history. No chemical data other than that provided by the DHES sampling are known for this site.

Sediments. Extractable concentrations of most trace elements are below detection limits or well within the range for hydrologically similar sites. Selenium and nickel were found near the high end of their ranges for similar sites. Mercury was reported at the detection limit. Copper, nickel, boron and mercury concentrations approximated mean values for soils and other surficial materials in the western U.S. Selenium exceeded the western U.S. mean by a factor of about 2 . 


\section{Bent Flat Fen Proposed RNA}

climatic setting. The net annual precipitation balance for the Bent Flat fen (from the MAPS database) is -4 inches, placing this wetland toward the middle of the range shown by Rocky Mountain sites. Mean monthly precipitation values for the Hungry Horse Dam climatic station shows a bimodal distribution with June and January peaks. The recent record for this climatic station is fragmentary; annual totals for 1991 and 1992 were below average for the period of record.

Geologic setting. Bent Flat is a calcareous fen underlain by 2 meters of less of peat and organic-rich marl. The fen sediments are deposited over a surface of dense, clay-rich till. Active precipitation of carbonate minerals occurs in a complex of pools, channels and vegetation mats forming string-and-flark patterning approximately along the topographic contour of the fen surface. The fen is supported by ground-water discharge from upland springs within a few hundred meters upgradient. Adjacent upland slopes are underlain by tufa and travertine deposited by these springs.

The springs are believed to represent ground-water discharge from Cambrian limestones underlying slopes and peaks to the east and northeast.

Hydrologic type. Bent Flat is a patterned fen (unusual in Montana) with inflow provided by short streams fed by nearby ground-water discharge. Outflow occurs by a peripheral stream and by channelized outflow from the toe of the wetland.

Basin characteristics. Ground-water supporting the Bent Flat fen is recharged over an unknown area. Flow within the fen is complex, following convoluted surface pathways through interconnected pools (flarks) and moving as shallow groundwater flow through the vegetation mat. The fen is developed on a low-gradient slope at the base of a steep glaciated ridge. Where examined, the hydraulic conductivity of the underlying glacial materials appears to be low.

Water chemistry. Bent Flat Fen contains relatively dilute, mildIy alkaline calcium-bicarbonate water which actively precipitates calcite as it moves from the ground-water environment to the fen. Saturation with calcium carbonate phases is shown by the ubiquitous deposition of authigenic calcite (and/or aragonite?) around the outlet springs and within the fen. Deposition may be seasonal, as equilibrium calculations indicate slight calcite undersaturation under cold ( 3 degrees C) temperatures.

Nitrogen (nitrate plus ammonium) concentrations rank in the upper third among hydrologically similar sites; phosphorous concentrations are near the lower end of the range. The total organic carbon concentration at the time of sampling was toward the upper end of the range shown by hydrologically similar sample sites. 

Chemical history. Prior to the DHES sampling, two water quality samples were collected from Bent Flat in November of 1993. One sample came from the immediate area of the springs supplying the fen. The other was collected from near the lower end of the fen, bracketing the WET04 site. Generally, major ion chemistry varied little between the three samples; the springs probably provide quite stable inlet water chemistry. Minor differences should be expected due to dilution and concentration effects and possibly because of changing rates of carbonate precipitation.

Nutrients, however, are more directly tied to biological activity within the fen and appear to show important spatial and seasonal variability. In November of 1993, nitrate and ammonium concentrations both decreased substantially (and disproportionately to minor dilution effects) between the inlet and lower fen sites, while total phosphorous and total organic carbon concentrations increased by factors of four and five respectively. In september 1994, the WETO4 site showed total phosphorous and TOC concentrations respectively seven and ten times higher than the lower fen site of November 1993.

Sediments. An exceptionally high concentration of extractable calcium (24\%) reflects the marly nature of Bent Flat sediments. Arsenic, boron, mercury, selenium and zinc occurred in detectable concentrations in the sample of Bent Flat sediment. All were found at low concentrations in comparison to the rest of the data set, with the exception of mercury and selenium. The reported mercury concentration was slightly above the western U.S. mean for soils and other surficial materials, and the selenium concentration exceeded the western U.S. mean by a factor of about 2 . 



\section{Benton Lake National Wildlife Refuge}

climatic setting. The net annual precipitation balance for Benton Lake (from the MAPS database) is -27 inches, placing the site toward the more evaporative end of the range for it's class. Average monthly precipitation for the Great Falls Airport climatic station shows a strong May-June peak. Between 1980 and 1993, the three-year running average of annual precipitation remained near the mean for the period of record, despite several extreme years. In 1993 (the year of sampling), annual precipitation exceeded the average by more than 7 inches. The 1992 total was about 2.5 inches below average.

Geologic setting. Benton Lake is underlain by a thick sequence of glaciolacustrine sediments deposited in Glacial Lake Great Falls during late Pleistocene time. Glacial Lake Great Falls sediments in the Benton Lake basin are described as composed dominantly of plastic clay. Till and other surficial materials underlie other portions of the catchment. Underlying pre-Quaternary formations include the Marias River shale and the Blackleaf Formation.

Hydrologic type. Benton Lake is a highly managed system relying on pumped importation of water from Muddy Creek. There is no surface water outflow and due to topographic position and geologic characteristics, no likelihood of significant ground-water outflow. A large fraction of the Muddy Creek water delivered to Benton Lake consists of irrigation return flows from the Greenfields Division of the Sun River Irrigation Project.

Basin characteristics. The catchment to wetland area ratio for Benton Lake is toward the low end of the range for the sample set. However, Benton Lake inflows are managed by manipulation of imports from Muddy creek. Benton Lake itself is subdivided by dikes into six separate pools with sequentially lower interconnecting spillways from the inlet pool to the southeastern end of the lake. Salinity and disease management involves flooding only some of the pools during any given year, while others stand dry.

Water chemistry. At the time of sampling in August 1993, Benton Lake Pool \#1 contained alkaline, "oligosaline" water of mixed cation/sulfate chemistry. Mineral equilibria indicate oversaturation with carbonate phases and moderate undersaturation with respect to gypsum. The nitrate concentration was very high, while phosphorous (total and orthophosphate) and total organic carbon concentrations were toward the low end of the range for the wetland type and region. The water column selenium concentration was the highest of the five sample sites for which detectable selenium was reported. WET05 was also among the five sites with detectable nickel reported from the water column. The reported arsenic concentration was among the lowest for the sample sites.

Chemical history. Monitoring programs of the U.S. Fish and Wildife service and the USGS have generated an intensive (if 

brief) water quality data set for Benton Lake. Since 1990, specific conductance in pond \#1 has varied across more than an order of magnitude, with a maximum reported concentration of 10920 microsiemens $/ \mathrm{cm}$. Three reported selenium concentrations ranged from .001 to $.011 \mathrm{mg} / 1$. Spatial variability within the Benton Lake complex can also be substantial. Synoptic sampling in August of 1986 showed pool \#5 (the southeastern quadrant of the lake) to have specific conductance approximately four times higher than pool \#1; reported boron concentrations were higher in pool \#5 by a factor of about 3 , and arsenic was reported from pool \#5 at 63 times the concentration reported for pool \#1.

Sediments. The WET05 site exhibited the highest sampled concentration of nickel and the highest $z$ inc and second highest selenium concentrations for a site in it's classification. WET05 was one of only five sites with a reported (barely) detectable concentration of extractable cobalt. Sediment trace element concentrations appear to show less spatial variability within the Benton Lake complex than do water column concentrations. The reported nickel concentration exceeds mean values for soils and other surficial materials of the western U.S. by a factor of 4 . Selenium, zinc and cobalt exceed the regional soil means by factors of 1.5 to 2 . 


\section{Big Lake}

climatic setting. The MAPS database value for the net annual precipitation balance at Big Lake is -28 inches, placing the site among the most strongly evaporative of the sample wetlands. Mean monthly values for the Rapelje climatic station show a strong MayJune peak in precipitation. The 3-year running average of total annual precipitation appears to show periodicity, with 6 to 9 years between peaks. Between 1975 and 1992, the 3-year average remained at or above the long-term mean during most year. Data for 1993 and 1994 were not retrieved for this station.

Geologic setting. According to published geologic mapping, the Big Lake basin is underlain by the Bearpaw shale and lies along the eastern limb of the Lake Basin Anticline, a structural trap for hydrocarbons which supports oil and gas production in the area. outcrops in the immediate vicinity of WET06 are a well-cemented, medium grained sandstone believed to be the virgelle sandstone. Surficial sediments at the sampling site are composed of moderately well-sorted sand, with finer grained material accumulated in surface depressions created during the alteration excavation and alteration of the site.

Hydrologic type. Big Lake proper is a structurally controlled depression lacking surface outflow, which receives runoff from the entire Cedar Creek basin. The WET06 site is a reconstructed basin at the inlet to cedar creek, intended to retain water from Cedar creek during low-water periods. The WET06 site drains to the greater Big Lake basin, which has slightly lower elevation than the reconstructed wetland. Water also probably exits the sample site by infiltration into the sandy, recently disturbed substrate.

Basin characteristics. The large ephemerally flooded Big Lake basin has a low ratio of catchment to wetland area. The small wildlife enhancement site sampled at WET06, however, has a very high catchment to wetland ratio. The enhancement site is controlled by overflow to Big Lake proper at a maximum water depth of approximately 3 feet, or about 1.5 feet deeper than during the conditions observed in October 1994. Turnover of water in the sample site would be relatively rapid during Cedar Creek runoff events. Excavated depths vary within the enhancement site.

Water chemistry. At the time of sampling, the WET06 site contained "hypersaline" sodium sulfate water with relatively low bicarbonate and carbonate concentrations. Mineral equilibria indicate substantial oversaturation with carbonate species and nearequilibrium with gypsum (corroborated by the formation of authigenic gypsum(?) in samples collected in october 1994).

Phosphorous concentrations were moderate in comparison to hydrologically similar sites, while the ammonium and total organic carbon concentrations were toward the high end of the range for sites of this type. 

Along with nearby Hailstone and Halfbreed Wildlife Refuges, Big Lake was one of a small handful of sample sites with detectable nickel found in the water column. Boron and zinc concentrations were relatively high in comparison to hydrologically similar sample sites. The arsenic concentration was below detection, unusual among the sampled sites.

Chemical history. No water quality analyses prior to the DHES sampling are known. During October of 1994 (six months after sample collection) field chemical parameters ( $\mathrm{pH}$ and specific conductance) were spatially variable within the small constructed wetland area. Specific conductance measurements ranged from less than half that reported at the time of sampling, to $10 \%$ higher; the configuration of the constructed site may discourage rapid mixing of inflow from Cedar creek. Water quality of Cedar Creek reflects evaporative concentration in upgradient water bodies (including Halfbreed Lake) and may be influenced by upgradient water management. No surface water quality data from Big Lake proper are known. In October 1994, the Big Lake basin retained surface water in a relatively small area near the center of the basin.

Sediments. In comparison to hydrologically similar sample sites, most trace elements were found in low to intermediate concentrations. The exceptions were selenium and vanadium; for these elements WET06 was at or near the top of the sampled range for similar sites. The selenium concentration was above the mean for soils and other surficial deposits of the western U.S. 



\section{Big Sandy DOT Mitigation Wetland}

climatic setting.

The net annual precipitation balance for the Big Sandy site (from the MAPS database) is -26 inches, placing it toward the middle of the range for sample sites with which it is classified. Mean monthly precipitation shows a well-defined June maximum. The three-year moving average of annual total precipitation remained near or above the long-term average for most of the 1975-1990 period. The annual total in 1993 (the year prior to sampling) exceeded the long-term average by about 5 inches.

Geologic setting. The WET07 site is underlain by fine-grained paludal deposits capping the in-filled channel of the preglacial Missouri River. Geologic mapping shows stratified ice-contact deposits (kame terrace and esker) immediately upslope of the site, which may receive ground-water discharge from these sediments. 100 feet or more of alluvial fill underlies the paludal deposits in this area; this alluvium provides ground-water of variable water quality. The bedrock surface underlying the surficial deposits is comprised of the late cretaceous claggett shale Judith River Formation.

Hydrologic type. Although located along a major intermittent(?) stream, the immediate sample site is an excavated basin reportedly lacking surface water outflow. Inflow is reported to be from ground-water sources.

Basin characteristics. The catchment to wetland area ratio for this site is very high if Big Sandy creek contributes to the wetland's water balance. The reported lack of surface water inflow indicates the site may not be integrated into the Big sandy drainage. Artificial excavation as a highway mitigation site is inferred to create disturbed and probably transient substrate conditions.

Water chemistry. Water of the Big Sandy wetland was of a relatively dilute (particularly for a Great plains site), moderately alkaline sodium bicarbonate character. The WET07 analysis is at the lower end of the dissolved solids range reported for ground-water from surficial deposits in the area, and considerably more sodic in composition than similarly dilute ground-water samples. This distinction suggests shallow groundwater may not be the primary water source for the wetland. Mineral equilibria indicate oversaturation with carbonate species.

Nitrogen (nitrate plus ammonium), phosphorous (total and orthophosphorous) and total organic carbon concentrations are all toward the lower end for the class including WET07. Selenium was reported at the analytical detection limit; water column selenium was reported at only four other sample sites. Arsenic and boron concentrations were toward the low end of the range for site of this class. Most other trace elements were below detection limits. 

Chemical history. No chemical data other than the DHES analysis are known for this site.

Sediments. Those extractable trace elements reported above detection limits were in the low to mid-range when compared with similar sampling sites. Only boron exceeded (marginally) the mean value for soils and other surficial materials of the western U.S. 



\section{Black Coulee National wildlife Refuge}

climatic setting. The net annual precipitation balance for Black Coulee (estimated from the MAPS database) is -26 inches, placing the site near the center of the range shown for Great Plains sample sites. Mean monthly precipitation for the (inactive) Turner climatic station shows a strong June peak. Annual totals for the Harlem $4 \mathrm{~W}$ station (the most relevant active station) are fragmentary since the early 1970s. From 1990 through 1992 (the three years prior to sampling) annual totals were below the longterm average.

Geologic setting. The Black coulee site is underlain by till of uncertain character, possibly deposited as part of a marginal moraine complex ringing the Turner Plateau. Local alluvium within the Black Coulee drainage is probably composed of reworked till and sediments derived from the late Cretaceous Bearpaw Shale, which underlies surficial deposits in the area.

Hydrologic type. Black coulee NWR is an artificial impoundment inferred (by low salinity) to have spilled water regularly during the recent past.

Basin characteristics. Black coulee has a catchment to wetland area ratio in the mid-range for sample sites in it's class. A number of other, smaller reservoirs within the basin probably influence the runoff characteristics of the catchment, as may areas of internal drainage within the northern portion of the mapped catchment. Surficial and bedrock materials exposed in the basin are generally not amenable to much ground-water flow.

Water chemistry. At the time of sampling, water at Black coulee NWR was of a relatively dilute, moderately alkaline mixedcation/bicarbonate character with proportionately low calcium concentration. Mineral equilibria indicate near-equilibrium with respect to calcite and aragonite. Nutrient concentrations were low to moderate in comparison to sample sites of this class. Arsenic and boron concentrations were low in comparison to similar sample sites, and with the exception of lead, other trace element concentrations were below detection limits. Lead was reported at the detection limit, one of a handful of sites with reportable concentrations.

Chemical history. No other water chemistry data from Black coulee are known. Previous sediment sampling was conducted by the U.S. Fish and Wildlife service (see below).

Sediments. Black Coulee was at or near the high end of the range for it's class in a number of trace elements, including arsenic, copper, chromium, and nickel. Western U.S. mean values for soils and other surficial deposits were exceeded for arsenic (by a factor of about 2), boron (2), copper (1.5), and cobalt (1.5). Reported values for nickel and zinc barely exceeded the regional soils 

means.

A sediment sample collected in 1987 by the U.S. Fish and Wildlife Service shows a similar pattern of trace element elevation, with reported concentrations for individual elements differing from the DHES results by as much as a factor of 2 . 



\section{Blackfoot Meadows}

climatic setting. The net annual precipitation balance for Blackfoot Meadows (from the MAPS database) is -2 inches, placing the site near the humid end of the range shown by the sample sites. Mean monthly precipitation for the Basin climatic station (across a major drainage divide from the site) shows a bimodal distribution, with a primary June maximum and a secondary January peak. The three-year running average of annual precipitation for the Boulder station (also at some distance from the site) shows values below the long-term mean for much of the $1980 \mathrm{~s}$ and near or above the long-term average for 1990-93, with precipitation in 1993 (the year of sampling) almost 6 inches above average. [Water supply to Blackfoot Meadows is probably supported mainly by winter snowpack, however, which is not reflected in data from these lowelevation stations.]

Geologic setting. Surficial deposits in the upper Little Blackfoot basin have been interpreted as glacial in origin, derived from local igneous lithologies. Blackfoot Meadows itself is underlain by alluvial and paludal deposits of unknown depth. Bedrock in the contributing drainage basin is composed of felsic to intermediate volcanic and intrusive lithologies of late Cretaceous and early Tertiary age. Outcrops in the immediate area of Blackfoot Meadows are Tertiary rhyolitic tuffs.

Hydrologic type. Blackfoot Meadows is an area of low hydraulic and topographic gradient along the channel of the Little Blackfoot River. Inflow is from the Little Blackfoot and tributary streams, and outflow is via the Little Blackfoot River. The valley profile. and cross-section suggest alluvial deposition in an over-deepened or geologically impounded valley segment. Beaver activity now influences throughflow and stream gradients.

Basin characteristics. The catchment contributing to this wetland has high relief and an intermediate catchment to wetland area ratio for Rocky Mountain sites. The distribution of different hydrologic regimes within the wetland is probably relatively transient due to the activities of beavers.

Water chemistry. Water chemistry at this site is mildly acidic and very dilute. Mineral equilibria indicate substantial undersaturation with respect to the phases evaluated, but censored data and poor ion balance limit the usefulness of these calculations. Nitrate and ammonium concentrations were below detection limits; the orthophosphorous concentration was mid-range among sites of this class, and the total organic carbon concentration was toward the lower end of the class range.

Arsenic was reported at twice the detection limit (mid-range for sites of this class), and iron was reported at a concentration midrange for the sample set. Most other trace element concentrations were below detection limits. 

Chemical history. No other chemical data for Blackfoot Meadows are known. Little spatial variability should be expected; somewhat higher mineralization would probably be seen at other times of year when base flow conditions in the Little Blackfoot River are approached.

Sediments. Extractable concentrations of most trace elements were below detection limits. The arsenic concentration was in the upper half among sites of this type; zinc, copper, manganese and iron were toward the lower end of their respective ranges. None significantly exceeded regional western U.S. means for soils. 


\section{Blackfoot waterfowl Production Area}

climatic setting. The net annual precipitation balance for the Blackfoot WPA (from the MAPS database) is -12 inches, putting the site toward the moist end the range shown by this site class. Mean monthly precipitation for the Ovando 9SSE climatic station shows a bimodal distribution, with a primary June maximum and a secondary January peak. The 3-year running average of total annual precipitation for this station has remained below (often well below) the long-term average for most of the period since the mid1970s. Total precipitation in 1993 (the year of sampling) approximated the long-term average.

Geologic setting. The Blackfoot WPA site is underlain by late pleistocene glacial outwash(?) elevated a few feet above, and graded to, the floodplain of the nearby Blackfoot River. The source area for the glacial sediments is the basin of the North Fork of the Blackfoot River.

Bedrock in the small contributing catchment includes formations of the Ravalli Group of the Proterozoic Belt series and cretaceous and Tertiary igneous rocks. Mineralization associated with these igneous rocks occurs nearby. Formations exposed in the North Fork basin include Proterozoic and Cambrian limestone and dolomite.

Hydrologic type. The Blackfoot WPA site is a shallow glacial basin (kettle?) augmented by dikes and equipped with an outlet control structure. Prior to the WPA enhancement project, the natural wetland had been ditched and largely drained. Inflow to the wetland is via culverts beneath Highway 200, which isolates the site from most of it's natural surface catchment and from reported spring sources on the upgradient side of the road.

Basin characteristics. The broad, shallow(?) natural basin of this wetland has been altered by both diking and excavation to provide deeper-water and more perennial conditions. The natural catchment is relatively small relative to the wetland area, but ground-water discharge apparently supporting the wetland would not necessarily be expected to follow the low northern drainage divide. Surface drainage from upgradient areas is altered by the existence of Highway 200.

Water chemistry. Water collected from the Blackfoot WPA was relatively dilute, mildly alkaline and dominated by bicarbonate, calcium and magnesium ions. Mineral equilibria indicate slight undersaturation with carbonate phases. Nitrate, ammonia and orthophosphorous concentrations were low; the total organic carbon concentration was mid-range for sample sites similarly classified.

Arsenic and copper were found at concentrations near the lower end of the ranges shown by sites of this class. Most other trace element concentrations were below detection limits. 

Chemical history. No other chemical data are known for this site. Unmanipulated closed-basin lakes and wetlands in the vicinity often develop more alkaline and somewhat more saline water chemistry characteristics than shown by WET10, possibly giving an indication of this site's general character prior to alteration.

Sediments. Extractable arsenic, copper and zinc were reported at mid-range concentrations for sample sites similarly classified. only copper exceeded the western U.S. mean for soils and other surficial materials (by a factor of about 1.25). 



\section{Brush Lake}

Climatic setting. The net annual precipitation balance for Brush Lake derived from the MAPS database is -23 inches, toward the less evaporative end for sites in this class. Based on analyses of evaporation pan data, this is a considerable underestimate Brush Lake's water deficit, and points out the need to view the MAPS estimates only as relative indicators of net site precipitation. Mean monthly precipitation for the Medicine Lake climatic station shows a pronounced June maximum. Annual totals for this station show apparent periodicity with a 5 to 7 year cycle. Throughout the 1980 s, the 3-year running average remained below (often well below) the long-term average, recovering in the early 1990s. In 1993 (the year before sampling) precipitation exceeded the long-term average by more than 1 inch.

Geologic setting. Brush Lake occupies an ice-block depression (kettle) in the sequence of late Pleistocene outwash sand and gravel forming the clear Lake aquifer. Surficial sediments within the lake basin are dominated by authigenic carbonate minerals precipitated from in-flowing ground water. Glacial sediments are underlain at depth by the early Tertiary Fort Union Formation.

Hydrologic type. Brush Lake is a glacial depression lacking surface water outflow or significant surface water inflow. Flowthrough ground water dynamics in an evaporative setting maintain water chemistry within a limited range. Brush Lake is believed to have been internally drained (with respect to surface water) and perennial throughout postglacial time. In-flowing ground-water is supersaturated with carbonate phases upon loss of $\mathrm{CO}_{2}$ to the atmosphere, resulting in the deposition of extensive tufa and marl deposits.

Basin characteristics. Brush Lake has a minimal surface catchment, exhibiting the lowest surface catchment to wetland area ratio of any sample site. The lake basin is relatively steep-sided and deep: maximum lake depth is approximately 60 feet. Regional ground-water flow through the clear lake aquifer and it's tributary Grenora channel flows through Brush Lake, controlled by local stratigraphy, aquifer head distribution and evaporative withdrawals.

Water chemistry. Brush Lake contains alkaline, "oligosaline" sodium-sulfate/carbonate water almost completely depleted in calcium. Major-ion aqueous chemistry is controlled by the precipitation of calcium and magnesium carbonates. At the time of sampling, nitrogen (nitrate and ammonia) concentrations were below detection limits, and phosphorous concentrations (total and orthophosphorous) were near the lower end of the range shown by sample sites in this class.

In arsenic and boron concentrations, Brush Lake was among the upper $25 \%$ among it's classification. The reported iron concentration was 

low with respect to all sample sites, and most other trace elements analyzed were below detection limits.

Chemical history. Brush Lake has a record of field and quantitative water chemistry analyses related to investigations of the Clear Lake aquifer system and to the dynamics of ground-water supported evaporative lakes. Specific conductance measurements dating back to 1984 show an overall range from 5360 to 6140 microsiemens/cm with a relatively well-mixed, near-homogeneous water column during summertime conditions. Monthly time-series water quality sampling conducted in 1984 and 1985 has not yet been analyzed. Brush Lake is believed to have been perennial throughout it's Holocene history.

Sediments. Sedimentation in Brush Lake is dominated by authigenic tufa and marl formation, in part mediated by biological activity. Detrital sediments are a relatively minor component of the system. However, the WET11 sampling site is along a relatively exposed, winnowed shoreline and allogenic detrital material may be overrepresented in this sample relative to other littoral areas. Extractable calcium and magnesium concentrations in the percent range would be expected from different shoreline settings.

Extractable arsenic was reported at the second-highest concentration for this sample site classification. Boron, iron, manganese and zinc were reported at concentrations near the lower end of the ranges shown for this site classification. Most other trace elements were below detection limits. Arsenic exceeded mean soil concentrations for the western U.S. by a factor of about 2 . 


\section{Burns Creek}

climatic setting. The net annual precipitation balance for the Burns Creek site (estimated from the MAPS database) is -26 inches, toward the less strongly evaporative end of the range shown by sites in this classification. Mean monthly precipitation for the Savage climatic station shows a pronounced June maximum. For most of the 1980s, the 3-year running average of annual precipitation remained below the long-term average for the Savage station. From 1990 through 1993, the 3-year average was near or above the longterm average. In 1993, the year prior to sampling, precipitation exceeded the long-term average by about 2 inches.

Geologic setting. The Burns creek drainage is incised into early Tertiary sandstone, shale and clinker of the Fort Union Formation, overlain in places by the Miocene Flaxville Formation or equivalents. Sediments deposited in the Burns Creek valley may reflect late Pleistocene glacial drainage across the Burns Creek/Redwater River divide; alluvium associated with the North Fork of Burns Creek appears to be unusually thick and permeable for a prairie stream, and probably includes glacially transported calcareous material. Ground water stored in this alluvium supports a wetland complex and is drained by lower Burns Creek.

Permeable surficial or near-surface material (Flaxville Formation gravels and/or clinker) caps the upland surface in many areas: where incised by Burns Creek, stratigraphically controlled groundwater discharge occurs. Contact springs of this type help support flows in Burns creek and the WET12 wetland.

Hydrologic type. The Burns creek wetland occupies an unglaciated setting influenced by periods of fluvial erosion and deposition by glacial drainage. The site has at least intermittent surface water inflow and outflow and may also be supported by local ground-water discharge. The contributing surface drainage basin probably receives contact-controlled ground water discharge in it's headwaters.

Basin Characteristics. The WET12 site is near the confluence of Burns creek and the North Fork of Burns Creek. The (estimated) ratio of catchment to wetland area is toward the high end of the range shown by sites classified with wET12. The North Fork of Burns Creek is known locally to flow only during runoff, probably due to the relative permeability and depth of the North Fork alluvium. Burns Creek (mainstem) is also underlain by permeable gravels which support moderately yields from a nearby irrigation well.

The Burns Creek road probably influences runoff and ground-water flow paths in the vicinity of the WET12 site.

Water chemistry. At the time of sampling, WET12 water was of a moderately alkaline "oligosaline" character. Divalent cations 

(calcium and magnesium) and sodium were present in similar proportions. Mineral equilibria indicate oversaturation with carbonate phases. Nitrate and ammonia concentrations were below detection limits, and phosphorous concentrations (total and orthophosphorous) were near the lower end of the ranges shown for all sample sites.

Arsenic, boron, copper and iron concentrations were low to moderate in comparison to similarly classified sites. Zinc and lead were reported at concentrations near the high end of the range shown for the classification. Most other trace element concentrations were below detection limits.

Chemical history. No other water quality data from this site are known. The site is probably leant hydrologic stability by groundwater storage in the Burns Creek alluvium and (possibly) in upland gravels and clinker; water quality variability may be less than for many of the plains sampling sites.

Sediments. Extractable copper, boron, arsenic, vanadium, nickel and $z$ inc were all reported at concentrations near the lower end of their respective ranges for sites classified with Burns Creek. The reported boron concentration exceeded the mean for western U.S. soils by a factor of two; concentrations of other elements were below regional mean soil values. 



\section{Colter Campground}

climatic setting. The net annual precipitation balance estimated from the MAPS database for the colter Campground is 44 inches. Because both precipitation and evaporation estimates are subject to large uncertainties in this high-relief setting, this value is not thought to have significance beyond indicating the precipitation-surplus character of the site. Mean monthly precipitation for the cooke City climatic station shows relatively evenly distributed precipitation throughout the year. Annual totals for Cooke City show below-average values throughout the late 1980 s and early 1990s. The total precipitation in 1993 (the year prior to sampling) was near the average for the period of record.

Geologic setting. Glacial deposits of unknown but probably coarsegrained character underlie the site and are inferred to impound the wetland basin. Local lithologies which are inferred to have contributed to glacial sediments include Archaean gneiss and (probably) mafic to intermediate volcanic and intrusive rocks and (possibly) Paleozoic sedimentary formations. At the site of the sample wetland, glacial deposits overlie metamorphic rocks of Archaean age.

Hydrologic type. The colter Campground wetland is a high-elevation glacial depression lacking mapped surface water inflow or surface water outflow. Because the site is in an area of precipitation surplus yet lacks surface outflow, it is inferred that ground-water outflow is important to the wetland's water balance.

Basin characteristics. The surface catchment to wetland area ratio derived from topographic mapping of this site is relatively high. Map information may underestimate the area of the wetland, however. Inflow to the wetland is inferred to be from runoff and local ground-water flow within the small catchment, driven by relatively high precipitation rates.

Water chemistry. The colter Campground wetland contains dilute, near-neutral calcium/bicarbonate water. Mineral equilibria indicate substantial undersaturation with respect to carbonate phases. Nitrate and ammonia concentrations were below detection limits at the time of sampling. Orthophosphorous and total phosphorous concentrations were low in comparison to sample sites of all classes. The total organic carbon concentration reported is mid-range with respect to the range shown by sample sites of this class.

Among sample sites in the same class, WET13 ranks near the middle in iron concentration. Most trace elements were reported to be below detection limits.

Chemical history. No other chemical data for this site are known. By inference, water chemistry in this site probably varies over a narrow and dilute range. 

sediments. The reported zinc, nickel, lead and selenium concentrations ranked this site toward the upper end of the ranges shown by this site classification. Reported arsenic, boron and copper concentrations ranked low to intermediate within the site classification. The reported selenium concentration exceeded the mean soil concentration for the western U.S. by a factor of 1.7; the zinc concentration exceeded the western U.S. mean by a factor of less than 1.2 . 

climatic setting. The net annual precipitation balance for the Comertown Preserve site (from the MAPS database) is -20 inches, ranking the site toward the less evaporative end of the range shown for this classification. Mean monthly precipitation for the Westby climatic station shows a pronounced June maximum. Annual total precipitation records are incomplete through the 1980 s for the westby station. For the years available during the 1980s, 3-year averages of the annual total were well below the average for the period of record. Regional trends during the missing years (198587) indicate precipitation was above average in 1986 and below average in 1985 and 1987. The 3-year average was near or above the long term average in the early 1990 s.

Geologic setting. The comertown Preserve is underlain calcareous till of late Pleistocene age. Geologic mapping shows isolated deposits of stratified glacial drift in the general vicinity of the preserve, but the site lies well to the west of the known distribution of regional gravel aquifers. The till and other surficial deposits are underlain by the early Tertiary fort Union Formation.

Hydrologic type. The comertown preserve site is a glacial depression (kettle) lacking surface outflow under most(?) conditions. During moist periods, the pond may be joined with adjacent intermittently flooded depressions. The comparatively dilute water chemistry observed at the site suggests ground-water outflow may be significant to the site's water and solute budgets.

Basin characteristics. Based on available topographic mapping, the Comertown preserve appears to have only a minimal surface catchment beyond the wetland itself. However, the fine scale knob-and-kettle topography characterizing the area makes it difficult to be sure of the true position of local drainage divides. Overflow from adjacent, apparently separate basins, may occur.

Water chemistry. At the time of sampling, comertown Preserve held alkaline, "oligosaline" water lacking dominant ionic composition. Equilibrium calculations indicate substantial oversaturation with carbonate phases. Ammonium, orthophosphorous and total organic carbon concentrations ranked this site ranked this site toward the upper end of it's classification. Most trace elements were below detection limits in the water column. Reported arsenic and boron concentrations ranked the site toward the lower end of it's class, while zinc and copper concentrations ranked in the upper half within the site's classification.

Chemical history. No other chemical data for this site are known.

Sediments. Arsenic, boron, copper and zinc concentrations rank this site toward the middle or lower end of it's classification. Chromium, nickel, selenium, and vanadium concentrations ranked 

toward the higher end of the classification. Boron exceeded mean soil concentrations for the western U.S. by a factor of 2 and selenium by a factor of 1.7. Other trace element concentrations were below the regional mean soil values. 



\section{Condon Creek Proposed RNA Pond 1}

climatic setting. The net annual precipitation balance for the Condon Creek sites (from the MAPS database) is -8 inches, ranking these sites toward the less evaporative end of the range shown by sites of this classification. Mean monthly precipitation for the Lindbergh Lake climatic station shows a relatively even distribution with a January maximum. Annual precipitation totals show the 3-year running average below the average for the period of record throughout the 1980s. The running average recovered to approximate the long-term average from 1990 to 1992. Data for 1993 were not recovered for this station.

Geologic setting. The Condon creek ponds are small glacial(?) depressions in till of late Pleistocene age. The texture and hydraulic characteristics of the till have not been described for this area. Other glacial, fluvial and colluvial sediments may be interbedded with till in the area. Any surficial sediments likely include calcareous material derived from source areas underlain by limestone and dolomite.

The ponds occupy positions near the toe of the fault-bounded Swan Range, which is underlain by argillitic and calcareous formations of the Proterozoic Belt series.

Hydrologic setting. The condon Creek sites are glacial basins lacking surface water outflow or discrete surface water inflow. Dilute water chemistry suggests that water is supplied mainly by precipitation and very local runoff.

Basin characteristics. The condon Creek ponds have very small surface catchments and low catchment to wetland area ratios. Depths of the ponds are unmeasured but probably shallow. Topographic position suggests the possibility of ground-water discharge to the ponds, but their dilute water chemistry is probably inconsistent with volumetrically important ground-water inflow.

Water chemistry. Water chemistry in WET15 is very dilute, mildly acidic and dominated by calcium and bicarbonate ions. Mineral equilibria indicate substantial undersaturation with carbonate species. Ammonium concentrations were high in this site, ranking near the top for sites of this classification. Orthophosphorous and total phosphorous concentrations ranked in the mid-range for sample sites of this class. The total organic carbon concentration was the highest for this class and among the highest for the entire sample set.

Arsenic and zinc were reported at their respective limits; the iron concentration ranked in the mid-range in this class. Most other trace elements were below reporting limits. 

Chemical history. No other chemical data are known for this site. Sediments. Arsenic, copper, selenium, vanadium and zinc were reported in concentrations above detection limits. Copper and selenium concentrations ranked toward the top for sample sites in this class, while arsenic, vanadium and zinc concentrations ranked near mid-range for their classification. Selenium exceeded the mean soil concentration for the western U.S. by a factor of two, copper by a factor of 1.5 and zinc by a negligible amount. 



\section{Condon Creek Proposed RNA Pond /2}

climatic setting. The net annual precipitation balance for the Condon Creek sites (from the MAPS database) is -8 inches, ranking these sites toward the less evaporative end of the range shown by sites of this classification. Mean monthly precipitation for the Lindbergh Lake climatic station shows a relatively even distribution with a January maximum. Annual precipitation totals show the 3-year running average below the average for the period of record throughout the 1980s. The running average recovered to approximate the long-term average from 1990 to 1992. Data for 1993 were not recovered for this station.

Geologic setting. The condon creek ponds are small glacial(?) depressions in till of late Pleistocene age. The texture and hydraulic characteristics of the till have not been described for this area. Other glacial, fluvial and colluvial sediments may be interbedded with till in the area. Any surficial sediments likely include calcareous material derived from source areas underlain by limestone and dolomite.

The ponds occupy positions near the toe of the fault-bounded Swan Range, which is underlain by argillitic and calcareous formations of the Proterozoic Belt series.

Hydrologic setting. The condon creek sites are glacial basins lacking surface water outflow or discrete surface water inflow. Dilute water chemistry suggests that water is supplied mainly by precipitation and very local runoff.

Basin characteristics. The condon creek ponds have very small surface catchments and low catchment to wetland area ratios. Depths of the ponds are unmeasured but probably shallow. Topographic position suggests the possibility of ground-water discharge to the ponds, but their dilute water chemistry is probably inconsistent with volumetrically important ground-water inflow.

Water chemistry. At the time of sampling, water at the WET16 site was very dilute, mildly acidic and calcium/bicarbonate in character. Mineral equilibria indicate substantial undersaturation with respect to carbonate phases. Nitrate and ammonium concentrations were lower than nearby WET15; nitrate was below detection limits and in ammonium concentration the site ranked toward the middle of sites in it's classification. The orthophosphorous concentration reported was considerably higher than for WET15 (ranking near the top for this site type), while the total phosphorous concentration was considerably lower than at WET15. The total organic carbon concentration was considerably lower than for WET15 but still ranked near the top for sites of it's class.

Arsenic was reported at the detection limit; copper and iron 

concentrations ranked mid-range for sample sites in this class. other trace elements were below detection limits.

Chemical history. No other chemical data are known for this site. Sediments. Extractable trace element concentrations showed a similar pattern to that for WET15. Copper and selenium concentrations ranked toward the high end for the site classification; arsenic and $z$ inc concentrations ranked in the midrange. Selenium and copper concentrations exceeded mean soil concentrations for the western U.S. by factors of 2 , while arsenic and zinc concentrations were less than the regional soil means. 

climatic setting. The net annual precipitation balance for the Creedman Coulee site (from the MAPS database) is -25 inches, midrange in comparison to sites of it's classification. Mean monthly precipitation for the Fort Assiniboine climatic station shows a pronounced June maximum. The 3-year moving average of annual total precipitation shows an apparent periodicity with maxima on 4 to 6 year intervals. The moving average remained near or above the long-term mean from 1974 through 1993; in 1993 (the year prior to sampling) total precipitation exceeded the long-term mean by about 7 inches.

Geologic setting. Creedman Coulee is underlain by late Pleistocene till of undescribed character. The till is inferred to be calcareous, shaley and of low permeability. The valley floor of creedman coulee is underlain by modern alluvium of unknown character and possibly by glaciofluvial sediments.

At the wetland site and throughout most of the creedman coulee basin, glacial sediments are underlain by the late Cretaceous Bearpaw Shale; in some of the upper basin the Judith River Formation underlies the surficial deposits.

Hydrologic type. WET17 is located on Creedman Reservoir, an artificial impoundment of Creedman coulee. The reservoir has an outflow structure and is inferred to discharge water fairly regularly due to the relatively dilute water chemistry shown.

Basin characteristics. No information on the maximum depth or volume of Creedman Reservoir is available. The catchment area to wetland area ratio ranks mid-range for sample sites in this classification. Numerous small stock-watering reservoirs scattered throughout the catchment probably influence the timing and quantity of runoff received by Creedman Reservoir.

Water chemistry. At the time of sampling, Creedman Reservoir's was relatively dilute and moderately alkaline, with similar equivalent proportions of divalent (calcium and magnesium) and monovalent (sodium and potassium) cations and bicarbonate-dominated anion chemistry. Mineral equilibria indicate moderate oversaturation with carbonate phases. Nitrogen concentrations (nitrate plus ammonium) were low in comparison to the range shown by this site classification: phosphorous concentrations (total and orthophosphorous) were mid-range for sites of this classification, as was the total organic carbon concentration.

The boron concentration reported for WET17 was among the highest in the data set, and the highest for any site with surface water outflow. The arsenic concentration ranked near the middle of the range for this class, and the chromium concentration was comparatively high. The iron concentration ranked comparatively low, and the other trace elements were below detection limits. 

Chemical history. No other water chemistry data are known for this site. It is inferred that surface outflow maintains salinity within a moderate range.

Sediments. Arsenic, boron, vanadium and zinc concentrations were all of intermediate rank in comparison to sites within this classification. Arsenic and boron concentrations were slightly above mean values for soils and other surficial sediments of the western U.S. Vanadium and zinc concentrations were below mean values for western U.S. soils. Other trace element occurrences were below reporting limits. 



\section{Dudley Slough Preserve}

climatic setting. The net annual precipitation balance for the Dudley Slough (from the MAPS database) is -12 inches, ranking the site as one of the more strongly evaporative of Rocky Mountain sites. Mean monthly precipitation for the Fortine climatic station shows a relatively even seasonal distribution with a June maximum. Annual totals show the 3 -year running mean remaining below the long term mean for most of the period from 1970 to 1987. Total precipitation in 1993 (the year prior to sampling) was about 5 inches above the long-term mean.

Geologic setting. Dudley slough lies in glaciated terrain and is inferred to be underlain by till and possibly other late Pleistocene glacial sediments. Based on available source lithologies, glacial deposits can be inferred to be calcareous. Bedrock formations underlying the site are of the Proterozoic Belt series, including the calcareous siyeh Formation. Glacial processes have given the general area a prominent northwest trending drumlinoid lineation.

Hydrologic type. Dudley slough is a natural glacial depression with channelized surface water inflow and outflow.

Basin Characteristics. The catchment area to wetland surface area ratio for Dudley Slough ranks mid-range among sample sites of similar type. The maximum reported depth of the pond is 6 meters.

Water chemistry. Dudley slough contains relatively dilute, moderately alkaline calcium-magnesium/bicarbonate water. Mineral saturation indices indicate moderate oversaturation with carbonate species; authigenic carbonate deposition appears to be verified by the exceptionally high extractable calcium concentration reported for Dudley slough sediments. Nitrate, ammonium and orthophosphorous concentrations were below detection limits. The total phosphorous concentration ranked in the mid-range for sample sites of this type, and the total organic carbon concentration was toward the lower end of the range for all sample sites. Copper was reported at the detection limit, and other trace elements were below detection limits.

Chemical history. A single previous partial chemical analysis is known for a sample collected in July of 1988. The reported specific conductance at that time was $75 \%$ of the August 1994 value. The concentrations of major cations and of alkalinity were very close in the two samples (raising some doubt about the 1988 specific conductance measurement.) Trace element concentrations were not analyzed for the 1988 sample. Generally, variability is not expected to be very great at this site.

Sediments. A very high extractable calcium concentration probably indicates a high fraction of authigenic calcium carbonate in Dudley slough's sediments. Arsenic, aluminum and iron concentrations were 

all ranked at or near the bottom of their ranges for this site type and near the bottom for the entire sample set. The manganese concentration ranked in the mid-range among comparable sites. other trace element concentrations were below detection limits. All were below mean soil concentrations for the western United States. 
, 


\section{Evans Lake}

climatic setting. The net annual precipitation balance for Evans Lake (from the MAPS database) is -16 inches, placing the site toward the more evaporative end of the range for it's hydrologic classification. Monthly average precipitation for the Ovando 9SSE station shows a bimodal distribution, with a primary May-June peak and a secondary winter peak. Since the mid-1970's, the 3-year running average of annual total precipitation has been below (often well below) the average for the period of record. Total precipitation in 1993 (the year of DHES sampling) was very near the long-term average.

Geologic setting. Evans Lake is a steep-sided glacial kettle developed in till deposited by ice advancing into the Ovando Valley from the North Fork of the Blackfoot River. Surficial sediments in the Evans Lake basin are notably cobbly in texture, and may include glaciofluvial deposits as well as till. Littoral sediments typically feature gravel and cobbles in a matrix of marly mud.

Bedrock geologic units underlying Evans Lake are not exposed in the immediate area; generally the ovando valley is underlain by a sequence of Tertiary valley-fill sediments overlying Proterozoic metasediments of the Belt series. Belt sediments exposed in the North Fork drainage (inferred to contribute to the North Fork) include large outcrop areas of the Helena Formation and other calcareous and dolomitic units.

Hydrologic type. Evans Lake is a glacial depression lacking surface drainage at current water levels. Strandlines represented by tree kills indicate historic water levels within the past few decades which may have allowed surface discharge. Ground water is inferred to be an important contributor to Evans Lake; based on the relatively high salinity observed in the lake, ground-water outflow is probably restricted.

Basin characteristics. Evans Lake has a small surface catchment with respect to lake area and volume. The basin is steep-sided and relatively deep, with a maximum measured depth of 25.5 feet in September 1994. High-water drainage, if any, would occur through a gap along the northeast quadrant of the lake.

Water chemistry. Evans Lake contains "mesosaline" sodium sulfate water nearly depleted in calcium. Very low calcium concentrations are probably maintained by solubility controls; equilibrium calculations indicate supersaturation with carbonate species.

In comparison to hydrologically similar sites, Evans Lake (at the time of sampling) was relatively low in orthophosphorous concentration. Nitrate and ammonium concentrations were mid-range among hydrologically similar sites. (Ammonium concentrations measured during winter conditions were considerably higher - see below.) The total organic carbon concentration was near the middle of the range for hydrologically similar sites. 
Evans Lake has one of the highest water column arsenic concentrations of the sample sites. Most other trace elements were below detection limits.

Chemical history. A single previous chemical analysis is known from Evans Lake. This sample, collected in september of 1972 , showed a total dissolved solids concentration of $6310 \mathrm{mg} / 1$ (compared to $9743 \mathrm{mg} / \mathrm{l}$ in 1993). The overall sodium - sulfate character of the water was similar the 1993 analysis; the calcium concentration was slightly higher but still very low.

Specific conductance measurements in september of 1994 were approximately 15\% higher than in August of 1993. Shoreline evidence of substantially higher water levels in the historic(?) past indicate significantly higher lake volume and more dilute water chemistry.

winter measurements through a continuous ice cover showed nearcomplete oxygen depletion of the water column above the lake's deepest point. Winter sampling showed ammonium concentrations 7 to 8 times the concentration measured at WET19 in August of 1993.

Sediments. Evans Lake sediments contain arsenic and iron concentrations near mid-range for hydrologically similar sites and zinc concentration near the lower end for sample sites of this class. Other trace element concentrations were below detection limits. High calcium concentrations probably reflect the precipitation of authigenic carbonate minerals. 

climatic setting. The net annual precipitation balance for Fox Lake (from the MAPS database) is -25 inches, placing the site near the less intensely evaporative end of the range shown by this classification. Mean monthly precipitation for the savage climatic station shows a pronounced June peak. The 3-year running average of total annual precipitation for this station remained near or below the long-term average through most of the 1980s; from 1991 to 1993 the 3-year average exceeded the long-term average. Total precipitation in 1993 (the year prior to sampling) exceeded the long-term average by about two inches.

Geologic setting. Fox creek and Fox lake lie along a mid(?)Pleistocene glacial drainage way continuous across the modern drainage divides between Redwater creek, Fox Creek and the North Fork of Burns creek. Glacial drainage through this system may have deposited glaciofluvial sediment in places along Fox creek; alluvium of unspecified character is reported to underlie Fox Creek to a depth up to 30 feet. Fox Lake existed as a natural feature prior to dam construction; Holocene-aged lacustrine sediments probably underlie the lake basin.

Surficial deposits are underlain by the Tullock Member of the Fort Union Formation.

Hydrologic type. Fox Lake is an artificial impoundment with a managed(?) outlet structure. Although beyond the maximum extent of Pleistocene glaciation, Fox creek appears to owe it's character to Pleistocene drainage of glacial meltwater from an ice front to the north.

Prior to damming, Fox Lake was described as perennial but seasonally highly variable in extent. outflow from the lake may have been seasonal, with periods of basin closure to surface water.

Basin characteristics. Fox lake is toward the large end of the size distribution for the DEQ wetland characterization sites, with a contributing basin to wetland area ratio near the median. Lowgradient streams occupying the Redwater River-Fox creek glacial drainageway provide inflow and outflow. The depth of Fox Lake is unknown but believed to be shallow throughout. The lake basin is divided lengthwise by a railroad berm separating the largest inlet stream (entering north of the railroad) from the outlet stream exiting from the southeastern quadrant. Restricted water circulation across this barrier may lead to exaggerated chemical gradients within the lake basin.

water chemistry. At the time of sampling, Fox Lake contained alkaline, "oligosaline" sodium sulfate water; mineral equilibria indicate considerable oversaturation with carbonate phases. Nitrogen concentrations (nitrate and ammonium) were below detection limits and in the lower class rankings, respectively. 

Concentrations of other nutrients ranked generally mid-range for sites in this classification.

Arsenic, boron, chromium, and copper concentrations ranked midrange for sites in this classification. Reported lead and iron concentrations ranked toward the upper end of their respective ranges.

Chemical history. No previous water quality data are known for Fox Lake. The reported character of the lake prior to impoundment (perennial but highly variable in extent) suggests that salinity and other chemical characteristics were probably more variable in the past than now.

Sediments. The concentration of arsenic reported for WET20 ranked near the upper end of the range shown by sample sites in this classification. Concentrations of boron, copper, chromium, nickel, vanadium and zinc ranked mid-range in their respective ranges for sites classified with WET20. Fox Lake was among a small handful of sites not known to be impacted by mining or mineralization where mercury was reported from sediment (at the detection limit).

The boron value exceeded the mean soil concentration for the western U.S. by a factor of 1.6 , and nickel and $z$ inc concentrations exceeded regional mean soil values by small factors. Other trace element concentrations were reported below the regional mean soil concentrations. 



\section{Freezeout Lake}

climatic setting. The net annual precipitation balance for Freezeout Lake is -27 inches, toward the more strongly evaporative end of the range shown by sites in this classification. Monthly average precipitation for the choteau climatic station shows a pronounced June maximum. Annual totals for this station show the 3-year running average below (often well below) the long-term average throughout most of period from 1970 to 1990 . The total precipitation in 1992 (the year prior to sample collection) was almost 4 inches below the long-term average, while the 1993 total exceeded the long-term average by over 4 inches.

Geologic setting. The Freezeout Lake basin is underlain by a sequence of glaciolacustrine silt and clay deposited toward the western limit of the extensive Glacial Lake Great Falls, and by the Late Cretaceous Marias River Shale, Telegraph Creek Formation and Two Medicine Formation. Permeable terrace gravel deposits underlie some upland areas.

Hydrologic type. Freezeout Lake and the surrounding ponds make up a complex of diked and managed water bodies receiving irrigation return flows from the Greenfields Division of the sun River Irrigation Project. Peripheral ponds drain to Freezeout Lake proper through regulation structures. Managed outflow occurs via Priest Butte Lakes to the Teton River at times of high streamflow. Water levels are manipulated to meet water storage objectives in the lake system and water quality objectives in both the lake system and the Teton River.

Basin characteristics. Freezeout Lake occupies the lower elevations of a broad, low-gradient depression altered by diking, ditching and transportation corridors. The catchment to wetland area ratio is relatively low, but a large fraction of the inflows to the lake system are irrigation return flows imported from outside the natural drainage basin. Water depths are shallow (maximum depth estimated to be 10-12 feet) and portions of the lake system are surrounded by low-gradient salinated flats.

Water chemistry. At the time of sampling, water at the WET21 site was mildly alkaline, "oligosaline" and sodium sulfate in character. Equilibrium calculations indicate near-saturation with calcium carbonate species and substantial oversaturation with respect to dolomite. With respect to sample sites in the same classification, WET2l ranked mid-range in ammonium and total organic carbon concentrations, relatively low in orthophosphorous concentration and relatively high in total phosphorous.

Within it class, the arsenic and copper concentrations ranked midrange and the boron concentration was near the high end of the range.

Chemical history. Several samples were collected by the U.S. 

Geological Survey near WET21 in 1991 and 1992, and sampling elsewhere in Freezeout Lake occurred in 1987; DHES collected timeseries sampling of the Freezeout-Priest Butte Lakes-Teton River system in 1980-82. In comparison to the WET21 sample, specific conductance near the WET21 site was up to 1.5 times higher in 1992. Within the short period of record, ammonium concentrations varied by a factor of 5 and orthophosphate concentration by a factor of 4 .

Specific conductance measurements collected by DHES from 1980 to 1982 at the outflow from Freezeout Lake show a range from 3000 to $8500 \mathrm{microsiemens} / \mathrm{cm}$. Six drains conveying irrigation return flows into Freezeout Lake ranged in average specific conductance from 832 to $4900 \mathrm{microsiemens/cm}$. The evaporative setting, shallow water depths and variability in inflow water quality imply significant spatial variability in water quality within Freezeout Lake. Trace element concentrations (notably selenium) are elevated in certain inflows remote from the WET21 site, and may be largely removed from the water column by geochemical process in the vicinity of inflow.

Sediments. The WET21 sediment sample contained arsenic and copper concentrations which ranked low within the site classification. Boron and zinc concentrations ranked mid-range within the site classification, and the vanadium concentration reported was among the highest for the entire sample set. Extractable cobalt was reported at slightly above the detection limit, one of only five sample sites with a reportable concentration. The boron and cobalt concentrations exceeded the mean values for soils and other surficial materials of the western U.S. by a factor of 1.7; other trace element concentrations were below the regional mean values. 



\section{Furnell WPA}

climatic setting. The net annual precipitation balance for the Furnell WPA (from the MAPS database) is -19 inches, showing Furnell to be the least evaporatively intense of the plains sampling sites. Monthly average precipitation for the Gold Butte climatic station shows a broad summer peak with a maximum in June. The 3-year moving averages for the Gold Butte station appears to show roughly cyclical peaks with a period of 6 to 11 years. The moving average has been mostly near or above the long-term mean since the mid 1980s; in 1993 (the year prior to sampling) the annual total exceeded the long-term mean by more than 10 inches.

Geologic setting. The Furnell WPA site is underlain by calcareous till deposited in a prominent end moraine complex. The moraine marks the terminus of a late pleistocene glacial lobe which occupied the gap in the sweet Grass Hills. Till underlying the sample site appears relatively loose-textured with a matrix of $f$ ine sand and silt.

Bedrock beneath the till cover is sandstone and shale of the late Cretaceous Eagle Formation and Claggett Shale, regionally intruded by the alkaline intrusive complex underlying the sweet Grass Hills. There are producing and shut in natural gas wells within a few hundred meters of the site.

Hydrologic type. The Furnell site is a small glacial kettle lacking surface drainage at water levels represented by the samples analyzed. Shoreline features and drainage development indicate outflow from the pond occurs at pond stage roughly 3 feet higher than that observed in August 1994. Ground-water outflow may occur, based on topographic position and the character of underlying glacial sediments.

Basin characteristics. The Furnell site is very small but has an intermediate catchment to wetland area ratio among hydrologically similar sites. The basin has a relatively flat bottom and a maximum depth of approximately 1.5 feet at water levels observed in August 1994. The pond has two prominent slope breaks appearing to correspond to periods of higher stage: the upper feature probably relates to an upper stage controlled by surface outflow. The outflow channel is a grassy swale with poorly defined meander patterns shown by vegetation; outflow appears to have occurred relatively recently and may occur on a regular seasonal basis.

Hater chemistry. The Furnell site contains water of a dilute calcium/potassium - bicarbonate character. The proportionately high potassium concentration is unusual among the sampled wetlands. Equilibrium calculations indicate moderate supersaturation with carbonate species.

Water column concentrations of trace elements were either below detection limits or (for arsenic and boron) near detection limits 

and at the lower extreme for hydrologically similar sample sites. orthophosphorous and total phosphorous concentrations were near the lower end of the range for sample sites of this type. Nitrate and ammonium concentrations were both below detection limits; the total organic carbon concentration was intermediate among similar sites.

Chemical history. No previous measurements of chemical characteristics for this site (or nearby wetlands) are known. Specific conductance measurements collected in August 1994 (two months after sampling) showed a $45 \%$ seasonal increase during that period. Periodic spill at high pond stage and/or recharge to the ground water system maintain dilute water chemistry at this site.

Sediments. By contrast with the water column data, several trace elements in Furnell WPA sediments occur at intermediate to high concentrations compared to hydrologically similar sample sites. Elevated sediment concentrations of chromium, nickel, vanadium and zinc (none of which occurred above detection limits in the water column) probably relate to sources in the shales underlying the site, and suggest the geochemistry of this wetland is effective in sequestering the natural influx of metals to the wetland. 



\section{Gaffney Lake}

climatic setting. The net annual precipitation balance for Gaffney Lake derived from the MAPS database is -24 inches, toward the middle of the range of evaporative intensity for sites in this class. Based on analyses of evaporation pan data, this is a considerable underestimate Gaffney Lake's water deficit, and points out the need to view the MAPS estimates only as relative indicators of net site precipitation. Mean monthly precipitation for the Medicine Lake climatic station shows a pronounced June maximum. Annual totals for this station show apparent periodicity with a 5 to 7 year cycle. Throughout the 1980s, the 3-year running average remained below (often well below) the long-term average, recovering in the early 1990s. In 1993 (the year before sampling) precipitation exceeded the long-term average by more than 1 inch.

Geologic setting. Gaffney Lake occupies an irregular and modified depression in the sequence of late Pleistocene outwash sand and gravel forming the clear Lake aquifer, near the contact with kame terrace(?) deposits to the south. The composite thickness of the outwash gravels is greater in the Gaffney-Medicine Lake vicinity than elsewhere along the clear Lake outwash channel. Glacial sediments are underlain at depth by the early Tertiary Fort Union Formation.

Hydrologic type. Gaffney Lake is a natural depression receiving ground-water inflow from the clear lake aquifer. A system of ditches and control structures provides managed surface-water inflow from lower Lake creek by way of "Lake 10" (U.S. Fish and Wildlife Service usage) and other ponds. Managed surface-water outflow occurs via Long Lake to Medicine Lake. Under unusually high stages of Medicine Lake, these flows may reverse, allowing inflow from Medicine Lake (with imported Big Muddy Creek water) to Gaffney Lake. Ground-water outflow to the Clear Lake aquifer and to Medicine Lake is inferred to occur under the typical stage conditions.

Basin characteristics. The natural surface catchment of Gaffney Lake is small relative to the area of the lake; without water imports, most of the inflow to the lake would be provided by ground water discharge. At management (preferred) stage, Gaffney Lake has an estimated volume of about 4700 acre-feet and an average depth of a little over 7 feet. In 1993 (the year of sampling) the lake elevation was more than 5 feet below management levels all year, with an estimated volume only about $25 \%$ of the management-level volume. From 1989 to 1992, Gaffney Lake's estimated water volume never exceeded $55 \%$ of the management-stage volume.

Water chemistry. At the time of sampling, water in Gaffney Lake was highly alkaline, "mesosaline", and sodium-sulfate/bicarbonate in composition. Equilibrium calculations reflect estimated parameter values and have no validity for this sample. The ammonium, orthophosphorous and total organic carbon concentrations 

ranked mid-range among hydrologically similar sites, while the total phosphorous concentration was the highest of any sample site with surface drainage and among the highest for the entire sample set.

Gaffney Lake's arsenic concentration ranked among the highest in the sample set and in it's classification. The reported boron concentration was among the highest for sample sites lacking surface water outflow. Most other trace element concentrations were below detection limits.

Chemical history. Previous water quality analyses from Gaffney Lake generally show more dilute conditions than at the time of the DHES sampling. Specific conductance measurements in september 1984 and August 1980 were 3100 and 4870 microsiemens/cm, compared to 10500 microsiemens/cm at the time of the DHES sampling. During 1994 and 1995 monthly monitoring of field water chemistry, specific conductance generally ranged from 2500 to $3000 \mathrm{microsiemens/cm;} \mathrm{(a}$ single March 1995 measurement of 310 microsiemens/cm seems likely to be either measurement error or the local effect of spring icemelt.)

The dissolved oxygen concentration in Gaffney Lake dropped to a measured value of 4 milligrams per liter during the winter of 1995 .

Sediments. The arsenic concentration in the Gaffney Lake sediment sample was among the lowest in the site classification. For the most part, concentrations of other trace elements were below analytical detection limits. The reported arsenic concentration was well below the mean value for soils and other surficial materials in the Western U.S. 



\section{Hailstone Reservoir}

climatic setting. The net annual precipitation balance for Hailstone Reservoir (from the MAPS database) is -28 inches, placing it among the most strongly evaporative of the sample sites. Average monthly precipitation for the Rapelje climatic station shows a strong May-June peak. The 3-year running average of total annual precipitation shows apparent periodicity, with 6 to 9 years between peaks. Between the early 1970s and 1992, the 3-year average remained mainly above the average for the period of record. Data for 1993 and 1994 were not recovered for this station.

Geologic setting. Hailstone Reservoir occupies a structurally controlled basin underlain by medium-to-fine-grained sandstone of an unidentified formation (Lennep Sandstone?) bearing intervals of oyster shell conglomerate with a sandy matrix. Surficial sediments within the lake basin include fine-grained, mucky silt, extensive areas of precipitated salts on low-gradient shorelines, and wellsorted, ripple-marked sand in higher-energy littoral areas.

Hydrologic type. Hailstone Reservoir is a managed impoundment which probably had a history as a natural wetland prior to the construction of the dam which now controls outflow. Although the reservoir has a spillway and has discharged water in the past, at the time of sampling in April 1993 and during follow-up investigations in October 1994, lake stage was more than 5 feet below the spillway crest. U.S. Fish and Wildlife Service personnel responsible for Hailstone Reservoir report that no spill has occurred since the early 1980s. For classification purposes, Hailstone Reservoir is considered to be effectively lacking surface discharge.

Basin characteristics. Hailstone reservoir has an intermediate ratio of catchment to wetland area when compared to hydrologically similar sample sites. Attempted sounding of the reservoir was terminated by the near-arrest of the surveyor; a single depth measurement of 6.5 feet is thought to be close to the maximum for the reservoir. Low topographic gradients around most of the reservoir imply highly transient shoreline positions as lake stage changes. The sampling site WET24 is along one of the steeper, comparatively less transient reaches of shoreline.

Active ground-water seepage through the dam supports a small flow in Cedar Creek immediately below the dam face, and provides for some export of solutes under the observed low-water conditions.

Water chemistry. When sampled in April of 1993, Hailstone Reservoir water was a "eusaline" sodium sulfate brine with low carbonate and bicarbonate concentrations. Mineral equilibria indicate substantial supersaturation with carbonate species and slight supersaturation with gypsum. [Possible errors in calcium, magnesium and alkalinity analyses render these saturation indices uncertain.] 

Phosphorous concentrations in Hailstone Reservoir were in the midrange for hydrologically similar sites, as were ammonium and total organic carbon concentrations.

Arsenic, boron, chromium and nickel concentrations were at or near the high end of ranges for hydrologically similar sample sites. chromium and nickel concentrations in Hailstone Reservoir were higher than for any other sample site.

Chemical history. No previous chemical analyses are known for Hailstone Reservoir. Anecdotal observations indicate that the reservoir has been experiencing progressive salinization for a number of years, probably since the construction of the dam. The concentration and volume at which the reservoir solute load would be in approximate equilibrium with ground-water outflow is not known.

In October of 1994 , specific conductance at the WET24 site was 59600 microsiemens/cm, a 358 increase over the conductance measured at the time of sampling in April 1993. At the same time, ground water discharging into cedar creek at the seepage face of the dam

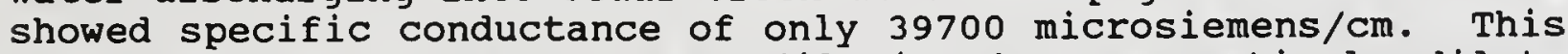
salinity contrast may reflect dilution by comparatively dilute ground water (a nearby spring produces water with specific

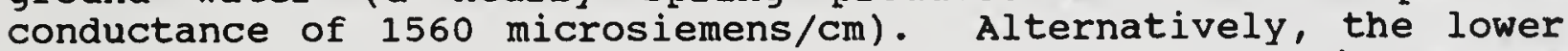
salinity may reflect reservoir seepage at times of more dilute lake chemistry.

Spatial variability in salinity within Hailstone Reservoir has not been measured but is probably not great under most circumstances due simple lake geometry and wind exposure.

Sediments. Trace element concentrations measured in Hailstone Reservoir sediments were for the most part below detection limits; those with detectable concentrations occur at low to moderate concentrations compared to hydrologically and regionally similar sites. Several trace elements prominent in the Halfbreed Lake sediment analysis and in the Hailstone Reservoir water column are below detection limits in Hailstone sediments. This contrast may reflect the physical character of sediments found at WET 24 ; trace elements in solution may have a relatively low affinity for the reworked sand observed in the vicinity of the sampling site. 



\section{Halfbreed Lake}

climatic setting. The net annual precipitation balance for Halfbreed Lake (from the MAPS database) is -28 inches, placing it among the most strongly evaporative of the sample sites. Average monthly precipitation for the Rapelje climatic station shows a strong May-June peak. The 3-year running average of total annual precipitation shows apparent periodicity, with 6 to 9 years between peaks. Between the early 1970 s and 1992, the 3-year average remained mainly above the average for the period of record. Data for 1993 and 1994 were not recovered for this station.

Geologic setting. Halfbreed Lake lies near the intersection of the Lake Basin fault zone and the trend of the Lake Basin anticline. Upland areas adjacent to the lake are scattered with noncalcareous sandstone float of an uncertain formation (Lennep Sandstone?)

The site is underlain by fine-grained, calcareous, plastic lake sediments with accumulations of organic debris at higher shoreline elevations.

Hydrologic type. Halfbreed Lake is a structurally controlled(?) depression, modified by ditching and impoundment, with controlled outflow.

Basin characteristics. Halfbreed Lake has a relatively high catchment to wetland ratio in comparison to hydrologically similar sample sites. At low water levels, the northeastern basin of the irregularly shaped lake is separated from the main basin, allowing distinct salinity to develop. A distinct "full pool" shoreline is developed at an elevation approximately 2.3 feet above the lake stage at the time of sampling, and approximately 1.7 feet above lake stage at the time of follow-up observations in October 1994. This shoreline feature may be controlled by the lake's outlet structure.

Water chemistry. At the time of sampling, Halfbreed Lake contained "mesosaline" sodium sulfate water. Equilibrium calculations indicate substantial oversaturation with carbonate species and slight undersaturation with gypsum. [Estimated calcium/magnesium ratios and uncertain carbonate and bicarbonate concentrations reduce the usefulness of these indices.]

Nutrient concentrations were unremarkable in comparison to hydrologically similar sites. Along with other sample sites in the region, Halfbreed Lake water contained copper, chromium and nickel concentrations at or near upper end of the sampled range.

Chemical history. No water chemistry data prior to the April 1993 DHES sampling are known from Halfbreed Lake. In October 1994, specific conductance at the WET25 site was only $37 \%$ of the conductance at the time of the 1993 sampling, probably reflecting flushing during the wet spring and summer of 1993. Historic water 

levels shown by shoreline development are inferred to reflect still more dilute water chemistry at times of higher throughflow. The water quality of inflow received by Halfbreed Lake is probably affected by saline seeps in the cedar creek drainage and by the evaporative salinization of water stored upgradient in Hailstone. Reservoir.

Sediments. Sediment concentrations of copper, boron, chromium, nickel and zinc were found near at or near the upper end of their ranges for hydrologically similar sample sites. Copper exceeded mean soil values for the western U.S. by a factor of about 2; boron by a factor of about 3, and nickel and zinc by factors of about 1.5. The chromium concentration was below the regional mean soil concentration. 

Hewitt Lake National Wildlife Refuge

climatic setting. The net annual precipitation balance for the Hewitt Lake site (from the MAPS database) is -28 inches, placing the site at the more evaporative end of the range shown by sites in this classification. Monthly mean precipitation for the Malta 7NE climatic station shows a broad summer peak with a maximum in May; the Malta climatic station, with a longer period of record but farther from Hewitt Lake, shows a pronounced June maximum. Annual totals for the Malta 7NE station, shows the years 1988 to 1992 below the average for the period of record. The total for 1993 (the year prior to sampling) exceeded the average for the period of record by about 2.5 inches.

Geologic setting. The Hewitt Lake catchment is underlain by the Late Cretaceous claggett Shale. Although the area is within the extent of Pleistocene glaciation, glacial deposits in the immediate Hewitt Lake area may be thin or absent. Hewitt Lake lies near the apex of the Bowdoin structural dome, apparently the trap for natural gas reservoirs exploited by the well field surrounding the refuge.

Hydrologic type. Hewitt Lake is an impounded reservoir with a surface water outlet structure; Hewitt Lake is the at the downstream end of a series of intermittent natural lakes and ponds, and may have a pre-impoundment history as a smaller natural basin. Hewitt Lake has been dry or essentially dry during some recent drought years. The history of discharge from the Hewitt Lake outlet structure is not known.

Basin characteristics. Hewitt Lake's catchment to wetland area ratio ranks in the mid-range among sample sites in it's classification. Depth and volume of the Hewitt Lake basin are not known. Based on the geologic setting, ground water is not thought to be an important contributor to Hewitt Lake's water budget. storage in (and evaporation from) intermittent lakes and ponds in the Hewitt Lake catchment probably influence the runoff characteristics of the basin.

Water chemistry. At the time of sampling, Hewitt Lake contained alkaline, "oligosaline" water of sodium sulfate character. Mineral equilibria indicate moderate oversaturation with respect to carbonate phases. The nitrate concentration was below detection limits, and the ammonium concentration ranked mid-range among sites in the same classification. The orthophosphorous concentration ranked mid-range for sample sites of this classification, but the total phosphorous concentration ranked near the upper end of the range shown by the sample set overall.

The Hewitt Lake water column contains an enriched suite of trace metals relative to other sites of the glaciated plains, looking more like sample sites of south-central Montana in this respect. Concentrations of chromium, copper, iron, lead and zinc rank at the 

top of the ranges shown by these elements. Arsenic and boron concentrations rank mid-range within this site's classification.

Chemical history. No previous water chemistry data from this site are known.

Sediments. Extractable concentrations of arsenic, boron, copper, iron, nickel, vanadium and zinc rank mid-range among sites within this classification. Most other trace elements were reported to be below detection limits. Only boron exceeded the mean value for soils and other surficial materials of the western United states. 



\section{Homestead Lake}

climatic setting. The net annual precipitation balance for Homestead Lake derived from the MAPS database is -25 inches, toward middle of the range of evaporative intensity for sites in this class. Based on analyses of evaporation pan data, this is a considerable underestimate Homestead Lake's water deficit, and points out the need to view the MAPS estimates only as relative indicators of net site precipitation. Mean monthly precipitation for the Medicine Lake climatic station shows a pronounced June maximum. Annual totals for this station show apparent periodicity with a 5 to 7 year cycle. Throughout the 1980s, the 3-year running average remained below (often well below) the long-term average, recovering in the early 1990s. In 1993 (the year before sampling) precipitation exceeded the long-term average by more than 1 inch.

Geologic setting. Homestead Lake lies along the margin of the Big Muddy Creek Valley; permeable gravel aquifers (glacial and preglacial?) underlie portions of the lake and are shown by groundwater monitoring data to be in hydrologic communication with it.

Hydrologic type. Homestead Lake is a modified and managed impoundment with controlled inflows from Big Muddy Creek and controlled outflow back to Big Muddy Creek, as well as internal routing of water within management subunits of the lake. The lake is hydrologically connected to regional gravel aquifers; the direction of water movement between aquifers and the lake is uncertain, and may be influenced by diversions of surface water into Homestead Lake. Portions of Homestead Lake may have existed as a seasonal water body prior to the construction of dikes and diversions.

Basin characteristics. Homestead Lake receives inflow both from the natural catchment areas or Sheep Creek and Lost Creek to the east and from the diversion of Big Muddy Creek. The ratio of the natural western catchment to the wetland area ranks mid-range within it's classification: most lake inflow comes from the Big Muddy diversion, however. Management structures include dikes separating lake subunits which are dependent on natural flows in Sheep and Lost creeks. These were reported to be dry throughout 1993, the year of sampling.

The reported capacity of Homestead Lake at "management elevation" is 8216 acre-feet, with an average depth between 6 and 7 feet. Large water deficits were reported for Homestead Lake throughout the 1989-1993 period; at the beginning of 1993 the Homestead Lake complex reportedly held only 122 acre-feet of water. High flows in July of 1993 (postdating the DHES sampling) allowed the diversion of an estimated 6525 acre-feet over a short period. Most of this water was impounded within the northern management unit of the lake, within which the WET27 site is situated.

Water chemistry. At the time of sampling, water at the WET27 site 

was alkaline, "oligosaline" and sodium-sulfate/bicarbonate in composition. (Salinity, relative ion concentrations and nutrient levels may have changed substantially shortly after sampling, with the rapid importation of a comparatively large volume of newly diverted Big Muddy creek water.) Mineral equilibria indicate substantial oversaturation with respect to carbonate phases.

The nitrate concentration was below detection limits and the reported ammonium concentration ranked toward the low end of the range shown by sites in this classification. The orthophosphorous concentration ranked mid-range within the site classification, while the total phosphorous concentration (sampled in 1994, the year following sampling of other parameters) was near the high end of the range shown by sample sites in this class. The total organic carbon concentration was low in comparison to similar sites.

Arsenic and boron concentrations ranked mid-range among sites of this classification. Chromium and lead were reported at the detection limit or slightly above, making WET27 one of the few sites in this class with reportable concentrations of these elements in the water column.

Chemical history. No water chemistry prior to the 1993 DHES sampling are known. Since 1994, the Fish and wildlife Service has been monitoring field water chemistry parameters. The northern end of Homestead Lake has shown a range of specific conductance from over 2500 microsiemens/cm (July of 1994) down to 288 microsiemens/cm in March of 1995, following diversion of dilute runoff from the Big Muddy. Specific conductance was higher on all occasions in the southern lake basin; this is probably typical of conditions in Homestead Lake. The measured dissolved oxygen concentration in January of 1995 was $1.32 \mathrm{mg} / 1$, showing neardepletion of oxygen under winter ice cover.

Sediments. Extractable concentrations of arsenic, copper and iron were found to be low to moderate in comparison to sample sites classified with WET27. Most other trace element concentrations were below detection limits. None exceeded mean values for soils of the western United States. 



\section{Hoskins Lake Research Natural Area}

climatic setting. The net annual precipitation balance for Hoskins Lake (from the MAPS database) is 7 inches, placing the site among the two wettest low-elevation sites in the sample set. Average monthly precipitation for the Troy $18 \mathrm{NE}$ climatic station shows a winter peak with a maximum in November. The records of annual total precipitation for the station are incomplete; available records from 1980 to 1991 show modest deviations from the average in both directions.

Geologic setting. Hoskins Lake occupies a glacially eroded trough paralleling the Yaak River valley and following the trace of one of a series of north-trending normal faults; preferential erosion along the fault may have influenced the location and orientation of the lake basin. The lake basin is underlain by paludal, lacustrine and (probably) glacial deposits of undescribed character. The underlying bedrock is composed of the wallace Formation of the Proterozoic-aged Belt series; the Wallace Formation is dominantly argillaceous in composition but includes a significant calcareous component. Locally, calcareous interbeds in the wallace Formation are described as frequently pyritic.

Hydrologic type. The upper open-water portion of Hoskins Lake (sometimes known as Hoskins Pond), where the WET28 site is located, has a discrete surface water outflow to Hoskins Lake but no channelized surface water inflow. Hoskins Lake itself has surface water drainage to the Yaak River. The outflow from Hoskins Pond has been described as intermittent, but no data regarding it's flow characteristics are known.

Basin characteristics. Hoskins Lake and Hoskins pond occupy a single linear bedrock basin with a veneer of glacial(?) and Holocene sediments, separated by a minor topographic high and a vegetated wetland surface. The catchment to wetland area ratio is mid-range for Rocky Mountain sites; local relief is steep. The maximum depth reported for Hoskins Pond is 8.5 meters ( 27.5 feet). Based on topographic position, the lake basin may receive groundwater discharge from the Belt series bedrock. The dilute water chemistry suggests ground-water to be a minor hydrologic input, however.

Water chemistry. Hoskins Pond exhibits mildly alkaline, very dilute calcium-bicarbonate water. For a site of such dilute chemistry, WET28 shows an unusually high ratio of sulfate to bicarbonate, possibly reflecting the presence of sulfide minerals (pyrite) in the local Wallace Formation outcrops. Equilibrium calculations indicate substantial undersaturation with resect to carbonate minerals.

The nitrate and total organic carbon concentrations at WET28 ranked mid-range among Rocky Mountain sites, while the ammonium concentration was below detection limits. The orthophosphorous 

concentration was at the lower end of the range shown by the entire sample set; the total phosphorous was not analyzed.

The Hoskins Pond sample showed an iron concentration ranking midrange among sites in it's classification. Most other trace element concentrations were below detection limits.

Chemical history. No other quantitative water chemistry data are known from Hoskins Pond. A partial analysis of water from Hoskins Lake proper, collected in 1994, shows similarly dilute, mildly alkaline characteristics. Generally, this site can be inferred show less variability in water chemistry than most of the sample sites.

Sediments. The concentrations of extractable copper and iron ranked in the mid-range for Rocky Mountain sites, while arsenic and $z$ inc were reported toward the lower end of their respective ranges for sites classified with Hoskins Lake. Most other trace element concentrations were below detection limits. The copper concentration exceeded the mean value for soils of the western United States by a factor of 1.2 ; arsenic and 2 inc concentrations were below their respective regional mean values. 



\section{Indian Meadows Proposed Research Natural Area}

climatic setting. The net annual precipitation balance for Indian Meadows (from the MAPS database) is -3 inches. This places the site toward the wetter end of the range shown by the sample sites and mid-range among sites similarly classified. Average monthly precipitation for the Lincoln Ranger station climatic station shows a bimodal distribution, with a primary May maximum and a secondary November peak. (The sample site is at a considerably higher elevation than Lincoln and probably does not reflect the same seasonal distribution of precipitation.) Annual total precipitation for the Lincoln station shows the 3-year running average exceeding the long-term average most years from the mid1970s to the mid-1980s, and falling short of the long-term average most years since the mid-1980s. In 1992, the year preceding the DHES sampling, total precipitation fell short of the long-term average by about 4.5 inches. In 1993 total precipitation exceeded the average by about 5 inches.

Geologic setting. The Indian Meadows area is underlain by glacial deposits of undescribed character. Inferred source areas for till or other glacial deposits include extensive exposures of the Helena Formation, a calcareous component of the Proterozoic-aged Belt series of metasediments. In the immediate area of Indian Meadows, glacial deposits are underlain by Tertiary-aged volcanic, volcaniclastic and sedimentary rocks. Similar volcanic rocks in nearby areas host gold and accessory mineralization, and similar mid-Tertiary sedimentary rocks are described as pyritic in nearby areas.

Hydrologic type. Indian Meadows occupies a glaciated topographic trough capturing snowmelt, runoff and (probably) local ground water recharged on ridges to the north and south. The Indian Meadows pond sampled at site WET29 has a channelized surface water outlet but lacks channelized inflow.

Basin characteristics. The Indian Meadows site has catchment to wetland area ratio ranking toward the low end of the range shown by Rocky Mountain sites. Local relief within the small catchment is relatively high. Ground-water flow is probably very local in nature. The water depth of the site is unknown.

water chemistry. The WET29 site exhibits dilute, near-neutral calcium bicarbonate chemistry. Equilibrium calculations indicate undersaturation with carbonate minerals. Nitrate and ammonium concentrations were below detection limits, orthophosphorous ranked mid-range among Rocky Mountain sites, and total organic carbon ranked toward the upper end of the range shown by this class of sample sites.

The Indian Meadows site contains comparatively high concentrations of several trace elements. Concentrations of arsenic, lead, copper and zinc all rank near the top of the ranges shown by Rocky 

Mountain sites. Indian Meadows was one of only 5 sample sites for which water-column selenium was reported.

Chemical history. No other chemical data known to be from this site are available. A partial chemical analysis collected somewhere in Indian Meadows in 1987 showed a slightly more dilute character than the DHES sample. The actual location of this sampling location is uncertain, however. Generally, the chemical variability expected of this site is low.

Sediments. The concentrations reported for arsenic, copper, iron and zinc ranked mid-range for sites in the Rocky Mountains. Most other trace elements were below reporting limits. Arsenic exceeded the mean soil value for the western United states by a small amount, while copper and zinc were less than the regional mean values. 



\section{Jarina Waterfowl Production Area}

climatic setting. The net annual precipitation for the Jarina WPA site (from the MAPS database) is -9 inches, making Jarina the least evaporative of sample sites within it's classification. Note, however, that the Jarina site is in an area of very steep precipitation gradients which may not be represented well by the MAPS cell averages. Monthly average precipitation for the Blackleaf Canyon climatic station shows a relatively strong MayJune peak with wide ranges between monthly minimum and maximum values. Annual totals for the 44 year period of record at the Blackleaf site show an apparent periodicity in precipitation with a wavelength of 5 to 7 years (shown by the 3-year running average). Precipitation for 1993, the year prior to the sample collection, exceeded the average for the period of record by approximately 8 inches.

Geologic setting. The Jarina WPA and surrounding areas are underlain by calcareous till deposited by an alpine glacier or glaciers terminating on the western edge of the plains. Shoreline areas display variable sediment character, apparently controlled by prevailing wind directions; the sample site proper is on the westerly (upwind) shore, and is underlain by fine-grained organic rich sediments. Easterly (downwind) shores of the sample site and nearby lakes tend to be underlain by coarse sand and gravel.

Bedrock in the area is sandstone and mudstone from unspecified Late cretaceous formations. The overlying till is thin to absent in places, exposing occasional sandstone outcrops, some of which appear to be associated with ground-water seeps.

Hydrologic type. The Jarina WPA site is a glacial depression lacking surface drainage at current water levels. Strandines of unknown age indicate periods in the past when water levels have been controlled by drainage to the southeast (to sheep Creek). During such times, water depths were 3 to 4 feet greater than those measured in 1994 and lake volume may have been greater by as much as a factor of $5($ ?).

Basin characteristics. The Jarina WPA site has a relatively small surface catchment with respect to wetland area and volume. The basin is shallow throughout, with a maximum measured depth in August 1994 of 2.8 feet and an average depth of about 2 feet or less. The cluster of numerous small lakes and wetlands surrounding the sample site display highly disjunct water chemistry; surveyed water bodies within a 2 square mile area ranged from 452 to $>50,000$ microsiemens/cm in specific conductance. More saline sites are typically underlain by unidentified evaporitic minerals; some lakes were desiccated in 1994. Construction of the berm supporting the Birch creek road isolated the northernmost end of the basin from the remainder of the sample site. However, the presence of a high-water outlet at the opposite (southeastern) end of the basin effectively prevents the road from exerting a major influence on water budgets of the sample site. 
. 
Water chemistry. The Jarina WPA site exhibits "oligosaline" magnesium-sulfate water chemistry. Water column trace element and nutrient concentrations are comparable to regionally and hydrologically similar sites. Mineral phase equilibrium calculations indicate the water column is supersaturated with carbonate phases and essentially in equilibrium with gypsum. Calcareous crusts were observed riming littoral sediments; authigenic gypsum was not observed. The magnesium-sulfate composition and high gypsum saturation in a site of moderate salinity are unusual within the DHES sample set.

A seep discharging from Cretaceous sandstone of unknown formation in a neighboring lake basin is proportionately much higher in sodium and lower in total dissolved solids.

Chemical history. No chemical data predating the DHES sampling of this site are known. Conductivity measurements from August of 1994 are approximately $33 \%$ higher than during the site inventory sampling in June of 1994. Substantially increased lake volume and regular surface outflow in the past can be inferred from erosional shoreline features. Salinity would be expected to be much lower under such hydrologic conditions.

Sediments. Boron, iron, nickel, selenium and zinc concentrations are near the upper extreme for regionally and hydrologically similar sample sites. Boron, nickel, zinc, arsenic and selenium exceed regional mean soil concentrations by factors of 2 to 5 , with boron exhibiting the highest relative enrichment relative to regional values. 



\section{Kingsbury Lake WPA}

climatic setting. The MAPS database indicates a net annual precipitation balance of -24 inches. This is near the less evaporative end of the range shown for hydrologically similar sample sites, reflecting somewhat higher precipitation than over most plains sites. Monthly average precipitation for the nearby Geraldine station shows a pronounced May-June peak. 3-year running averages since the mid 1970 's have mostly remained near or above the long-term average, but totals from 1990 through 1992 (the latest year of compiled record) were below the long-term average.

Geologic setting. Kingsbury Lake occupies a position immediately south of the limit of maximum pleistocene glacial advance. Kingsbury and nearby lakes are interpreted to lie along icemarginal drainage channels developed along the glacial margin. The lake basin is underlain by sandstones and shales of the colorado Group, intruded by dikes connected to the shonkinite intrusion of the Highwood Mountains to the south. Surficial sediments include extensive chemical precipitates, fine-grained organic-rich and reduced lakebed silt and clay, and poorly sorted littoral sand and gravel along winnowed shorelines.

Hydrologic type. Kingsbury Lake is a glaciofluvial(?) depression lacking surface drainage at historically experienced water levels. significant ground water discharge from the basin is considered unlikely due to topographic position, the character of basin geology, and high lake salinity.

Basin Characteristics. Kingsbury Lake is a relatively large playa with a low catchment to wetland area ratio in comparison to hydrologically similar sample sites. The lake basin describes a dogleg, apparently controlled in part by resistant outcrops of intrusive rocks. Most of the inflow to the lake is contributed by Alder creek, which enters western end of the lake. Strong evaporative conditions, a low volume to surface area ratio (lake depths are reported to be less than 3 feet), and restricted circulation into the eastern arm of the lake create substantial salinity gradients within the lake under the observed conditions.

Water chemistry. Water at WET3I at the time of sampling was a highly saline sodium sulfate type with low bicarbonate and carbonate concentrations. Salinity at the sampling site was near the upper extreme for hydrologically similar settings in the sampling network. Equilibrium calculations indicate supersaturation with carbonate species and slight supersaturation with gypsum. Active gypsum(?) precipitation was observed at the sampling site (under somewhat more concentrated conditions than represented by the sample analysis.)

Water column concentrations for arsenic, boron, and iron were the highest among sampling sites of this type. Chromium concentrations are characteristically elevated for sample sites of this type. 

Orthophosphorous and total phosphorous are among the highest of the sampled sites, and at the upper extreme of hydrologically similar sites. Nitrate and ammonium concentrations were both below detection limits. The total organic carbon concentration was also the highest among this site type.

Chemical history. No previous quantitative chemical analyses are known for Kingsbury Lake. U.S. Fish and wildlife Service records contain reference to two reported specific conductance measurements of 32,000 and 39,000 microsiemens $/ \mathrm{cm}$, one dating from 1981 and the other date unrecorded. Specific conductance in the eastern lake arm (which includes WET31) exceeded 100,000 microsiemens per centimeter in August 1994, indicating a twofold or greater seasonal increase in specific conductance over the date of sample collection two months earlier. It is likely that at least the eastern lake arm has desiccated entirely within historic times. Elevated relict shorelines indicate much more dilute conditions have prevailed at times in the recent geologic (and possibly historical) past. The general area is prone to developing saline seeps in cropped areas, which possibly have contributed to the lake's present salt load.

Spatial salinity gradients were observed in both horizontal and vertical dimensions. In August of 1994, specific conductance ranged from greater than $100,000 \mathrm{microsiemens} / \mathrm{cm}$ in the hypersaline eastern arm down to 23,100 microsiemens/cm along the southern shore of the western arm. It is likely that water near the Alder Creek inflow was considerably more dilute still. Among vegetation mats along the southern shore, a substantial vertical salinity gradient was observed in shallow water, with specific conductance near the lake bottom exceeding that at the surface by approximately $30 \%$.

Sediments. Kingsbury Lake sediments include a large component of chemical precipitates, including both carbonates (inferred from $\mathrm{HCl}$ reactivity and mineral saturation indices) and sulfates (inferred from saturation indices and euhedral hand specimens). Bottom sediments in the eastern arm are extremely sticky and reduced, with a bituminous appearance beneath an oxidized surface layer.

Extractable concentrations of boron are at the upper extreme for hydrologically similar sites; other trace elements are typically present in concentrations within the range of other hydrologically and regionally similar sites. Boron exceeds the regional soils average by a factor of six; zinc and copper exceed regional soils means by a few percent. other trace element concentrations are below the regional soils means for those constituents. 
climatic setting. The net annual precipitation balance for the Kleinschmidt Lake site (from the MAPS database) is -18 inches, placing the site toward the middle of the range for hydrologically and regionally similar sites. Monthly average precipitation for the Ovando 9 SSE climatic station shows a bimodal distribution, with a primary June peak and a secondary January peak. The 3-year moving average of total annual precipitation remained below (often considerably below) the long-term average from the mid-1970s through 1993. The total precipitation for 1993 (the year prior to sampling) was very near the long-term average.

Geologic setting. Kleinschmidt Lake occupies an irregular basin within a terminal moraine complex deposited by a glacier advancing down the North Fork of the Blackfoot River during the late pleistocene. Permeable outwash gravels dating from the retreat of the North Fork glacial lobe forms Kleinschmidt Flat to the northeast; advance outwash deposits may underlie the till forming the end moraine complex. Tertiary valley-fill sediments underlie glacial deposits at an unknown depth.

Hydrologic type. Kleinschmidt Lake lies in glaciated terrain with generally poorly integrated drainage, but has channelized inflow and outflow. The outflow elevation was altered by a wetland enhancement project in the mid-1980s(?). Relatively low salinity indicates that discharge from the lake occurs frequently. Groundwater relationships are undescribed.

Basin characteristics. Kleinschmidt Lake receives inflow from nearby Brown's Lake via a small drainage meandering through an area of small internally drained depressions. Most of the contributing catchment is upgradient of Browns Lake. The timing and quantity of inflow received by Kleinschmidt is influenced by residence time of the larger Brown's Lake. Prior to alteration of the outflow, the estimated volume of the lake was 1083 acre-feet, with an average depth on the order of 5 feet. The present lake depth and volume are uncertain.

water chemistry. At the time of sampling, Kleinschmidt Lake contained relatively dilute, highly alkaline magnesium-bicarbonate water. Mineral equilibria indicate substantial oversaturation with respect to carbonate phases. Ammonium and nitrate concentrations were below detection limits, and the orthophosphate concentration was near the low end of the range shown for sites in this class. The total organic carbon concentration ranked mid-range within the site class. The total phosphorous concentration was not determined.

Arsenic and iron concentrations ranked mid-range among sites classed with Kleinschmidt Lake; the selenium concentration made Kleinschmidt Lake one of only 5 sample sites with reportable water column values for this element. 

Chemical history. No previous laboratory water chemistry data are known for Kleinschmidt Lake. In the late 1950s, dissolved oxygen monitoring was performed as part of a fishery enhancement effort. wintertime dissolved oxygen concentrations dropped to the 1-2 milligram per liter range at that time. Changes to lake volume and depth since then may have altered the lake's wintertime dissolved DO.

Sediments. Arsenic was reported at a concentration ranking the site toward the low end of the range shown by sites in the same class. Copper, iron and zinc concentrations ranked mid-range in comparison to similar sites. None exceeded the mean values for soils and other surficial materials of the western United states. 



\section{LaFoe Lake}

climatic setting. The net annual precipitation balance for LaFoe Lake (from the MAPS database) is approximately 8 inches. This makes LaFoe Lake the wettest of the lowland sites among the sample set. Mean monthly precipitation for the Libby Ranger station climatic station (at a lower elevation than the WET33 site) shows a bimodal distribution, with a broad primary winter maximum and a secondary June peak. Annual totals for the Libby station show a 3-year running average since 1950 generally meeting or exceeding the average for the period of record, with the exception of the 1977 to 1982 period. Annual precipitation in 1993 (the year prior to sampling) met the long-term average for the station.

Geologic setting. LaFoe Lake and the contributing drainage basin are underlain by the calcareous wallace Formation of the Proterozoic Belt series. Alpine glaciers occupied nearby headwater areas, but their down-valley extent is uncertain. Glacial and other surficial sediments overlying bedrock are undescribed, but inferred to be relatively thin. LaFoe Lake lies over the trace of the Quartz Creek Fault, a north-trending normal fault downdropped to the west.

Hydrologic type. LaFoe Lake occupies a small depression of uncertain origin, fed by intermittent(?) streamflow and drained by a perennial(?) stream.

Basin characteristics. The LaFoe Lake drainage basin features high local relief and a comparatively high catchment to wetland area ratio relative to other western sample sites. The lake itself lies near a low drainage divide which may be controlled in some fashion by the Quartz creek Fault, the trace of which passes through this gap.

Water chemistry. The water chemistry of LaFoe Lake is dilute, near-neutral and calcium-bicarbonate in composition. Mineral equilibria indicate undersaturation with respect to carbonate phases. The ammonium and phosphorous (total and orthophosphorous) concentrations rank toward the upper end of the ranges shown by Rocky Mountain sites; The total organic carbon concentration ranks mid-range among Rocky Mountain sites.

Iron and aluminum concentrations rank near the high end of the range shown by Rocky Mountain sites; the reported copper concentration ranked mid-range, and most other trace element concentrations were below detection limits.

Chemical history. One previous (partial) chemical analysis is known from Lafoe Lake. This sample, collected in June of 1987, had a specific conductance of only $62 \mathrm{microsiemens} / \mathrm{cm}$, about one-third the value recorded at the time of the DHEs sampling. This may provide some idea of the kind of seasonal variation in salinity expected at this site from early to late summer. No analyses of 

trace elements or micronutrients were included in this analysis. Generally, the rapid flux of water through this site implied by the moist climatic setting and high catchment to wetland ratio would be expected to maintain dilute water chemistry.

Sediments. The extractable arsenic concentration reported for LaFoe Lake is one of the lowest for the entire data set. Boron, iron, selenium and zinc concentrations rank mid-range among Rocky Mountain sites. Most other trace elements were below detection limits.

The selenium concentration reported exceeded the mean value for soils and other surficial materials of the western U.S. by a factor of 1.7 ; other reported values were below their regional soil means. 



\section{Lahrity Lake}

climatic setting. The net annual precipitation balance for the Lahrity Lake site (from the MAPS database) is -17 inches, placing the site toward the middle of the range for hydrologically and regionally similar sites. Monthly average precipitation for the Ovando 9 SSE climatic station shows a bimodal distribution, with a primary June peak and a secondary January peak. The 3-year moving average of total annual precipitation remained below (often considerably below) the long-term average from the mid-1970s through 1993. The total precipitation for 1993 (the year prior to sampling) was very near the long-term average.

Geologic setting. Lahrity Lake occupies a glacial ice-block depression (kettle) in till (and other glacial sediments?) deposited by ice advancing into the ovando valley from the Monture creek drainage. The adjacent bedrock outcropping of Monture Hill is a prominent resistant knob underlain by the snowslip Formation of the Proterozoic Belt series. The Monture creek source area for the glacial deposits in the area includes large exposures of the calcareous and dolomitic Helena Formation.

Inspection of the glacial sediments surrounding Lahrity Lake shows abundant cobbles and boulders in a calcareous silty matrix.

Hydrologic type. Lahrity Lake is a glacial depression lacking surface drainage at present water levels. Strandlines represented by beach erosion features indicate water levels which may have allowed surface water discharge. High salinity indicates that ground-water outflow is restricted, allowing accumulation of solutes.

Basin characteristics. Lahrity Lake is a steep-sided basin with minimal surface catchment area relative to the size of the lake; the ratio of catchment to wetland area ranks near the bottom of the range for the entire sample set. Additional areas of small closed basins surrounding Lahrity lake may contribute ground-water inflow. Irregular knobs of till within the lake basin suggest deposition as ablation debris in a region of stagnant ice.

Measured water depths at the time of sampling ranged up to 11.5 feet; average depth was on the order of 6 feet and lake volume was estimated to be about 150 acre-feet (or $6.5 \mathrm{milli}$ in cubic feet.) The sampled lake level was approximately 10 feet below the base of a prominent erosional shoreline feature and approximately 13.5 feet below the stage which would allow lake outflow to the southwest. At these lake stages, lake volume probably was several-fold greater than at the time of sampling, as low-gradient areas at the north end of the lake flood.

Water chemistry. Presently, Lahrity Lake contains highly alkaline, "polysaline" sodium/potassium-sulfate brine virtually depleted in calcium; the proportional potassium concentration is uniquely high 

for the saline sample sites. Equilibrium calculations indicate oversaturation with carbonate phases. The ammonium and total organic carbon concentrations are among the highest for western Montana sample sites (as are those for the adjacent WET35 site) while the total and orthophosphorous concentrations rank mid-range among sites in the same class.

The arsenic concentration is the highest among western sites, and is exceeded only by two hypersaline northeastern sampling sites. Copper and iron concentrations rank toward the middle of the range shown by sites in this class; most other trace element concentrations were reported to be below detection limits. However, interferences led to higher detection limits than typical for several elements.

Chemical history. No other quantitative chemical data for Lahrity Lake are known. Field measurements collected in July 1993 showed a $\mathrm{pH}$ of 9.92 and specific conductance $>20,000$ microsiemens $/ \mathrm{cm}$. Geomorphic indicators imply that Lahrity Lake has probably spilled water during past climatic conditions. At such times, and at intermediate lake stages where the solute load is diluted, salinity can be much lower than during the modern observations.

Sediments. Littoral sediments are composed of a gelatinous, highly organic and reduced (H2S generating) muck up to 1 foot in depth, overlying a firm cobbly surface of till.

Among western sample sites, only mine-impacted sediments showed higher concentrations of arsenic. Boron, copper, iron, selenium and zinc concentrations ranked toward the middle of the ranges shown for similar sites. The arsenic concentration exceeded the mean value for western United States soils by a factor of 5 . Boron and selenium exceeded mean regional values by factors of 1.4 and 1.7 , respectively; other trace element concentrations were below their regional mean soil concentrations. 



\section{Lahrity Lake Southwest wetland}

climatic setting. The net annual precipitation balance for the Lahrity Lake Southwest site (from the MAPS database) is -17 inches, placing the site toward the middle of the range for hydrologically and regionally similar sites. Monthly average precipitation for the ovando 9 SSE climatic station shows a bimodal distribution, with a primary June peak and a secondary January peak. The 3-year moving average of total annual precipitation remained below (often considerably below) the long-term average from the mid-1970s through 1993. The total precipitation for 1993 (the year prior to sampling) was very near the long-term average.

Geologic setting. Lahrity Lake southwest occupies a shallow glacial ice-block(?) depression in till (and other glacial sediments?) deposited by ice advancing into the ovando Valley from the Monture creek drainage. The adjacent bedrock outcropping of Monture Hill is a prominent resistant knob underlain by the Snowslip Formation of the Proterozoic Belt series. The Monture Creek source area for the glacial deposits in the area includes large exposures of the calcareous and dolomitic Helena Formation.

Inspection of the glacial sediments surrounding Lahrity Lake shows abundant cobbles and boulders in a calcareous silty matrix.

Hydrologic type. The Lahrity Lake southwest site is a relatively shallow glacial depression with at least seasonal surface water outflow. The outlet elevation prevents water levels in the wetland from rising substantially above that observed at the time of sampling. The wetland surface was approximately 7.9 feet higher than the surface elevation of adjacent Lahrity Lake, possibly restricting ground-water outflow from Lahrity lake to the south.

Basin characteristics. The Lahrity Lake Southwest wetland appears to capture a larger area of surface drainage than Lahrity Lake proper, and has a higher catchment to wetland area ratio. surface drainage and low volume (estimated maximum depth of 3-5 feet) imply relatively rapid flux of water and solutes through the site when compared to Lahrity Lake. Head relationships preclude this site from receiving ground-water outflow influenced by the Lahrity Lake brine.

Water chemistry. At the time of sampling, WET35 exhibited moderately alkaline "oligosaline" water lacking strongly dominant cation characteristics. Calcium, magnesium, sodium and potassium concentrations (in meq/l) were all within a factor of five of each other - an unusual distribution among the sample sites. CO2 species (bicarbonate and carbonate) dominate the anion distribution. Equilibrium calculations indicate substantial oversaturation with carbonate minerals.

The ammonium concentration reported for WET35 was the highest of any of the sample sites. Total organic carbon, orthophosphorous 

and total phosphorous concentrations were also very high, ranking at or near the top of the ranges shown for sites in the same classification. Most nutrients at this site are conspicuously high for settings with surface drainage and without very high salinity.

The arsenic concentration reported for WET35 was very high, exceeded only at three highly alkaline and saline sample sites. The iron concentration ranked mid-range among similar sites, and copper (reported at the detection limit) ranked toward the lower end of the range for sites of this class. Other trace element concentrations were reported below detection limits.

Chemical history. No other quantitative chemical data from this site are known. Field parameters measured in June of 1993 showed higher $\mathrm{pH}(9.04 ; 8.3$ during the DHES sampling) and considerably lower specific conductance (775 microsiemens/cm; 2640 during the DHES sampling.) Surface outflow and comparatively high fluid flux through the basin are expected to limit the range of salinity at this site. The DHES analysis, collected at the end of a dry summer, may represent concentrations near the upper end of the expected range for this site.

Sediments. The wetland basin is underlain by 1 foot or more of peaty organic sediments with clots of apparent authigenic sediments (marl?). the selenium concentration ranked toward the upper end of the range for similar sites; arsenic and boron concentrations ranked toward the mid-range for sites in this classification, and iron and zinc concentrations ranked at the bottom of their respective ranges, with iron a significant low-end outrider among intermontane valley sites. Most other trace element concentrations were below detection limits.

Arsenic and selenium concentrations exceeded the mean concentrations for soils and other surficial materials of the western United States by factors of 2.4 and 1.7 , respectively. other trace element concentrations reported were below the regional mean values for soils. 

climatic setting. The net annual precipitation balance for Lake Bowdoin (from the MAPS database) is -28 inches, placing the Bowdoin sites at the more evaporative end of the range shown by sites in this classification. Monthly mean precipitation for the Malta 7NE climatic station shows a broad summer peak with a maximum in May; the Malta climatic station, with a longer period of record but farther from Lake Bowdoin, shows a pronounced June maximum. Annual totals for the Malta 7NE station, shows the years 1988 to 1992 below the average for the period of record. The total for 1993 (the year prior to sampling) exceeded the average for the period of record by about 2.5 inches.

Geologic setting. The natural catchment of Lake Bowdoin is underlain primarily by the Late Cretaceous claggett Shale, with the overlying Judith River Formation exposed in some higher-elevation areas. The apex of the Bowdoin Dome lies a few miles to the north; this structural dome is a significant hydrocarbon trap and supports an active natural gas field. Surficial sediments underlying the Lake Bowdoin basin are generally described as "alluvium", mapped as a broad east-west band underlying the lake. These deposits are apparently continuous with permeable gravels underlying lower Beaver Creek to the east, which are believed to be glacial in origin.

Hydrologic type. Lake Bowdoin is an area of natural internal drainage augmented and greatly expanded by a complex system of dikes, water control structures and water imports. Under favorable conditions, managed outflow can occur both to the Dry Lake Unit (a satellite basin to the east of Lake Bowdoin) and directly to Beaver Creek. Outflows are possible only during high water levels, however. Discharge to Beaver Creek did not occur for 7 years prior to the 1994 DHES sampling, during which time the Lake Bowdoin system was effectively closed to surface water outflows.

Basin characteristics. The natural catchment of the Lake Bowdoin Basin is comparatively small, consisting mainly of intermittent drainages from the south which are routed to peripheral wetland areas and ultimately to Lake Bowdoin when flows allow. Since most of the inflow is diverted from the Milk River Irrigation Project, the entire upper Milk River above the Dodson diversion is effectively contributing water and solutes to the Lake Bowdoin system. Delineated contributing areas and tabulated acreage figures for the Bowdoin sites thus include the MIlk River basin above Dodson. The WET36 sampling site is immediately adjacent to the inlet structure from the Dodson canal; the site of the inflow from Black Coulee (via peripheral wildlife ponds) is also nearby.

Water chemistry. At the time of sampling, the WET36 site was characterized by highly alkaline "oligosaline" sodium sulfate water. Mineral equilibria indicate oversaturation with carbonate phases. Ammonium, phosphorous (total and orthophosphate) and total 

organic carbon concentrations all rank toward the mid-range of values shown by sites classified with lake Bowdoin. The arsenic concentration ranked toward the lower end of the range shown by Great plains sites; boron, copper and iron concentrations ranked mid-range within the site classification, and other trace element concentrations were below reporting limits.

Chemical history. Since 1978, the U.S. Fish and Wildlife Service has conducted periodic monitoring of limited water quality parameters at a site very near WET36. These data show a wide range in specific conductance and $\mathrm{pH}$. Reported values of specific conductance range over two orders of magnitude ( 610 to 60,000 microsiemens/cm) and reported $\mathrm{pH}$ values range from an apparently anomalous low of 7.5 to a high of 10.6. The specific conductance measured for this sample (6070 microsiemens/cm) was below the simple average for the USFWS data for this site $(7582$ microsiemens/cm for 131 measurements).

Dissolved oxygen measurements also show a rather wide range, including summertime lows in the 4 to $5 \mathrm{mg} / \mathrm{l}$ range. No wintertime data have been collected as part of this monitoring program.

While there is some question about the extreme pH values reported, generally these data show a very wide seasonal and interannual variability at this site, driven by periodic importation of dilute water from the Dodson Canal, followed by periods of evaporative concentration in an essentially closed-basin setting.

The spatial variability shown by the DHES sampling is substantial; near-synoptic sampling of this site and WET38 near the lake outlet showed $30 \%$ increase in total dissolved solids from inlet to outlet areas. The mean specific conductance values for U.S. Fish and Wildlife Service measurements from correlative sites show a $43 \%$ higher mean for the outlet end of the lake. Generally, the salinity gradient is likely to be steeper during more strongly evaporative conditions.

Sediments. The wide range of reported concentration of solutes in the water column implies that periodic dissolution and reprecipitation of authigenic mineral phases may occur at this site, perhaps with complex effects on aqueous concentrations of nutrients and trace elements. The sample collected from this site showed arsenic, boron and iron concentrations near the low end of the ranges shown for Plains sites. Other trace element concentrations were below detection Iimits. Arsenic and boron concentrations were below the reported mean soil concentrations for the Western United states. 

. 
climatic setting. The net annual precipitation balance for Lake Bowdoin (from the MAPS database) is -28 inches, placing the Bowdoin sites at the more evaporative end of the range shown by sites in this classification. Monthly mean precipitation for the Malta 7NE climatic station shows a broad summer peak with a maximum in May; the Malta climatic station, with a longer period of record but farther from Lake Bowdoin, shows a pronounced June maximum. Annual totals for the Malta 7NE station, shows the years 1988 to 1992 below the average for the period of record. The total for 1993 (the year prior to sampling) exceeded the average for the period of record by about 2.5 inches.

Geologic setting. The natural catchment of Lake Bowdoin is underlain primarily by the Late cretaceous Claggett Shale, with the overlying Judith River Formation exposed in some higher-elevation areas. The apex of the Bowdoin Dome lies a few miles to the north; this structural dome is a significant hydrocarbon trap and supports an active natural gas field. Surficial sediments underlying the Lake Bowdoin basin are generally described as "alluvium", mapped as a broad east-west band underlying the lake. These deposits are apparently continuous with permeable gravels underlying lower Beaver Creek to the east, which are believed to be glacial in origin.

Hydrologic type. Lake Bowdoin is an area of natural internal drainage augmented and greatly expanded by a complex system of dikes, water control structures and water imports. Under favorable conditions, managed outflow can occur both to the Dry Lake Unit (a satellite basin to the east of Lake Bowdoin) and directly to Beaver creek. Outflows are possible only during high water levels, however. Discharge to Beaver Creek did not occur for 7 years prior to the 1994 DHES sampling, during which time the Lake Bowdoin system was effectively closed to surface water outflows.

Basin characteristics. The natural catchment of the Lake Bowdoin Basin is comparatively small, consisting mainly of intermittent drainages from the south which are routed to peripheral wetland areas and ultimately to Lake Bowdoin when flows allow. Since most of the inflow is diverted from the Milk River Irrigation Project, the entire upper Milk River above the Dodson diversion is effectively contributing water and solutes to the Lake Bowdoin system. Delineated contributing areas and tabulated acreage figures for the Bowdoin sites thus include the MIlk River basin above Dodson.

Water chemistry. Two samples were collected at this site as part of the DHES program, in May and September of 1993. Neither can be compared directly to the inlet and outlet samples, which were collected in May of 1994. No U.S. Fish and Wildlife Service monitoring point corresponds closely with this site. Changes in gross water chemistry over this period were modest. The total 

dissolved solids concentration decreased slightly between sampling events. The $\mathrm{pH}$ was a full point higher in the september, and the proportional sodium concentration (as measured by the sodium adsorption ratio) was moderately lower. Orthophosphorous and ammonium concentrations were essentially unchanged over this period; the total organic carbon concentration increased by a factor of 5 between the two sample collections. Trace element concentrations were also essentially unchanged, with mid-range concentrations of arsenic and boron and most others below detection limits.

Note, however, that this degree of seasonal stability may not be representative of the usual trends at Bowdoin. USFWS records from monitoring stations at the inlet and outlet ends of the lake show specific conductance increasing by as much as a factor of three, and decreasing by as much as a factor of 4 within a given year in response to evaporation and episodic inflows of dilute water.

Chemical history. See above.

Sediments. The sediment samples collected at this site showed greater differences than did water, probably due to local spatial heterogeneity in sediment characteristics rather than temporal variability. Arsenic concentrations were similar, but boron concentrations differed by more than a factor of three, with the September sample the lower of the two. Copper differed by more than a factor of 2 , again with september showing the lower value. Copper, reported at slightly above the detection limit in the May sample, was reported as below detection in september. Selenium showed the opposite pattern. Only the boron concentration of the May sample was above the mean concentration for soils of the western United States, by a factor of only 1.3 . 



\section{Lake Bowdoin Outlet}

climatic setting. The net annual precipitation balance for Lake Bowdoin (from the MAPS database) is -28 inches, placing the Bowdoin sites at the more evaporative end of the range shown by sites in this classification. Monthly mean precipitation for the Malta $7 \mathrm{NE}$ climatic station shows a broad summer peak with a maximum in May; the Malta climatic station, with a longer period of record but farther from Lake Bowdoin, shows a pronounced June maximum. Annual totals for the Malta 7NE station, shows the years 1988 to 1992 below the average for the period of record. The total for 1993 (the year prior to sampling) exceeded the average for the period of record by about 2.5 inches.

Geologic setting. The natural catchment of Lake Bowdoin is underlain primarily by the Late cretaceous claggett shale, with the overlying Judith River Formation exposed in some higher-elevation areas. The apex of the Bowdoin Dome lies a few miles to the north; this structural dome is a significant hydrocarbon trap and supports an active natural gas field. Surficial sediments underlying the Lake Bowdoin basin are generally described as "alluvium", mapped as a broad east-west band underlying the lake. These deposits are apparently continuous with permeable gravels underlying lower Beaver creek to the east, which are believed to be glacial in origin.

Hydrologic type. Lake Bowdoin is an area of natural internal drainage augmented and greatly expanded by a complex system of dikes, water control structures and water imports. Under favorable conditions, managed outflow can occur both to the Dry Lake Unit (a satellite basin to the east of Lake Bowdoin) and directly to Beaver creek. Outflows are possible only during high water levels, however. Discharge to Beaver Creek did not occur for 7 years prior to the 1994 DHES sampling, during which time the Lake Bowdoin system was effectively closed to surface water outflows.

Basin characteristics. The natural catchment of the Lake Bowdoin Basin is comparatively small, consisting mainly of intermittent drainages from the south which are routed to peripheral wetland areas and ultimately to Lake Bowdoin when flows allow. Since most of the inflow is diverted from the Milk River Irrigation Project, the entire upper Milk River above the Dodson diversion is effectively contributing water and solutes to the Lake Bowdoin system. Delineated contributing areas and tabulated acreage figures for the Bowdoin sites thus include the MIlk River basin above Dodson. The wET38 sampling site is adjacent to the outlet structure conveying water to the Dry Lake Unit.

Water chemistry. At the time of sampling, the WET36 site was characterized by highly alkaline "oligosaline" sodium sulfate water. Mineral equilibria indicate oversaturation with carbonate phases. Ammonium, phosphorous (total and orthophosphate) and total organic carbon concentrations all rank toward the mid-range of 

values shown by sites classified with Lake Bowdoin. Phosphorous (total and orthophosphorous concentrations) and total organic concentrations were noticeably higher than at the WET36 site at the lake inlet. The arsenic concentration ranked toward the lower end of the range shown by Great Plains sites; boron, copper and iron concentrations ranked mid-range within the site classification, all somewhat higher than at WET36. Other trace element concentrations were below reporting limits.

Chemical history. Since 1978, the U.S. Fish and Wildlife Service has conducted periodic monitoring of limited water quality parameters at a site on the eastern arm of Lake Bowdoin, less than a mile from WET38. As with the inlet-area station, these data show a wide range in specific conductance, $\mathrm{pH}$ and dissolved oxygen. Reported values of specific conductance range from less than 1000 $\mathrm{microsiemens} / \mathrm{cm}$ to $39000 \mathrm{microsiemens} / \mathrm{cm}$, and reported $\mathrm{pH}$ values range from 8.1 to an extremely high 11.0 . The specific conductance measured for this sample (7800 microsiemens/cm) was considerably below the simple average for the USFWS data for this site ( $10871 \mathrm{microsiemens/cm}$ for 151 measurements).

As at WET36, reported dissolved oxygen measurements also show a rather wide range, including summertime lows in the 1 to $2 \mathrm{mg} / 1$ range. No wintertime data have been collected as part of this monitoring program.

While there is some question about the extreme $\mathrm{pH}$ values reported, generally these data show a very wide seasonal and interannual variability at this site, driven by periodic importation of dilute water from the Dodson Canal, followed by periods of evaporative concentration in an essentially closed-basin setting.

The spatial variability shown by the DHES sampling is significant; near-synoptic sampling of this site and WET36 near the lake inlet showed a $30 \%$ increase in total dissolved solids from inlet to outlet areas. The mean specific conductance values for U.S. Fish and Wildlife Service measurements from correlative sites show a $43 \%$ higher mean for the outlet end of the lake. Generally, the salinity gradient is likely to be steeper during more strongly evaporative conditions. Nitrogen (nitrate and ammonium) concentrations were indistinguishable between WET38 and WET36. Total and orthophosphorous concentrations, however, increased disproportionately with respect to salinity from inlet to outlet areas ( $80 \%$ and $74 \%$ respectively).

Sediments. The wide range of reported concentration of solutes in the water column implies that periodic dissolution and reprecipitation of authigenic mineral phases may occur at this site, perhaps with complex effects on aqueous concentrations of nutrients and trace elements. The sediment sample collected from this site showed generally enriched trace element concentrations in comparison to the other Bowdoin sites. This may reflect heterogeneities in sediment grain size and other characteristics; alternatively, irrigation return flows delivered to the 

southeastern lake arm via the Drumbo Unit may carry higher concentrations of some trace elements than do other inflows.

Arsenic, boron, chromium, iron, nickel, vanadium, and zinc concentrations ranked toward the upper end of the ranges shown by sites classified with Lake Bowdoin. The copper concentration ranked mid-range with respect to sites in the same class, and other trace elements were below reporting limits. Boron exceeded soil concentrations for the western United States by a factor of 3 and arsenic by a factor of 1.3 ; most other concentrations were near or below regional mean soil concentrations. 



\section{Lake Mason National Wildlife Refuge}

climatic setting. The net annual precipitation balance (from the MAPS database) is -30 inches, placing Lake Mason at the extreme of the range of evaporative intensity shown by the sampling sites. Mean monthly precipitation for the Roundup climatic station shows a pronounced June maximum. Annual total precipitation in Roundup shows the 3-year running average meeting or exceeding the long-term average since the mid-1980s. Total precipitation in 1992 (the year prior to sampling) was about 1.5 inches above the long-term average, and in 1993 precipitation exceeded the average by about 5 inches.

Geologic setting. The Lake Mason basin is underlain by surficial deposits of inferred lacustrine and paludal origins, apparently of low permeability and up to 40 feet in thickness. The lake lies within a structurally controlled basin situated near the axis of a syncline; in most of the basin, the Lance Formation (a dependable low-yield sandstone aquifer) underlies surficial sediments or is exposed at the surface. Peripheral areas of the basin are underlain by Bearpaw Shale and Judith River Formation; dissected areas of permeable terrace gravels lie elevated along drainage divides.

Hydrologic type. Lake Mason is a natural, structurally controlled, unglaciated basin altered by the construction of a dam and outlet control structure. The lake has surface water inflow and outflow; the record of discharge through the control structure is not known. Recent outflow may be inferred, however, from the dilute water quality at the time of sampling.

Basin characteristics. Lake Mason occupies a low-gradient basin receiving controlled inflow from the willow creek drainage and overflow from upgradient intermittent lakes. The catchment to wetland area ratio ranks toward the middle of the range for sites of the unglaciated plains. Mapped stream patterns suggest a shallow ground-water system may influence Lake Mason. Upstream water storage, irrigation diversions and (probably) return flows affect the quantity and timing of the runoff received by the lake. Permeable upland terrace gravels in the Willow Creek drainage may support streamflows with ground-water storage.

Water chemistry. At the time of sampling, Lake Mason water was of an alkaline, "oligosaline" magnesium/sodium-bicarbonate character. Mineral equilibria indicate substantial oversaturation with carbonate phases. Ammonium, phosphorous and total organic carbon concentrations all ranked mid-range for sites in this classification. Arsenic and boron concentrations were toward the lower end of the ranges shown by sites of the unglaciated plains. Lake Mason was among a cluster of 5 sites from the region with much higher chromium concentrations than the rest of the sample set. The copper concentration was also very high, matched or exceeded only by nearby Warhorse National Wildlife Refuge and by western Montana 

sites with known mining impacts. The lead concentration reported was also the highest for this class.

Chemical history. No other water chemistry data from Lake Mason are known.

Sediments. Arsenic, copper and iron concentrations rank toward the high end of the ranges shown by sites of the unglaciated plains. Boron, chromium, nickel, vanadium and zinc concentrations ranked low to mid-range. Most other trace elements were below detection limits. Copper and boron concentrations exceeded mean concentrations for soils and other surficial materials of the western United States by factors of about 2; other trace elements were below regional mean soil values. 



\section{Lake Thibadeau Northeast}

climatic setting. The net annual precipitation balance for the lake Thibadeau Northeast site (from the MAPS database) is -26 inches, at the upper end of evaporative intensity for sample sites of the glaciated plains. Mean monthly precipitation for the Havre climatic station shows a pronounced June maximum. Annual precipitation totals for the Havre station show an apparent periodicity with a period of 5 to 7 years. From 1987 to 1990 , the three-year running average was below the average for the period of record; from 1991 through 1993, the running average met or exceeded the average for the period of record. In 1993, the year prior to sampling, total precipitation exceeded the average by about 5 inches.

Geologic setting. No satisfactory geologic mapping of this site was discovered in a search of published resources. Small-scale geologic mapping shows the area to be underlain by the Late Cretaceous Bearpaw Shale. The site is within the extent of Pleistocene glaciation, and Bearpaw Shale outcrops in the area are probably underlain by calcareous, poorly permeable till; no description of surficial sediments was discovered, however.

Hydrologic type. The wetland area sampled is an artificial impoundment of an intermittent first-order stream. Contour closure suggests that the site may been a wetland prior to the construction of the impoundment, though no documentation of the site history is available. The impoundment has an outlet structure, but the frequency and duration of outflow are not known. The dilute water chemistry exhibited at the time of the DHES sampling suggests recent surface water discharge and flushing of the impoundment.

Basin characteristics. The catchment is a low-gradient upland basin with a moderate catchment to wetland area ratio. The depth of the small, elongate basin is unknown but probably does not exceed 10 feet based on topographic considerations. Another impoundment upgradient from the sample site probably influences the duration and timing of inflow to the sample site.

Water chemistry. At the time of sampling, the WET40 site contained highly alkaline, dilute water of calcium/sodium-bicarbonate composition. Mineral equilibria indicate over-saturation with carbonate phases. Ammonium, phosphorous (total and orthophosphorous) and total organic carbon concentrations all rank mid-range with respect to other sample sites in the same classification. The arsenic concentration was moderate for sites of the glaciated plains, and the boron concentration was the lowest for any site in this class. Copper and iron concentrations, on the other hand, ranked near the high end for sites in this class. Lead was present at the detection limit, and most other trace elements were reported below detection.

Chemical history. No other chemical data from this site are known. 

Sediments. Extractable concentrations of arsenic were toward the low end of the range shown for sites of the glaciated plains. Most other trace elements with reportable concentrations (boron, copper, chromium, iron, nickel, vanadium and zinc) ranked toward the upper end of their respective ranges. Only boron (by a factor of 2 ) and zinc (1.2) exceeded the mean soil values for the western United states. 



\section{Lakeside Wetland}

climatic setting. The net annual precipitation balance for the Lake Bowdoin area (including the Lakeside wetland) is -28 inches, placing the Bowdoin sites at the more evaporative end of the range shown by sites in this classification. Monthly mean precipitation for the Malta $7 \mathrm{NE}$ climatic station shows a broad summer peak with a maximum in May; the Malta climatic station, with a longer period of record but farther from Lake Bowdoin, shows a pronounced June maximum. Annual totals for the Malta 7NE station, shows the years 1988 to 1992 below the average for the period of record. The total for 1993 (the year prior to sampling) exceeded the average for the period of record by about 2.5 inches.

Geologic setting. The natural catchment of the Lake Bowdoin area is underlain primarily by the Late cretaceous claggett Shale, with the overlying Judith River Formation exposed in some higherelevation areas. The apex of the Bowdoin Dome lies a few miles to the north; this structural dome is a significant hydrocarbon trap and supports an active natural gas field. Surficial sediments underlying the Lake Bowdoin basin are generally described as "alluvium", mapped as a broad east-west band underlying the lake. These deposits are apparently continuous with permeable gravels underlying lower Beaver creek to the east, which are believed to be glacial in origin.

Hydrologic type. The Lakeside wetland is a small internally drained basin altered and augmented by dikes, ditches, inlet and outlet control structures, and transportation and utility corridors. Inflow is diverted directly from the Dodson south canal. Outflow is controlled by a headgate and ditch delivering water to the Dry Lake Unit and to peripheral ponds nearby.

Basin characteristics. The natural catchment of the Lakeside wetland is minimal in area, with almost all water in the system imported from the Milk River Irrigation Project. Water management objectives for the Lakeside Unit emphasize maintaining low salinity, requiring that a proportionately high water flux through the basin be maintained. The depth of the basin is not available but is inferred to be only a few feet.

Water chemistry. At the time of sampling, the lakeside wetland contained dilute (for the region), alkaline water of nonspecific composition; divalent and monovalent cations contributed about equally to the solute load, and $\mathrm{CO} 2$ species and sulfate both contributed significantly to the anion equivalence. The dilute nature of the site reflects the import of Milk River Project water to the site in accordance with the refuge management objectives. Equilibrium calculations indicate oversaturation with carbonate minerals. Ammonium and nitrate concentrations were both below detection limits (unusual for Great Plains sites) and orthophosphorous and total phosphorous concentrations were both near the bottom of the ranges for sample sites outside of the Rocky 

Mountains province. The total organic carbon concentration was the lowest for the glaciated plains region and among the five lowest in the data set.

Boron was the only trace element present above reporting limits in the Lakeside site; it's concentration was among the lowest of the Great Plains sites.

Chemical history. The U.S. Fish and wildlife Service has conducted periodic water quality monitoring at the WET41 site since 1978. Generally, these data demonstrate refuge managers' success in maintaining low salinity in the Lakeside unit. The mean of over 150 specific conductance measurements (707 microsiemens/cm) is about $30 \%$ higher than specific conductance measured at the time of the DHES sampling, but only rarely has specific conductance

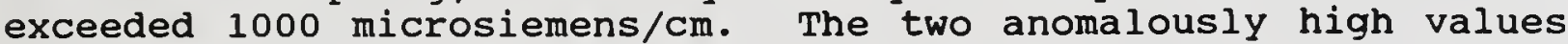
( 9780 and 7500 microsiemens on May 26 and June 11, 1992) appear suspect, and must represent either short-term importation of saline water from Lake Bowdoin or, more probably, erroneous measurements. The single anomalously low value (50 microsiemens/cm on April 17, 1979) is also probably an erroneous measurement. Reported pH values range from 8.2 to 11.2 , and dissolved oxygen ranged from very high concentrations in excess of $16 \mathrm{mg} / 1$ down to the 5 to 6 $\mathrm{mg} / \mathrm{l}$ range. No wintertime measurements are included in the USFWS monitoring.

Sediments. Arsenic, boron and zinc concentrations rank toward the low end of the ranges shown for Great Plains sampling sites. The iron concentration ranks mid-range among sites in this class, and the copper concentration ranks toward the top of the range shown by the glaciated Great Plains sites. None exceeded the mean values for soils and other surficial materials of the western United states. 

climatic setting. The net annual precipitation balance for Lame steer NWR (from the MAPS database) is -23 inches, toward the less evaporative end of the range shown for sample sites of the unglaciated plains. Mean monthly precipitation for the Wibaux $2 \mathrm{E}$ climatic station shows a broad summertime peak with a June maximum. Annual total precipitation for the wibaux $2 \mathrm{E}$ site shows an apparent periodicity with a 5 to 7 year cycle shown by the 3-year running average. Annual totals were below the mean for the period of record during most of the 1980s. Data for the two years prior to sampling were not retrieved for this site.

Geologic setting. The Lame steer site and the contributing drainage basin are underlain by the Tongue River Member of the early Tertiary Fort Union Formation, made up of sandstone, siltstone, mudstone and coal. Surficial deposits are inferred to be local in origin and distribution, and to reflect the lithologies composing the Fort Union Formation.

Hydrologic type. The Lame steer wetland is an artificial impoundment of an intermittent second(?) order stream. The reservoir has an outlet structure and surface outflow; the frequency and duration of surface outflow are unknown, however.

Basin characteristics. The Lame steer impoundment has one of the higher catchment to wetland area ratios among sample sites of the unglaciated plains. Sandstone aquifers of the Fort Union Formation (and possibly clinker) are inferred to provide shallow ground-water storage within the Lame steer catchment. The water depth is unknown but is inferred from the surrounding topography to be probably no more than 10 feet.

Water chemistry. At the time of sampling, Lame steer Reservoir contained moderately alkaline, "oligosaline" sodium-sulfate water. Mineral equilibria indicate oversaturation with carbonate species. Ammonium and nitrate concentrations were both below detection limits; phosphorous concentrations (total and orthophosphate) and the total organic carbon concentration also ranked toward the lower end of the range shown for Great Plains sites. Arsenic, boron and iron concentrations ranked relatively low in the ranges shown for Great Plains sites. At slightly above the reporting limit, the lead concentration ranked high among similar sites. Other trace element concentrations were reported to be below reporting limits.

Chemical history. No previous water chemistry data from this site are known.

Sediments. Arsenic, boron, copper, iron, nickel, vanadium, and zinc all rank toward the middle of the ranges shown by sites of this classification, while other trace element concentrations were mainly below reporting limits. Of the reported concentrations, only boron exceeds the mean soil concentration for the western 

United States (by a factor of 1.8). 



\section{Lavina DOT Mitigation Wetland}

climatic setting. The net annual precipitation balance for the Lavina site (from the MAPS database) is -29 inches, placing WET43 near the more strongly evaporative extreme of the range shown by the sample sites. Mean monthly precipitation for the Barber climatic station shows a June maximum. The 3-year running average of annual precipitation for the Barber station remained below often well below) the long-term average throughout the 1984-1992 period. Annual precipitation in 1993 (the year prior to sampling) exceeded the long-term average by 4 inches.

Geologic setting. The WET43 site is underlain by alluvium of the Musselshell River and of the unnamed northern tributary draining to the wetland site. The character of the alluvium in the immediate vicinity of the wetland is undescribed; in the general vicinity, the Musselshell alluvium is permeable enough to support wells of low to moderate yield. The Judith River Formation underlies surficial deposits at the wetland site; higher-elevation areas within the northern tributary basin are underlain by Bearpaw Shale.

Hydrologic type. WET34 is a modified site, apparently receiving inflow from the unnamed northern tributary and (probably) from the groundwater system of the Musselshell River alluvium. The wetland does not appear to have surface water outflow under the sampled conditions.

Basin characteristics. The contributing catchment for this small site is not well defined. If the catchment is taken to be the northern tributary drainage, the catchment to wetland area ratio ranks mid-range with respect to other sample sites of the unglaciated plains. However, the Musselshell River alluvium (interacting with the Musselshell River throughout the upper river basin) may provide ground-water inflow to the site. The U.S. Highway 12 corridor and excavation for wetland enhancement affect local site hydrology.

Water chemistry. The wET43 site exhibits moderately alkaline, "oligosaline" sodium-sulfate water chemistry. Mineral equilibria indicate oversaturation with carbonate phases. Ammonium and nitrate concentrations were below reporting limits at the time of sampling: phosphorous (total and orthophosphate) and total organic carbon concentrations are low with respect to sites in the same classification.

Boron and iron concentrations were reported at the lower end of the ranges for Great Plains sample sites; most other trace elements were below reporting limits.

Chemical history. No other chemical data for this wetland are known. 

Sediments. Relatively recent wetland mitigation activities may have disturbed sediments at the WET43 site. Extractable trace element concentrations are generally low; arsenic, boron, iron, vanadium and zinc concentrations were all at or near the lower end of the ranges shown for sample sites in this classification. Other trace element concentrations were below reporting limits. None exceeded mean soil concentrations for the western United States. 

climatic setting. The net annual precipitation balance (from the MAPS database) is -5 inches, near the middle of the range of evaporative intensity shown by Rocky Mountain sample sites. Mean monthly precipitation for the olney climatic station shows a bimodal distribution, with a pronounced June peak and a broad wintertime (November to January) peak. (Much of the catchment contributing runoff to this site is 1000-2000 higher than the olney gauge, so precipitation records serve only as a general indication of recent precipitation history.) Annual totals for the olney station are fragmentary; regionally, annual precipitation was above average in 1993 (the year prior to sampling) and below average in 1994.

Geologic setting. The WET44 site is along the margins of the glacially scoured stillwater valley and is presumed to be underlain by sediments of glacial origin. No local description of the character of these sediments is available, however. Surficial sediments in the contributing catchment are underlain by formations of the Proterozoic-aged Belt series, including large areas of the dominantly calcareous and dolomitic Helena Formation. Numerous northwest-trending normal faults (structural elements of the Rocky Mountain Trench) cross the general area.

Hydrologic type. The WET44 site occurs along a mapped tributary to Lebeau creek and has surface water inlet and outlet channels which are mapped as intermittent; discharge rates and duration are not known for this stream. Forest road construction may contribute to the wetland by artificially impounding the outlet stream.

Basin characteristics. The Lebeau creek site has a high catchment to wetland area ratio in comparison to other Rocky Mountain sites. In conjunction with the moist climate and steep slopes, this characteristic implies a relatively rapid hydrologic flux through the wetland.

Water chemistry. Water in the Lebeau wetland is dilute, mildly alkaline and calcium-bicarbonate in character. Mineral equilibria indicate near-equilibrium with calcite and aragonite and only slight oversaturation with dolomite. Ammonium and nitrate concentrations were below reporting limits; phosphorous (total and orthophosphorous) and total organic carbon concentrations were toward the lower end of the ranges shown by Rocky Mountain sites.

The recoverable iron concentration was near the lower end of the range shown for sites in this class, and copper was reported at the detection limit. Other trace elements were below reporting limits.

Chemical history. No other chemical data are known from this site.

Sediments. The extractable selenium concentration reported for this site is the highest for any of the Rocky Mountain sample 

sites, and among the highest in the data set. The reported zinc concentration is among the highest for sites not known to be impacted by mine wastes. WET 44 is also one of the few sites not known to be impacted by mining waste where extractable lead was reported. The selenium concentration exceeded the mean soil value for the western United States by a factor of $4 ;$ the zinc concentration exceeded the regional mean by a small factor. Other trace element concentrations were either low with respect to sites in this class, or below reporting limits. 

climatic setting. The net annual precipitation balance for the Lee Metcalf NWR (from the MAPS database) is -24 inches, near the more strongly evaporative extreme for sites in the intermontane valleys and in western Montana generally. Mean monthly precipitation for the Western Agricultural Experiment station (near stevensville) shows a relatively broad distribution with a maximum in May. The 3-year moving average of annual precipitation totals for the Western Ag Station was below the long-term average from 1985 to 1992. In 1993 (the year prior to sampling) precipitation exceeded the long-term average by about 2.5 inches. Data for 1994 (the year of sampling) were not retrieved; regionally, 1994 totals were below average.

Geologic setting. The Lee Metcalf Refuge is underlain by permeable alluvium of the Recent Bitterroot River floodplain. Alluvial terraces of the Bitterroot River and floodplain and fan deposits of tributary streams border the refuge. Glaciofluvial gravels and fine-grained Tertiary-aged sediments underlie the Holocene alluvium at depth and form elevated benches to the east. Shallow water table depths and ground-water discharge areas occur beneath and around the refuge, contributing some of the water budget of the wetland complex.

Hydrologic type. The Lee Metcalf site is an artificial impoundment holding both natural ground-water discharge and imported water from the Burnt Fork and Threemile Creek drainage. The impounded wetland sampled at site WET45 has surface water outflow and probably also has ground-water outflow under at least some conditions.

Basin characteristics. The natural surface catchment of the WET45 wetland is relatively small. The natural surface catchment is little importance to the site's water balance, however, since most water is contributed either by ground water in probable connection with the Bitterroot River, or by surface water imported from tributary drainages. Water depths are not available, but are probably quite shallow.

Water chemistry. At the time of sampling, the Lee Metcalf wetland contained dilute water of mixed cation-bicarbonate composition and high (biologically influenced) pH. Equilibrium calculations indicate oversaturation with carbonate minerals under the high $\mathrm{pH}$ conditions measured. Ammonium, nitrate and orthophosphate concentrations were below reporting limits, and total phosphorous and total organic carbon concentrations were near the lower end of the ranges shown for sites in any class.

Arsenic and iron (both reported at their detection limits) and copper concentrations were at the lower end of the ranges shown by sample sites within this class. Most other trace element concentrations were below reporting limits. 

Chemical history. No other chemical data from this site are known. Water quality concerns at the refuge have included sediment and herbicides in conveyances linked to refuge water supplies.

Sediments. Extractable arsenic, boron, iron and zinc were reported at concentrations near or at the lower end of the ranges shown by the entire data set. Most other trace elements were below reporting limits. None exceeded the mean values for soils and other surficial materials of the western United States. 



\section{Long Lake}

climatic setting. The net annual precipitation balance for the Long Lake site (from the MAPS database) is -26 inches, placing the site near the mid-range of evaporative intensity for hydrologically similar sites. Monthly average precipitation for the sunburst $8 \mathrm{E}$ climatic station show a broad summer peak with a maximum in June. since the mid-1970's, the 3-year running average of annual precipitation for the Sunburst station was mainly at or above the mean for the period of record. Data for 1993 and 1994 were not recovered for this station; regionally, 1993 totals were well above average and 1994 totals were below average.

Geologic setting. The willshaw Flats basin is underlain by lacustrine and paludal sediments (including chemical precipitates) with calcareous glacial till forming the immediately adjacent upland slopes. The Willshaw Flats topographic depression has been interpreted as a south flowing ice-marginal drainage during late Pleistocene time. If this interpretation is correct, it is possible that glaciofluvial sediments underlie Holocene lacustrine deposits beneath the wetland complex.

Surficial deposits are underlain by shale and sandstone of the Colorado Group.

Hydrologic type. Long Lake is a depression (glacial drainage?) lacking surface outflow. (Although it lies within the limits of Pleistocene glaciation and is developed in glacial deposits, the basin is not thought to be the direct result of the action of ice, as are most sites with which Long Lake is classified.) The extent of flooded area in willshaw Flats is unusually transient with respect to the set of sample sites. Surface water outflow would require major changes in the willshaw Flats water budget.

Basin Characteristics. The Willshaw Flats basin is an extensive complex of playa surface and vegetated wetland receiving runoff from upland areas to the east. Topographic gradients within the basin are very low and observed water depths were on the order of 1 foot near the center of the sampled wetland; raising the stage the 10 feet or more needed to allow surface outflow would require storing a very large volume of water within the basin. No abandoned shorelines which might correlate to outflow-controlled stage were observed. It seems probable that the basin has been internally drained throughout the Holocene. Water storage in Beaupre coulee, the major drainage contributing runoff to the willshaw Flats Basin, may have reduced the runoff received by the wetland complex during recent historic times. Wetland extent and shoreline position are unusually transient.

Water chemistry. At the time of sampling, Long Lake contained mixed-cation/sulfate "oligosaline" water with specific conductance of 4840 microsiemens/cm. Equilibrium calculations indicate moderate supersaturation with carbonate species and undersaturation 

with gypsum.

Water column zinc and copper concentrations were among the higher values for hydrologically similar sites. Other trace element concentrations were below detection limits or were near mid range for hydrologically similar sites.

Orthophosphate and total phosphorous concentrations were the second highest among the entire sample set. As with other very high phosphorous sites, almost all of the total phosphorous occurred as orthophosphate. Nitrate was reported at the detection limit of .01 $\mathrm{mg} / \mathrm{l}$ and ammonium was found to be below detection limits. The total organic carbon concentration was near the upper end of the range for all sample sites.

Chemical history. No chemical data prior to the DHES sampling are known for the Long Lake site. Measurements in August of 1994, two months after sample collection, showed specific conductance of 20500 microsiemens $/ \mathrm{cm}$. This represented a fourfold seasonal increase in two months. With this concentration increase, Long lake probably reached saturation with gypsum and other mineral phases. Water quality is inferred to be typically very transient due to shallow basin geometry, high effective evaporation rates and the lack of surface outflow.

Sediments. Concentrations of nickel, chromium, vanadium, selenium and $z$ inc were at or near the upper end of the range for sample sites of this hydrologic type. Concentrations of zinc, nickel, selenium and arsenic exceed mean soil values for the western United states. Very high iron concentrations, in combination with obviously reduced sediment conditions, suggest possible iron sulfide (pyrite) formation. 



\section{Mallard Pond}

climatic setting. The net annual precipitation balance for Mallard Pond derived from the MAPS database is -23 inches, toward the less evaporative end for sites in this class. Based on analyses of evaporation pan data, this is a considerable underestimate Mallard Pond's water deficit, and points out the need to view the MAPS estimates only as relative indicators of net site precipitation. Mean monthly precipitation for the Medicine Lake climatic station shows a pronounced June maximum. Annual totals for this station show apparent periodicity with a 5 to 7 year cycle. Throughout the 1980s, the 3-year running average remained below (often well below) the long-term average, recovering in the early 1990s. In 1993 (the year before sampling) precipitation exceeded the long-term average by more than 1 inch.

Geologic setting. Mallard Pond occupies an ice-block depression (kettle) in the sequence of pitted late Pleistocene outwash sand and gravel forming the clear Lake aquifer. Glacial sediments are underlain at depth by the early Tertiary Fort Union Formation.

Hydrologic type. Mallard Pond is a glacial depression lacking significant surface water inflow but possessing surface water (and probably ground-water) outflow. Inflow to the pond is primarily discharging ground water from the clear Lake aquifer.

Basin characteristics. Mallard Pond has only a minimal surface catchment; the catchment to wetland area ratio ranks toward the lower end of the range shown by sample sites of the Great Plains. The pond is surrounded on three sides by steep kettle walls; on the low-gradient west side, the pond drains by discontinuous(?) channels and ground-water flow toward the Lake Creek channel. The depth of the pond is unknown but believed to be shallow. The WET47 site is on the upgradient side of Mallard Pond with respect to the regional clear Lake aquifer flow system; important spatial water quality gradients can exist within this small pond, as shown by previous sampling (see below).

Water chemistry. At the time of sampling, Mallard Pond contained "oligosaline" sodium-sulfate water of moderately alkaline $\mathrm{pH}$ and depressed dissolved oxygen content. Substantial calcium remained in solution and mineral equilibria indicated slight oversaturation with calcite and aragonite. The sample was collected in an area of probable ground-water discharge and is interpreted to have been out of equilibrium with surface conditions (see below). The ammonium concentration was the highest of sites in this classification, and among the highest in the sample set; significant nitrate (among the four highest sample sites) was also present. Phosphorous (total and orthophosphorous) and total organic carbon concentrations ranked mid-range among sites of the glaciated Great Plains, but toward the upper end of the ranges shown by sites possessing surface water outlets. 

Arsenic, boron and iron concentrations ranked mid-range among sites classified with WET47; most other trace element concentrations were below reporting limits.

Chemical history. The previous known chemical sampling of Mallard Pond (conducted in August of 1990) included specific conductance measurements from three points on the pond perimeter, including one site very near WET47, and analytical water chemistry for a single sample collected on the opposite (western) shoreline. The specific conductance measurements demonstrated a substantial crosspond gradient in salinity; specific conductance at the two sites on the western shoreline was higher than that near WET47 (measured 3 days earlier) by a factor of 1.75 . The WET47 sample was also higher in specific conductance than the 1990 measurement collected nearby, by a factor of 1.4 .

Although moderately higher in total dissolved solids, the 1990 sample from the western shore was substantially lower in calcium concentration than was the 1994 DHES sample from WET47. The field $\mathrm{pH}$ of the 1990 sample was reported as 9.48 , very similar to the laboratory value reported for the WET47 sample. Taken together with the depressed mid-day dissolved oxygen concentration for the WET47 sample, it can be inferred that the WET47 sample was collected from an area of ground-water discharge where $\mathrm{CO}_{2}$, dissolved oxygen and dissolved carbonate phases had not yet equilibrated with the surface environment. The 1990 data show that this adjustment, along with evaporative concentration and increasing specific conductance, occurs during circulation of lake water from the upgradient (eastern, WET47) shoreline to the downgradient (western) side of the lake.

Sediments. As with Brush Lake and other relatively dilute groundwater fed lakes in the area, the water chemistry data described above imply loss of calcium (as calcium carbonate) from the water column as ground-water enters the lake environment. The high calcium concentration reported in the sediment analysis presumably reflects active marl formation as part of Mallard Pond's sedimentary regime.

Extractable arsenic, boron, iron and zinc concentrations rank low to mid-range with respect to similarly classified sites. None exceed the mean soil values for the western United States. 



\section{Mary's Frog Pond Botanical Area}

climatic setting. The net annual precipitation balance for Mary's Frog Pond (from the MAPS database) is 20 inches, placing this sampling site among the five moist high-elevation sites in the data set. None of the NOAA climatic stations provide data particularly applicable to the Mary's Frog Pond site; Lolo Hot springs, the nearest climatic station, is at a considerable lower elevation and has a sporadic recent record. Mean monthly precipitation at the Lolo Hot Springs station shows a bimodal distribution, with a January maximum and a secondary June peak. Regionally, precipitation totals in 1993 were above average and in 1994 (the year of the DHES sampling) were below average.

Geologic setting. Mary's Frog Pond is underlain by the Ravalli Group of the Proterozoic-aged Belt series. The intrusive contact of the Idaho Batholith is very nearby, however, and mineralization presumably related to hydrothermal intrusive processes occurs in the immediate vicinity. Surficial deposits in the area are apparently undescribed, and the origins of the pond basin are unclear from the available information. One source describes the pond as a "glacial scour", but there is no supporting documentation given for this interpretation, and the drainage in which the pond lies does not have obvious glacial landforms.

Hydrologic type. Mary's Frog Pond is a small, internally drained depression of uncertain origin, which lacks both surface water inflow and outflow at the water levels observed during sampling.

Basin characteristic. Mary's Frog Pond has a small, steep surface water catchment and a catchment to wetland area ratio which ranks low among Rocky Mountain sites. The depth of the pond is unknown. Given the setting in an area of high net precipitation, the pond is inferred to discharge either via ground-water or by unmapped surface-water outflow (or both). Surface features within the wetland catchment include a portion of an access road to the abandoned Ward Lode mine.

Water chemistry. Mary's Frog Pond contains extremely dilute, somewhat acidic water with sodium and potassium in excess of calcium and magnesium. The anion distribution is uncertain due to the dilute nature of the water. Mineral equilibria indicate highly undersaturrated conditions with respect to carbonate phases; saturation indices are not quantitatively meaningful, however, due to the large charge balance error in the analysis.

Nutrient concentrations are very low; ammonium and nitrate concentrations were below reporting limits, and orthophosphate and total phosphorous concentrations were at or near the lower end of the ranges for the entire sample set. The total organic carbon concentration was also relatively low.

With the exception of aluminum, iron, and silica (all reported at 

concentrations at or near the lower end of the ranges shown for the entire sample set), water column trace element concentrations were below reporting limits.

Chemical history. There is a single partial chemical analysis for Mary's Frog Pond known prior to the DHES sampling. This sample, collected in June of 1987, was slightly more dilute than the DHES sample, and had grossly similar major-ion chemistry. Generally, seasonal and interannual variation at this site is probably minimal.

Sediments. Extractable arsenic, copper, iron and zinc concentrations rank low or mid-range for sample sites within this classification. Mary's Frog Pond is among the handful of sampling sites with reported lead concentrations; most other trace element concentrations were below reporting limits. The lead concentration exceeded the mean value for soils of the western U.S. by a factor of 1.4 . 



\section{Medicine Lake}

climatic setting. The net annual precipitation balance for Medicine Lake derived from the MAPS database is -24 inches, toward middle of the range of evaporative intensity for sites in this class. Based on analyses of evaporation pan data, this is a considerable underestimate Medicine Lake's water deficit, and points out the need to view the MAPS estimates only as relative indicators of net site precipitation. Mean monthly precipitation for the Medicine Lake climatic station shows a pronounced June maximum. Annual totals for this station show apparent periodicity with a 5 to 7 year cycle. Throughout the 1980s, the 3-year running average remained below (often well below) the long-term average, recovering in the early 1990s. In 1993 (the year before sampling) precipitation exceeded the long-term average by more than 1 inch.

Geologic setting. Medicine Lake occupies a large depression in the sequence of late Pleistocene outwash sand and gravel forming the clear Lake aquifer. The composite thickness of the outwash gravels is greater in the Gaffney-Medicine Lake vicinity than elsewhere along the clear Lake outwash channel. Preglacial terrace gravel aquifers are apparently incised by outwash sediments in the vicinity of Medicine Lake, creating hydrologic linkages between stratigraphically distinct aquifers and surface water bodies. Glacial and sediments and preglacial alluvium are underlain at depth by the early Tertiary Fort Union Formation.

Hydrologic type. Medicine Lake is a natural ground-water discharge area for the clear Lake Aquifer which has been modified to stabilize water levels and to accommodate water imports diverted from Muddy creek. Additional inflow is supplied by Lake Creek, which delivers limited runoff and ground-water discharge to Medicine Lake and other basins. Outflow from Medicine Lake to Muddy Creek is also managed by control structures. Often the full water right for the Big Muddy diversion cannot be exercised, however, and the lake may go several consecutive years without spilling surface water.

Basin characteristics. The water budget of Medicine Lake is dominated by ground-water inflow and by extra-basin imports from Big Muddy Creek; neither is closely linked to the natural surface water catchment of the lake. Regionally, evaporative losses from Medicine Lake (and other lakes) are the predominant outflow component of the Clear Lake Aquifer's water budget and are an important influence on ground-water gradients and ground-water flux. Imports of Big Muddy Creek water to Medicine Lake are believed to have a corollary effect on the aquifer, stabilizing ground-water levels in the vicinity of the lake.

The U.S. Fish and Wildlife Service estimates the capacity of Medicine Lake at "management elevation" at about 88300 acre-feet, with an average lake depth of about 10 feet. From 1988 to 1993 year-ending lake volumes ranged from $66 \%$ to $75 \%$ of this management 


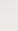


capacity; at the beginning of 1994 (the year of the DHES sampling) the lake was at approximately $69 \%$ of "management capacity". This represented a slight gain in storage over the previous year. I midsummer of 1993, runoff in Big Muddy Creek allowed for diversion of several hundred cfs, raising the lake level almost two feet in a matter of a few days. This kind of rapid episodic fill and lake level rise, followed by periods of progressive water-level decline, is probably characteristic of the management of Medicine Lake.

Water chemistry. At the time of sampling, the WET49 site exhibited "oligosaline" sodium-sulfate water with near-neutral pH and low dissolved oxygen concentration. Substantial calcium and carbonate remained in solution, and mineral equilibria indicate moderate oversaturation with respect to carbonate phases. The ammonium and total phosphorous concentrations were high in comparison to the sample sites in this class; orthophosphate and total organic carbon concentrations ranked mid-range within the site classification.

Concentrations of arsenic, boron and iron ranked low among sites of this class; most other trace element concentrations were below reporting limits.

Chemical history. Occasional measurements of field water quality parameters ar available since 1984, with quantitative water chemistry from one Medicine Lake site in 1990. Beginning in 1994, the U.S. Fish and Wildlife service has measured limited field parameters (specific conductance, dissolved oxygen and temperature) on an approximately monthly basis from five sites in Medicine Lake, including one relatively near the DHES site WET49. These data demonstrate substantial spatial gradients in salinity within the lake, as well as temporal variability in water quality within regions of the lake basin.

In September of 1984, measurements of specific conductance at ten different points along the lake shoreline yielded a mean of 2060 microsiemens/cm, with a minimum of 1590 and a maximum of 3053 microsiemens $/ \mathrm{cm}$. Eight specific conductance measurements in August of 1990 ranged from 650 (at the Muddy creek diversion inflow?) to 4760 microsiemens/cm, with a mean of 4034 . A DHES survey of 4 shoreline sites in May of 1993 yielded a mean of 5555 microsiemens/cm and a range from 3460 to $6410 \mathrm{microsiemens/cm}$. In all cases where sites near WET49 were measured they were the least saline within the lake at that time, with the exception of the August 1990 low reading of $650 \mathrm{microsiemens/cm,} \mathrm{which} \mathrm{may} \mathrm{have} \mathrm{been}$ collected from the Muddy creek inlet itself rather than from the lake. This is consistent with the presence of ground-water inflow to Lake Creek and to the eastern (upgradient) end of Medicine Lake; surface runoff from the Lake creek catchment, when it occurs, will further dilute water at the WET49 site relative to other parts of the lake basin.

The $\mathrm{pH}$ and dissolved oxygen concentrations are both relatively low in the WET49 sample. The 1990 analysis, conducted on a sample 

collected from the southern side of the lake, had a field pH in excess of 9.0, as did all four sites in the 1993 DHES survey of Medicine Lake field chemistry. The 1990 sample, with a substantially higher dissolved solids concentration, had a lower absolute concentration of calcium than the WET49 sample, suggesting the process of atmospheric equilibration and consequent calcium carbonate precipitation characteristic of many lakes linked to the Clear Lake aquifer is ongoing in Medicine Lake. The WET49 sample, collected at the eastern (upgradient) end of the lake, appears to have consisted largely of ground-water discharge not yet equilibrated with the surface environment. Samples collected from the WET49 site should not be expected to represent the chemical characteristics of the main Medicine Lake basin.

Historically, Medicine Lake is reported to have been essentially dewatered during the extended drought of the 1930's, stimulating the construction of the diversions and control structures now used for water management. Under naturally fluctuating conditions, water chemistry, as well as shoreline position and water depth, was probably more transient than now, and average salinity likely was higher prior to the import of Big Muddy Creek runoff.

Sediments. Arsenic and boron concentrations in the WET49 sample were near the upper end of the ranges shown for this classification, and the selenium concentration reported for this site was the highest in it's class. Iron, nickel, vanadium and zinc concentrations ranked mid-range within the site classification; most other trace elements occurred at concentrations below their reporting limits. 

climatic setting. The net annual precipitation balance for the MCKillop Creek site (from the MAPS database) is -3 inches, ranking the site mid-range in moisture regime among Rocky Mountain sites. Mean monthly precipitation for the Libby Ranger station climatic station shows a bimodal distribution, with a wintertime (NovemberJanuary) maximum and a secondary June peak. Annual total precipitation for the Libby RS station shows the 3-year running average at or above the long-term annual average from 1983 through 1993. The annual total in 1993 (the year prior to sampling) was equal to the long-term average.

Geologic setting. The McKillop creek wetland is underlain by glacial(?) deposits of undescribed character. Bedrock formations underlying the site and the contributing drainage basin belong to the Proterozoic-aged Belt series, including the dominantly calcareous and dolomitic Wallace Formation. The wetland site closely overlies the intersection of two mapped normal faults, one trending northwest along lower McKillop creek and it's unnamed south fork, and the other trending northeast across the two forks of McKillop Creek. The McKillop Creek wetland's peculiar water chemistry (see below) suggests that the wetland may receive a component of inflow from deeply circulating bedrock ground-water.

Hydrologic type. The McKillop creek wetland occupies one of a pair of basins of uncertain (glacial?) origin, lacking a surface water outlet at the observed water levels and possessing a surface water inlet stream mapped as intermittent in flow. The relatively moist setting and dilute water chemistry imply outflow from the site either by ground-water recharge or by unmapped surface water outflow.

Basin characteristics. The McKillop creek wetland has a notably steep catchment and a relatively large catchment area to wetland area ratio, implying rapid hydrologic flux through the wetland. The northeastward orientation of the catchment may favor retention of winter snowpack. The depth of the wetland water body is unknown but probably quite shallow. Bedrock structural controls may influence basin topography and wetland water chemistry.

water chemistry. The McKillop creek wetland exhibits a mildly acidic, dilute sodium/potassium-bicarbonate/chloride composition which is unique among the sample sites. The high ratios of sodium to total cations and chloride to total anions suggests either contamination with sodium chloride road salt (an uncommon deicing salt) or inflow from dilute but deeply circulating ground water. The latter explanation is favored on the basis of other chemical characteristics described below. Mineral equilibria indicate substantial undersaturation with respect to carbonate phases despite the presence of calcareous and dolomitic rocks within the basin. 
The ammonium concentration in this sample is uniquely high for sample sites in the Rocky Mountains, exceeding all other sample sites by an order of magnitude. The orthophosphate concentration was also the highest for Rocky Mountain sites, though not disjunct from the range shown by other sites as was the ammonium concentration. The total organic carbon concentration ranked midrange among Rocky Mountain sites.

The boron concentration was the highest shown by Rocky Mountain sites, most of which did not contain the element in reportable concentrations. Arsenic, iron and copper were reported at concentrations ranking mid-range within the site classification. Most other trace elements occurred at concentrations below the reporting limits.

Chemical history. No other chemical data from this site are known.

Sediments. In comparison to other dilute Rocky Mountain sites, the McKillop Creek wetland appears to display a diverse array of detectable trace elements. Arsenic, boron, copper, nickel, selenium, vanadium and zinc were all reported at concentrations ranking the site mid-range among similarly classified sample wetlands. Only selenium (by a factor of 1.7) and zinc (by a small amount) exceeded the mean concentrations for soils and other surficial materials in the Western United States. 



\section{Mill-Willow Silver Bow wetland.}

climatic setting. The net annual precipitation balance for the Mill-Willow site (from the MAPS database) is -22 inches, placing the site toward the more evaporative end of the range shown by sample sites in the western intermontane valleys. Mean monthly precipitation for the Anaconda climatic station shows a broad summertime peak. Annual precipitation totals for the Anaconda station show the 3-year running average falling below the long-term average from 1987 through 1992, the year of the DHES sampling. The 1992 total was about 1 inch below the long-term average. Water supply at this site is probably more dependent on the condition of mountain snowpack than on the low-elevation precipitation measured at the Anaconda station.

Geologic setting. The WET51 site is underlain by Quaternary-aged unconsolidated alluvial deposits, probably to a thickness of a few tens of feet. Tertiary-aged valley-fill sediments underlie the Quaternary alluvium; these sediments may be near their local maximum in thickness beneath the sampling site, thinning rapidly to the east and west. Recent alluvial sediments and shallow ground-water in the Mill-Willow-Silver Bow area are pervasively contaminated with mineral processing wastes.

Hydrologic type. The WET51 site is in a riparian wetland in an area of apparent local ground-water discharge, with perennial surface water inflow and outflow and close surface water-ground water linkages. The site has been modified to some degree by ditching, with unknown effects on wetland hydrology.

Basin characteristics. The mountain basin of willow Creek provides a relatively large, high-elevation catchment for the WET51 site; the catchment to wetland area ratio ranks toward the upper end of the range shown by sites in this classification. Willow creek and other local streams provide recharge to shallow ground-water systems; ground-water discharge occurs along gaining stream reaches and in wetland areas such as that sampled at WET51. Historic mine wastes are broadly distributed in the Silver Bow and Mill Creek drainages. Contamination with mineral processing waste is also suspected to have caused soil and ground-water contamination in the Willow creek drainage. Low stream gradients, overbank sedimentation and probable channel migration in the vicinity of the WET51 site suggest that the sample site (located near the present Willow Creek channel) may be underlain by contaminated sediments derived from Silver Bow Creek and Mill Creek, as well as Willow Creek sediments.

Water chemistry. The WET51 site is characterized by dilute calcium-bicarbonate water of near-neutral $\mathrm{pH}$. The sulfate concentration appears to be proportionately higher than for many other dilute sample sites in western Montana. Mineral equilibria indicate approximate saturation with carbonate phases. The nitrate concentration ranked mid-range for sample sites of this class; 

ammonium was below reporting limits. The orthophosphate concentration was toward the lower end of the range shown by sites in this classification. Total phosphorous and total organic carbon analyses were not conducted on this sample.

Copper and zinc concentrations ranked mid-range among sites of the intermontane valleys, exceeded mainly at other mine-impacted sites. Iron and aluminum concentrations were not analyzed for this sample, and other trace element concentrations were below reporting limits.

Chemical history. No other comparable chemical analyses are known for this site. Generally, increased concentrations of toxic metals have been observed at times of runoff and high flows in the silver Bow/Mill Creek system as sediment deposits contaminated with mineral processing waste are remobilized.

Sediments. Exceptionally high concentrations of extractable arsenic, copper, lead and zinc are matched only by other sites with known mine or mineral processing impacts. Iron, chromium, nickel and vanadium concentrations are also relatively high in comparison to similarly classified sites. Arsenic, copper, lead and zinc concentrations far exceed mean soil concentrations for the western United States; other trace element concentrations are below their respective mean soil values. 

climatic setting. The net annual precipitation balance for the Ninepipe Reservoir area (from the MAPS database) is -18 inches, placing this site toward the middle of the range of evaporative intensity shown by sample sites of the intermontane valleys. Mean monthly precipitation for the st. Ignatius climatic station shows relatively even distribution with a maximum in May and June. Total precipitation for the st. Ignatius station shows the three-year running average remaining near or above the long-term average from 1980 through 1993. Water supply in Ninepipe Reservoir, however, is largely dependent on the storage and controlled release of runoff from mountain snowpack. Hence the low-elevation St.Ignatius station cannot be expected to closely reflect hydrologic conditions in the reservoir or associated wetland areas.

Geologic setting. The Mission Valley generally is underlain by glacial sediments deposited by the southward advance of the late Pleistocene lobe which occupied the Flathead Lake basin. Sediments in the Ninepipe area include till of different textures, glaciolacustrine sediments and outwash in complex stratigraphic sequences. Regional source areas for glacial sediment are mainly underlain by metasedimentary rocks of the Proterozoic-aged Belt series, including calcareous and dolomitic lithologies. Generally the kettle-pitted surface underlying the Ninepipe National Wildlife Refuge is composed of till of relatively low permeability. Permeable aquifer gravels within the upper 200 feet of the glacial sequence support high-yield wells nearby.

Hydrologic type. The WET52 site is within a ponded riparian area fed by the regulated outflow from Ninepipe Reservoir. Inflow to the reservoir is largely imported water from streams draining the Mission Mountains to the east, routed to Ninepipe via other reservoirs and an extensive ditch system.

Basin characteristics. The natural catchment of Ninepipe Reservoir includes a relatively small area along the Mission Mountain front. As managed, the catchment includes upper Post creek, draining the highest peaks of the Mission Mountains.

Water chemistry. The WET52 sample shows dilute calcium-bicarbonate composition with near-neutral pH. Mineral equilibria indicate slight undersaturation with carbonate phases. Ammonium, phosphorous and total organic carbon concentrations rank mid-range among similarly classified sampling sites. Chromium was reported at the detection limit (one of only 3 western samples with reportable concentrations), and the iron concentration ranked toward the upper end of the range shown by this class of sampling site. Other trace elements were reported to be below detection limits.

Chemical history. No other chemical data are known from this site. 

Sediments. Extractable concentrations of arsenic, boron, copper, vanadium and $z$ inc ranked mid-range among sites within this class. other trace elements analyzed were reported to be below detection limits. Boron and zinc concentrations exceeded (by small factors) mean concentrations for soils and other surficial materials of the western United States; other reported trace element concentrations were below the regional mean soil concentrations. 

climatic setting. The net annual precipitation balance for the Ninepipe Reservoir area (from the MAPS database) is -18 inches, placing this site toward the middle of the range of evaporative intensity shown by sample sites of the intermontane valleys. Mean monthly precipitation for the st. Ignatius climatic station shows relatively even distribution with a maximum in May and June. Total precipitation for the St. Ignatius station shows the three-year running average remaining near or above the long-term average from 1980 through 1993. Total precipitation in 1993 (the year prior to sampling) exceeded the long-term average by about 3 inches.

Geologic setting. The Mission Valley generally is underlain by glacial sediments deposited by the southward advance of the late Pleistocene lobe which occupied the Flathead Lake basin. Sediments in the Ninepipe area include till of different textures, glaciolacustrine sediments and outwash in complex stratigraphic sequences. Regional source areas for glacial sediment are mainly underlain by metasedimentary rocks of the proterozoic-aged Belt series, including calcareous and dolomitic lithologies. Generally the kettle-pitted surface underlying the Ninepipe National wildlife Refuge and surrounding areas is composed of till of relatively low permeability. Permeable aquifer gravels within the upper 200 feet of the glacial sequence support high-yield wells nearby.

Hydrologic type. The WET53 wetland occupies a small ice-block depression (kettle) within the kettle wetland complex surrounding Ninepipe Reservoir. The wetland receives surface runoff from a restricted area and possibly shallow ground-water inflow from the Post E Canal, situated close by and apparently upgradient from the WET53 wetland. The site is believed to lack surface-water drainage under the present conditions. The permanence of this site is uncertain; the sample collection, however, occurred later in the summer during a generally dry year.

Basin characteristics. The surface catchment and relief of this site are minimal, though impossible to define with any precision using available maps. The water depth is unknown but inferred to be no more than a few feet. Ground-water relationships are also unknown; local pond outflow (restricted by low hydraulic conductivity) probably occurs under at least some conditions. It is possible (though not considered likely) irrigation canal seepage supports ground-water inflow to the site.

Water chemistry. At the time of sampling, the wET53 site contained alkaline "oligosaline" magnesium-carbonate water. WET53 exhibited the highest reacting percent of magnesium seen in the sample set. It also contained an unusually high fraction of chloride for a site of relatively low salinity. Equilibrium calculations indicate substantial oversaturation with respect to carbonate minerals; the poor charge balance shown by this analysis places these 

calculations in doubt, however. The ammonium and total organic carbon concentrations ranked mid-range in comparison to regionally and hydrologically similar sites. The orthophosphorous concentration was among the highest found in western Montana sites.

Arsenic, copper and iron concentrations rank mid-range within the site class. Other trace elements were below reporting limits.

Chemical history. No other chemical data from this site are known. The somewhat unusual chloride fraction raises the possibility that low-level contamination with chloride salts is occurring.

Sediments. Reported extractable concentrations of arsenic, vanadium, and zinc ranked mid-range among sample sites of the intermontane basins. Extractable boron, copper, nickel and selenium concentrations were relatively high when compared with western Montana sites lacking mine and mineral processing impacts. The boron and selenium concentrations exceeded the mean concentrations for soils of the western United states by factors of 1.6 and 1.7 , respectively. other trace element concentrations were below the regional mean soil concentrations. 

climatic setting. The net annual precipitation balance for Goose Lake derived from the MAPS database is -21 inches, toward the less evaporative end for sites in this class. Based on analyses of evaporation pan data and the hydrologic behavior of Brush Lake, this is a considerable underestimate of the regional water deficit, and points out the need to view the MAPS estimates only as relative indicators of net site precipitation. Mean monthly precipitation for the Grenora climatic station shows a pronounced summertime maximum centered in June. Recent annual totals for the Grenora station are fragmentary. Annual totals for the Medicine Lake station show apparent periodicity with a 5 to 7 year cycle. Throughout the $1980 \mathrm{~s}$, the 3-year running average remained below (often well below) the long-term average, recovering in the early 1990s. In 1993 (the year before sampling) precipitation exceeded the long-term average by more than 1 inch.

Geologic setting. Goose Lake occupies an irregular linear depression in the late Pleistocene-aged glacial outwash gravel forming the Clear Lake aquifer. The 5-foot isopach of outwash gravel thickness transects the lake; the southern portion is underlain by a thicker section of outwash, while the thickness of sand and gravel under the northern part of the lake, including the distinct basin known as North Goose Lake, is thin (less than 5 feet). Till and other glacial sediments underlie surfaces outside the lateral extent of the outwash gravels. Surficial glacial materials are underlain by the Fort union Formation of early Tertiary (Paleocene) age. North Goose Lake lies within the williston Basin, a structural feature supporting important petroleum and natural gas production. There are producing wells within the immediate vicinity.

Hydrologic type. North Goose Lake is a glacial depression lacking significant surface water inflow and lacking surface water outflow under present conditions. The lake is primarily dependent on ground-water inflow; highly saline lake chemistry implies that ground-water outflow is limited.

Basin characteristics. North Goose Lake is an elongated basin separated from Goose Lake by a low, narrow divide which may be inundated under high-water conditions. The surface catchment of North Goose Lake is minimal, providing one of the lowest catchment to wetland area ratios of the data set. No data on lake depth are available, but most highly saline lakes in the area are relatively shallow.

Water chemistry. At the time of sampling, North Goose Lake contained hypersaline, highly alkaline sodic brine with roughly equal equivalent concentrations of sulfate and $\mathrm{CO} 2$ species and a comparatively high chloride concentration. Calcium and magnesium concentrations are very low (less than $1 \%$ of the total cation concentration in meq/l). Mineral equilibria indicate substantial 

oversaturation with carbonate phases and approximate equilibrium with mirabilite ( $\left.\mathrm{Na}_{2 \mathrm{SO}}{ }^{*} \mathrm{IOH}_{2} \mathrm{O}\right)$. Ammonium, total organic carbon and phosphorous concentrations were relatively high.

Most trace element concentrations analyzed were below reporting limits. Arsenic and boron concentrations, however, were at or near the maximum levels found in the sample set. The chromium concentration was one of the two highest reported for sites outside of the southern Montana (unglaciated) plains.

Chemical history. Previous sampling shows North Goose Lake to be subject to large temporal variations in salinity. The available data suggest the lake is fairly well mixed internally at any given time, however. Field measurements of specific conductance in September 1984 showed an $18 \%$ increase from the southern to northern ends of the lake. Similar measurements in August 1990 showed essentially no difference in specific conductance or $\mathrm{pH}$ between the northern and southern ends of the lake.

Between 1984 and 1990, the specific conductance of North Goose Lake increase by a factor of approximately 2.4; between 1990 and the DHES sampling in 1993, specific conductance increased again by a factor of 1.4. North Goose Lake probably has a Holocene history of complete desiccation during some periods of extreme drought.

The proportionately high chloride concentration ( $21 \%$ of anions as $\mathrm{meq} / \mathrm{l}$ ) and a known history of poor oilfield brine disposal practices in the area raise the possibility that North Goose Lake is subject to some impacts from contaminated ground water. Most of the lake's solute load is interpreted to be of natural origin, however.

Sediments. Relatively high concentrations of calcium and magnesium probably reflect the formation of authigenic carbonate minerals in the North Goose Lake basin. Most trace elements analyzed were below reporting limits in the North Goose Lake sediment sample. Extractable boron was near the upper end of the range shown for sites in the glaciated plains; the extractable arsenic, iron and manganese concentrations were toward the lower end of their respective ranges for this site class. 

Climatic setting. The net annual precipitation balance for North widgeon Slough (from the MAPS database) is -20 inches, placing this site near the less intensely evaporative end of the range shown by Great Plains sites. (Research on Brush Lake indicates that this value considerably underestimates actual evaporative losses in this area, and emphasizes the need to view these values only as comparative indicators of evaporative intensity.) Mean monthly precipitation for the nearby westby station shows a broad summertime peak with a June maximum. Annual totals for the Westby station, though incomplete for recent years, show the persistent regional deficit of the 1980s, and totals exceeding the long-term average in the early 1990s. Total precipitation in 1992, the year prior to sampling, was about an inch below the long-term average.

Geologic setting. The North widgeon Slough area is underlain by a pitted surface of late wisconsin-aged calcareous glacial till; other glacial deposits of local distribution may occur within the lake catchment. North widgeon slough and it's catchment are outside of the area of distribution of the clear Lake aquifer and other permeable gravel aquifer systems. Surficial glacial deposits are underlain by sandstone and shale of the early Tertiary (Paleocene) Fort Union Formation.

Hydrologic type. North widgeon slough is an ice-block depression (kettle) with ephemeral channelized surface-water inflow, and lacking surface water outflow under present hydrologic conditions. The relationship of North widgeon slough to local ground-water systems is undescribed; both local ground-water inflow and outflow may be inferred for different conditions.

Basin characteristics. Unlike the other smaller sampling sites in the Medicine Lake area (Brush Lake, Comertown Preserve, Mallard Pond, North Goose Lake), North widgeon slough has a catchment extending well beyond the wetland basin itself, and a catchment to wetland area ratio ranking mid-range among sampling sites of the glaciated plains. The depth of the slough is unmeasured but inferred to be no more than a few feet. North widgeon slough may drain to the northwest during periods of higher precipitation.

Water chemistry. At the time of sampling, North widgeon slough contained moderately alkaline "mesosaline" water of sodium-sulfate composition. Mineral equilibria indicate substantial oversaturation with carbonate phases. The ammonium concentration ranks toward the upper end of the range shown for sites in this class; phosphorous (total and orthophosphate) and total organic carbon concentrations rank low to mid-range in comparison to sites in the same classification.

Arsenic and boron concentrations ranked toward the upper end of the ranges shown by sampling sites in this class. Lead and nickel were reported at their respective detection limits. In the case of 

nickel, WET55 was one of only five sites with a reportable water column concentration.

Chemical history. A single specific conductance measurement collected in August 1990 from an uncertain point on North Widgeon slough is the only other chemical information known for this site. The value reported (1510 microsiemens/cm) was almost an order of magnitude lower than at the time of the DHEs sampling. The history of North widgeon Slough probably includes complete desiccation during times of prolonged drought.

Sediments. Relatively high concentrations of extractable calcium and magnesium may reflect deposition of authigenic carbonate minerals in North Widgeon Slough sediments. Extractable concentrations of arsenic, boron and copper were at or near the upper end of the ranges shown for this site class. Iron, nickel, vanadium and zinc ranked mid-range in comparison to other sites in this class. The concentrations of most other trace elements analyzed were below reporting limits. The extractable boron concentration reported exceeded the mean concentration for soils of the western United States by a factor of 4.6 ; arsenic exceeded the western U.S. soil mean by a factor of 1.25. Other trace element concentrations were equal to or lower than regional mean soil values. 

climatic setting. The net annual precipitation balance for the WET56 site (from the MAPS database) is -4 inches, ranking Odellskull creek near the middle of the moisture range shown for Rocky Mountain sampling sites. The available low-elevation climatic data are not considered directly relevant to this subalpine setting, where water supply is probably derived mainly from winter snowpack.

Geologic setting. The wetland and it's catchment are underlain by bouldery till deposited on a glaciated surface formed on formations of the Missoula Group, a subset of the Proterozoic-aged Belt series. Areas to the west of the immediate catchment expose large areas of cretaceous and early Tertiary-aged intrusive rocks with granitic and granodioritic compositions. The wetland is immediately to the east of an area of chemical soil anomalies identified as a potential mineral exploration target.

Hydrologic type. The WET56 site (lower skull Creek Meadows on published maps) is a headwater area lacking discrete surface water inflow, and having a distinct (perennial?) surface water outlet.

Basin characteristics. The catchment to wetland area ratio ranks mid-range in comparison to other Rocky Mountain sampling sites. WET56 is situated on the downgradient in a series of two wetlands: water storage in the upper wetland may influence the timing and duration of water received by the WET56 site. No information on ground-water behavior in the area is available. The site is vegetated throughout, and the maximum free water depth inferred to be shallow throughout the year.

Water chemistry. Water in Skull creek Meadows, as represented by the WET56 sample, is very dilute, moderately acidic and sodiumbicarbonate in composition. Mineral equilibria indicate highly undersaturated conditions with respect to carbonate phases. Nitrate and ammonium concentrations were both below reporting limits; phosphorous concentrations were high in comparison to most other Rocky Mountain sites, and the total organic carbon concentration ranked mid-range within the site class.

WET56 was one of the few Rocky Mountain sampling sites with reportable boron and zinc concentrations. The copper concentration was near the upper end of the range shown for Rocky Mountain sites, and was exceeded mainly by sites with known mining impacts. The arsenic concentration ranked mid-range within the site class.

Chemical history. No other water chemistry data are known from this site. Stream sediment samples for mineral exploration may have been collected nearby.

Sediments. The WET56 sediment sample contained a diverse array of extractable trace elements. The vanadium concentration was among 

the three highest in the sample set, exceeded only by sites with known mining impacts. WET56 was among the handful of sites with a reportable mercury concentration. Arsenic, boron, copper, selenium and zinc all occurred in detectable concentrations, all ranking mid-range with respect to other Rocky Mountain sites. None exceeded the mean concentrations for soils of the Western United states. 



\section{Oilmont Wetland}

climatic setting. The net annual precipitation balance for the oilmont site (from the MAPS database) is -27 inches, placing oilmont toward the more intensely evaporative end of the range for the sample sites. Monthly average precipitation for the sunburst $8 \mathrm{E}$ climatic station shows a broad summer peak with a maximum in June. Since the mid-1970's, the 3-year running average of annual precipitation for the Sunburst station was mainly at or above the mean for the period of record. Data for 1993 and 1994 were not recovered for this station; regionally, 1993 totals were well above the average and 1994 totals were below average.

Geologic setting. The oilmont site is underlain by calcareous till, lying just north of a prominent end moraine marking a late pleistocene glacial advance. Shorelines and bottom sediments observed under desiccated conditions consist of zoned chemical precipitates and weakly cemented beach sand and gravel.

Bedrock underlying the till is described as an unspecified formation of the colorado Group. The site is near the apex of the Kevin-Sunburst structural dome and in the midst of the (producing) Kevin-Sunburst oil field.

Hydrologic type. The oilmont wetland is a saline playa drained by a culvert under higher water conditions, and lacking surface drainage under low water conditions. Surface drainage, when it occurs, is to another small wetland basin to the west.

Basin characteristics. The oilmont wetland has a small contributing basin and a low ratio of catchment area to wetland surface area. The wetland basin has a very flat, shallow crosssection; the maximum water depth (controlled by the outlet culvert crossing beneath the north-south county road) is estimated to be less than three feet. The drainage of this basin has been altered by road construction, especially by the berm upon which the eastwest road to oilmont is constructed. The existence of this berm appears to impound local runoff in the sampled wetland at the expense of other small playas, once connected, south of the road. observations by local residents support this inference.

Water chemistry. At the time of sampling in June of 1994, water in this wetland was a "eusaline" sodium sulfate brine with notably low bicarbonate and carbonate concentrations. In september of 1994, there was no surface water at this site. Mineral equilibria indicate that at the time of sampling, the water column was substantially oversaturated with carbonate species and near equilibrium with gypsum.

Orthophosphorous and total phosphorous concentrations at the oilmont wetland were in the upper third among hydrologically similar sites. Nitrate and ammonium concentrations were both low, 

with ammonium below detection limits. The total organic carbon concentration was among the three highest of the sampled wetlands.

The boron concentration at the oilmont site was among the highest for the sample set. Arsenic and iron concentrations were also relatively high, but well within the range shown by hydrologically similar sites. Other analyzed trace elements were below detection limits.

Chemical history. No chemical data other than that from the June 1994 sampling are known from this site. No prior sampling is known, and when revisited 3 months later the site lacked any free water. Under normal circumstances water levels are now controlled by the combination of a drainage culvert and road berms. No apparent surface water route exists for flushing solutes beyond the neighboring basin linked by culvert to the sample site, and the site may be accumulating salts as a result.

Sediments. Extractable boron and arsenic concentrations are near the high end of the range for hydrologically similar sites. Other trace elements which were detected in sediments occurred near or below median values for hydrologically similar sites. The arsenic concentration exceeded the average value for soils and other surficial material of the western U.S. by about 20\%; the boron concentration exceeded the western U.S. average by a factor of four.

The desiccated playa surface displays concentric zonation of precipitate textures and mineralogy. Precipitate facies observed include carbonate cementation of littoral sand and gravel; earthy, anhedral effloresences on the higher-elevation playa surfaces; and euhedral gypsum(?) near the center of the playa. 



\section{Ontario Creek Headwaters}

climatic setting. The net annual precipitation balance for ontario Creek Headwaters (from the MAPS database) is -3 inches, placing the site near the humid end of the range shown by the sample sites, but mid-range for those in the Rocky Mountains. Mean monthly precipitation for the Basin climatic station (at a much different elevation than the site) shows a bimodal distribution, with a primary June maximum and a secondary January peak. The three-year running average of annual precipitation for the Boulder station (also at some distance from WET58) shows values below the long-term average for much of the 1980s and near or above the long-term average for 1990-93, with precipitation in 1993 (the year of sampling) almost 6 inches above average. [Water supply to the ontario creek headwaters is probably supported mainly by winter snowpack, however, which is not reflected in data from these lowelevation stations.]

Geologic setting. The Ontario creek wetland is underlain by deeply weathered glacial till interpreted as early wisconsin in age. Glacial deposits, which are probably very thin, overlie the Cretaceous-aged Elkhorn volcanics and quartz monzonite the Boulder batholith. Hydrothermal mineralization has encouraged extensive prospecting and historic ore production at numerous nearby sites along the Ontario Creek-Telegraph Creek divide.

Hydrologic type. WET58 is a small headwaters site with intermittent(?) surface water outflow and without channelized inflow. Although ground-water relationships are not known, the position of the wetland near a drainage divide suggests recharge from the wetland to ground-water may occur.

Basin characteristics. The ontario creek wetland is a shallow basin with a small, low-gradient catchment and a low catchment to wetland area ratio in comparison to other Rocky Mountain sampling sites. No mines or prospects are known within the immediate catchment, but some level of sulfide mineralization is probably ubiquitous in the area.

Water chemistry. The Ontario creek wetland is acidic, extremely dilute and calcium/sodium-sulfate in composition. Nitrogen and orthophosphorous concentrations are very low, and the total organic carbon concentration ranks mid-range in comparison to Rocky Mountain sites.

The copper concentration reported is very high, exceeded in the site class only by sample sites with known mining impacts. Arsenic and iron concentrations rank mid-range within this site class, and lead was reported at the detection limit.

Chemical history. No other chemical data from this site are known.

Sediments. The extractable concentrations of arsenic and copper 

rank toward the upper end of the ranges shown for Rocky Mountain sites, with most higher concentrations reported from sites with known mining impacts. Iron, manganese and zinc concentrations rank at or near the lower end of their respective ranges, and other trace element concentrations were below reporting limits. 



\section{Ontario Mine Wetland}

climatic setting. The net annual precipitation balance for the ontario Mine (from the MAPS database) is -3 inches, placing the site near the humid end of the range shown by the sample sites, but mid-range for those in the Rocky Mountains. Mean monthly precipitation for the Basin climatic station (at a much different elevation than the site) shows a bimodal distribution, with a primary June maximum and a secondary January peak. The three-year running average of annual precipitation for the Boulder station (also at some distance from WET59) shows values below the long-term average for much of the 1980s and near or above the long-term average for 1990-93, with precipitation in 1993 (the year of sampling) almost 6 inches above average. [Water supply to the Ontario Creek headwaters is probably supported mainly by winter snowpack, however, which is not reflected in data from these lowelevation stations.]

Geologic setting. The WET59 site in underlain by quartz monzonite of the Boulder Batholith, near the contact with a mass of aplitic intrusive rock underlying o'Keefe Mountain. Surficial deposits are not shown on geologic maps of the immediate area and are probably thin or absent. Historic mine workings drain to the unnamed creek supporting the wetland. No specific information on the nature of mineralization in these particular workings was found. Sulfide mineralization is widespread in the area.

Hydrologic type. The WET59 site is in a headwater riparian wetland area supported by a small first-order stream receiving ground-water discharge which is contaminated by acid mine drainage.

Basin characteristics. The surface water catchment is small and relatively steep; the wetland area is not definable at published map scales. Ground-water delivered as mine drainage may possibly originate outside the boundaries of the surface catchment.

Water chemistry. The water sampled at WET59 is characterized by obvious effects of acid mine drainage (AMD), including very low $\mathrm{pH}$, dominance of the anion makeup by sulfate, and elevated concentrations of metals. Nitrate and ammonium concentrations were below detection limits, the orthophosphate concentration ranked mid-range in comparison to other Rocky Mountain sites. The total organic carbon concentration was among the lowest in the sample set. Arsenic, cadmium, copper, lead and zinc concentrations were the highest among the Rocky Mountain sites. In the case of cadmium, lead and zinc, WET59 showed the highest water-column concentrations in the entire data set.

Chemical history. No other chemical data from this site are known.

Sediments. A very high concentration of extractable iron probably reflects deposition of iron hydroxides precipitated from the water column. Extractable arsenic and lead concentrations are the 


.


highest in the sample set by wide margins. Copper, mercury and zinc concentrations also rank near the upper end of the ranges shown. Arsenic, copper, lead and zinc concentrations exceed mean concentrations for soils of the western United States by one to three orders of magnitude. 



\section{Pine Butte Fen}

climatic setting. The net annual precipitation balance for Pine Butte fen (from the MAPS database) is -20 inches, at the humid end of the range shown by Great plains sites. Mean monthly precipitation for the Blackleaf Canyon climatic station shows a broad summertime peak with a June maximum. Total annual precipitation records at the Blackleaf Canyon station are incomplete for recent years; reported totals since 1990 were above the long-term average for the station, with total precipitation in 1993 (the year of sampling) exceeding the long-term average by more than 7 inches.

Geologic setting. Pine Butte Fen occupies a broad area of groundwater discharge from shallow aquifers recharged largely by seepage from the channel of the Teton River. The unconsolidated aquifer supporting the fen is composed of calcareous outwash and alluvium of late Pleistocene age, deposited near the terminus of an alpine glacier flowing out of the Teton River canyon (nearby to the northwest.) Reduced aquifer cross-sectional area and upward potentiometric gradients drive ground-water discharge to the fen.

The outwash gravel and other surficial sediments overlie shale, siltstone and minor sandstone of the late Cretaceous-aged Two Medicine and Telegraph Creek Formations. Cretaceous rocks are believed to behave mainly as boundaries to ground-water flow through surficial materials.

Hydrologic type. Pine Butte Fen is an area of perennial groundwater discharge from calcareous unconsolidated aquifers deposited as outwash immediately beyond the local limits of alpine glaciation. Surface water inflow from the small surface catchment is a minor component of the fen water budget; ground-water discharge supports perennial surface water outflow from the fen.

Basin characteristics. Low topographic divides describe a surface catchment only slightly larger than the fen itself; ground-water supporting the fen originates as recharge outside the local surface catchment. Most of the fen is vegetated; up-welling ground-water maintains limited open-water pools of undescribed(?) depth. The underlying aquifer narrows and probably thins to the southeast, generating the ground-water discharge which supports the fen and perennial outflow by two spring creeks to the North Fork of Willow creek.

Water chemistry. Water sampled at WET60 is dilute, slightly alkaline and calcium-bicarbonate in composition. Mineral equilibria indicate oversaturation with carbonate phases. Trace element concentrations generally are low; iron and zinc were reported at intermediate concentrations and most other trace element concentrations were below reporting limits.

Chemical history. No other chemical data for WET60 were found. 

Some additional water quality data may be available from The Nature Conservancy, however.

Sediments. Arsenic, boron and vanadium concentrations rank midrange among sites in this class. Iron and selenium concentrations were comparatively high, as was iron (suggesting and boron and zinc concentrations low within the site class. Most other trace elements occurred at concentrations below reporting limits. Arsenic and selenium exceeded mean values for soils of the western United States by factors of 1.25 and 2.6 , respectively. Other trace elements analyzed were below the regional mean soil concentrations. 



\section{Sands Waterfowl Production Area}

climatic setting. The net annual precipitation balance for the Sands WPA (from the MAPS database) is -27 inches, placing Sands toward the more evaporatively intense end of the range shown for sites of the glaciated plains. Mean monthly precipitation for the Havre climatic station shows a prominent June maximum. Total annual precipitation for the Havre station shows apparent periodicity, with peaks in the 3-year running average every 4 or 5 years. From 1988 to 1990 , the running average was below the long-term mean. From 1991 through 1993, the running average met or exceeded the long-term average.

Geologic setting. The WET61 site (part of the Sands WPA situated on Halfway Lake, but not to be confused with nearby Sands Lake) is underlain sandstone and shale of the late Cretaceous Judith River Formation and, at the northern end of the lake, the late Cretaceous Bearpaw Shale. The catchment contributing to Halfway Lake exposes significant areas of Tertiary volcanic rocks in addition to the sedimentary rocks underlying Halfway Lake. Surficial deposits are inferred to include lacustrine sediments within the lake basin and glacial deposits(?) in lower-elevation portions of the Halfway Lake catchment; descriptions of surficial sediments are not available for the area, however.

Hydrologic type. Halfway Lake has surface water inflow from a large catchment and no apparent surface water outflow. The origin of the lake basin is uncertain; glacial processes and structural geologic controls may both contribute to the basin's presence.

Basin characteristics. Halfway Lake has a relatively large natural catchment and a catchment to wetland area ratio ranking mid-range among Great Plains sampling sites. Water is also imported into the catchment from the Beaver creek basin to the west; some of this imported water may contribute to Halfway Lake. The depth and volume of the lake are unknown, but low basin gradients suggest shallow lake depths and transient shoreline position. The WET61 site is very near one the lake's inlet streams and may during runoff conditions show more dilute water chemistry than other point in the lake.

Water chemistry. At the time of sampling, wET61 exhibited nearneutral, "oligosaline" sodium-bicarbonate water quality characteristics and a depressed dissolved oxygen concentration. The sampling hour (8:30 am) suggests that the Do depression may be due to overnight plant respiration in a productive setting. The ammonium concentration ranked mid-range in comparison to sites in this classification; phosphorous and total organic carbon concentrations were high, with the phosphorous concentrations (total and orthophosphate) exceeded mainly at sites much more saline than Halfway Lake.

Arsenic and boron concentrations rank mid-range within this site class, while copper, iron, lead and zinc concentrations were 

comparatively high.

Chemical history. No previous chemical data are known from this site. The salinity of Halfway Lake represented by the DHES analysis is low for a site in the plains which apparently lacks surface water outflow. Sample collection occurred during high lake stage and may also have reflected the proximity of WET61 to a contributing drainage.

Sediments. Arsenic, boron, iron, nickel, vanadium and zinc concentrations all rank mid-range among sites of the glaciated plains, but are lower than for most plains sites lacking surface water outflow. The boron concentration exceeds the mean concentration for soils and other surficial materials of the glaciated plains by a small factor; other trace element concentrations analyzed are below the regional mean soil concentrations. 



\section{Schrammeck Lake WPA}

climatic setting. The net annual precipitation balance for Scrammeck Lake (from the MAPS database) is -25 inches, an intermediate value for hydrologically similar sampling sites. Monthly average precipitation for the cascade climatic station shows a strong May-June peak. Annual records for the Cascade station show the 3-year running average at or above the long-term average for most of the past 20 years. The annual total in 1993 , the year prior to sampling, exceeded the long-term mean by about 3 inches.

Geologic setting. The schrammeck Lake basin is underlain by bentonitic shale and sandstone of the colorado group. Colorado Group sediments in the area reportedly include pebble conglomerates derived from the phosphatic Phosphoria Formation.

The area is beyond the maximum advance of Pleistocene glaciation. Surficial sediments observed in and around the lake include lacustrine sediments ranging from organic-rich, highly reduced sticky mud to relatively well-sorted, fine to medium-grained calcareous littoral sand on the northern shoreline. Vegetated ridge-and-swale features at the northern end of the lake may be small dunes, suggesting past desiccation of the lake. The lake exhibits at least one relict shoreline at an elevation approximately 10 feet above the observed lake stage, indicating lake volume more than an order of magnitude greater than at the time of sampling. In nearby Geyser Creek, groundwater discharge reportedly causes small "eruptive" features in weathered colorado Group sediments.

Hydrologic type. Schrammeck Lake is a nonglaciated (probably structurally controlled) basin lacking surface outflow. Surface outflow has probably occurred at higher water levels, shown topographically by an apparent outflow channel north of the wetland. Ground-water outflow through winnowed littoral sediments may occur.

Basin characteristics. Schrammeck Lake has a relatively small surface catchment with respect to the area of the wetland. At current water levels the volume of Schrammeck Lake is low relative to it's surface area. The maximum measured water depth in August of 1994 (at somewhat lower stage than during sampling) was 1.4 feet, with little variability across the open water portion of the basin.

Water chemistry. Schrammeck Lake water is a sodium carbonate type, of moderate salinity at the time of sampling. This major-ion water composition is unique within the wetland sample set. Equilibrium calculations indicate substantial oversaturation with carbonate species.

Schrammeck Lake shows relatively high water-column concentrations of several trace elements, including boron, chromium, iron, lead 

and zinc. Relative to hydrologically similar sites, however, none of these concentrations appear extraordinary.

Orthophosphorous and total phosphorous concentrations were near the maximum for all sample sites, while both nitrate and ammonium concentrations were below detection limits. Total organic carbon was within the range shown by hydrologically similar sites.

Chemical history. No water quality data predating the DHES sampling are known. Observations during June, August and September of showed a threefold seasonal increase in specific conductance during 1994. In August of 1994, measured specific conductance within the wetland varied spatially by no more than $3 \%$. Schrammeck Lake has probably experienced both desiccation and overflow during the recent geologic (and possibly historic) past. Water quality at the high stage indicated by relict shoreline features would probably be quite dilute, approaching the concentration of runoff from similar geologic materials.

Sediments. Schrammeck Lake sediments contain trace element concentrations within the range shown by hydrologically similar sample sites. Extractable concentrations of boron and zinc exceed regional mean values for soils and other surficial materials in the western U.S. 



\section{Spidel Waterfowl Production Area}

climatic setting. The net annual precipitation balance for the Spidel WPA (from the MAPS database) is -29 inches, ranking this as one of the most intensely evaporative sites in the data set. Mean monthly precipitation for the Broadview climatic station shows a maximum in May; annual totals for the Broadview station are incomplete but show generally below-normal values during the 1980 s. Annual totals after 1990 were not recovered for this station. Regionally, precipitation totals for 1991 through 1993 were above average for many stations.

Geologic setting. The spidel basin is a depression along the western limb of the Bull Mountains structural basin. The spidel basin itself appears to be structurally controlled; WET63 is underlain by the Lance Formation of latest Cretaceous age; western portions of the spidel catchment are underlain by the Bearpaw Shale and Judith River Formations of late cretaceous age, while the eastern portion of the catchment is underlain by the Fort Union Formation of early Tertiary age. The central portion of the spidel basin has accumulated an unknown thickness of lacustrine sediments.

Hydrologic type. The spidel wetland occupies a basin lacking surface water outflow, and receiving surface water inflow from a number of intermittent drainages. Local ground-water inflow may also occur but probably is not volumetrically important. The surface extent and shoreline position of the spidel wetland is inferred to be highly variable.

Basin characteristics. The spidel basin has a large catchment and, based on the mapped extent of the wetland, a catchment to wetland area ratio intermediate with respect to other sample sites of the unglaciated great plains. A number of small impoundments within the catchment may have altered the quantity and timing of runoff received by the spidel basin. The low gradient basin implies large variations in surface area; water depths are unknown but inferred to be no more than a few feet.

Water chemistry. At the time of sampling, the spidel WPA contained transition "oligosaline/mesosaline" sodium sulfate water of moderately high alkalinity. Mineral equilibria indicate substantial oversaturation with carbonate phases. The ammonium concentration was low in comparison both to unglaciated plains sites and to other sites lacking surface water outflow. Phosphorous concentrations ranked mid-range with respect to regionally and hydrologically similar sites, and the total organic carbon concentration was comparatively high.

Arsenic, boron and iron concentrations ranked mid-range in comparison to other sites in this class. Most other trace element concentrations were below reporting limits.

Chemical history. No other chemical data from this site are known. 

The basin configuration and climatic setting imply wide variability in salinity at this site; late summer and fall dissolved solids concentrations may be several times that observed at the time of sampling.

Sediments. Extractable arsenic, copper, nickel and zinc concentrations ranked mid-range or below in comparison to other unglaciated plains sites. Boron, chromium, iron and vanadium concentrations ranked relatively high, and the selenium concentration was among the three highest reported for the entire data set.

The selenium concentration exceeded the mean concentration for soils of the western United States by a factor of 3 , and the boron concentration exceeded the regional mean soil concentration by a factor of 2.4. The extractable nickel and zinc concentrations exceeded regional mean soils concentrations by small factors. 
climatic setting. The net annual precipitation balance for swamp Gulch (from the MAPS database) is -4 inches, mid-range among Rocky Mountain sites. Mean monthly precipitation for the Lincoln Ranger station climatic station shows a late spring peak, with relatively even distribution the remainder of the year. (Water supply in the headwater streams contributing to the Swamp Gulch wetland probably are much more heavily influenced by winter snowpack than is the Lincoln climatic station.) Annual total precipitation for the Lincoln station was generally below average during the mid-1980s and near or above the long-term average in the late 1980 s and early 1990s. Total precipitation in 1993 (the year of the DHES sampling) exceeded the long-term average by about 5 inches.

Geologic setting. The Swamp Gulch wetland and upstream catchment areas are underlain mainly by the spokane and Empire formations of the Proterozoic-aged Belt series; late-Proterozoic mafic intrusive rocks (diorite) also occur in the lower swamp Gulch drainage. Early Tertiary-aged monzonite porphyry and intrudes the Proterozoic-aged rocks near the mouth of swamp Gulch; mineralization of the diorite near this intrusive contact was developed by the abandoned Carbonate Mine. Drainage from the Carbonate Mine enters lowermost Swamp Gulch and the WET64 wetland area. The immediate wetland area is underlain by undescribed alluvial (and glacial?) sediments and by up to 15 feet of peat and other palustrine sediments.

Hydrologic type. The Swamp Gulch wetland is a complex of lowgradient riparian and ponded areas at the confluence of streams forming the upper Blackfoot River. Surface water inflow occurs from several streams. Surface-water outflow is to the Blackfoot River. Ground-water movement through the wetland occurs through peat and presumably through the underlying unconsolidated sediments, probably discharging to the Blackfoot River downstream of the WET64 site.

Basin characteristics. The Swamp Gulch wetland has a substantial catchment and a relatively high catchment to wetland area ratio. water sources in the immediate WET64 area include both Swamp Gulch and the Upper Blackfoot River, which is formed a short distance upstream by the confluence of Pass Creek and Anaconda Creek. Blackfoot River water is carried past the WET64 site by beaver ponds and a minor diversion channel. The distribution of ponds and channels within the wetland area surrounding the WET64 site is believed to have been stable throughout the twentieth century.

The overall thickness of peat and other high-organic sediments is on the order of 3 feet or less, with 3 to 12 feet of silty "catotelm" beneath. Ground-water flow through the shallow organic peat is relatively rapid and occurs along preferential flow paths.

At least two of the several streams entering the wetland complex 
(Anaconda Creek and Swamp Gulch) suffer serious mining or mineral processing impacts. The Swamp Gulch wetland has functioned as a physical and geochemical sink for some of the mine wastes transported out of these drainages.

Water chemistry. The water sampled at the WET64 site is dilute, mildly acidic, calcium-sulfate in composition, and heavily impacted by acid mine drainage (AMD) from the Carbonate Mine in lower swamp Gulch. Equilibrium calculations indicate highly undersaturated conditions with respect to carbonate minerals. Nitrate and ammonium concentrations were below detection limits, and orthophosphate and total organic carbon concentrations were near the lower end of the ranges shown for the sample set.

Copper, iron, lead and zinc concentrations were near the upper end of the ranges shown for Rocky Mountain sites, and were generally exceeded only at other sites exhibiting impacts from mining or mineral processing. The arsenic concentration was comparatively low, cadmium occurred at the reporting limit, and other trace elements analyzed were below reporting limits.

Chemical history. The development of the Carbonate Mine predates 1933, and mine drainage has presumably been impacting the WET64 site since that era. Detailed data collection on this site was conducted as part of a 1987 investigation into the AMD-treatment capability of the wetland (see Dollhopf et al in the WET64 site bibliography). None of the sampling sites used in the 1987 study correspond to the WET64 site; the 1987 sampling sites show considerable spatial variability within the general area receiving inflow from Swamp Gulch. $\mathrm{pH}$ values below 3, sulfate concentrations in excess of $400 \mathrm{mg} / \mathrm{l}$, and cadmium concentrations in the $\mathrm{mg} / 1$ range were reported for sampling points near the Swamp Gulch outfall. In contrast to the DHES sample, measurable nitrate concentrations were reported for almost all of the samples analyzed in 1987 and 1988, with concentrations in the $\mathrm{mg} / 1$ range at several sites.

Sediments. The Swamp Gulch sediment sample was heavily contaminated with metals precipitated from AMD inflow to the wetland. Extractable iron accounted for approximately a third of the sample. Boron, copper, cadmium, cobalt, nickel, vanadium and zinc concentrations were the maximum reported for Rocky Mountain sites and in many cases for the entire data set. Extractable boron, cadmium, iron, and zinc concentrations exceeded those for all other sample sites by several hundred percent. Most trace elements with reportable concentrations exceeded mean soil concentrations for the western United States, in the case of boron, copper and zinc by more than an order of magnitude. 



\section{Swan River Research Natural Area}

climatic setting. The net annual precipitation balance for the Swan River site (from the MAPS database) is -8 inches, placing the site toward the more evaporative end of the range shown by Rocky Mountain sample sites. Mean monthly precipitation for the Swan Lake climatic station shows a bimodal distribution, with a major winter maximum and a secondary June peak. Annual totals for this station were not available for years after 1990; the late 1980s experienced annual precipitation below the average for the period of record.

Geologic setting. The WET65 site lies near the contact between Recent alluvium of the Swan River and upland slopes composed of late pleistocene-aged glacial till described as relatively loose and sandy. Ground-water discharge (from glacial sediments?) occurs nearby to the west, supporting a peat dome centered around the discharge area. Low hills immediately to the east are interpreted as remnants of a kame terrace, supporting a glacial origin for sediments immediately underlying the wetland. The surficial till mantle of upland slopes is underlain by the Helena Formation, a calcareous and dolomitic unit of the Proterozoic-aged Belt series.

Hydrologic type. The WET65 site is in a flow-through setting with surface water inflow and outflow; the site may also receive some ground-water inflow discharging from glacial deposits underlying upland slopes to the east and west or from the alluvial sediments underlying the site, which appear to narrow and thin in the (inferred) downgradient direction.

Basin characteristics. The surface catchment contributing to this site includes upland areas in the Mission Mountain foothills, and (apparently) the western third of the Swan River floodplain for several miles upstream. Ground-water inflow from a larger area may contribute to the wetland, depending on flow paths within the Swan River alluvium. The geometry of the valley-margin channel along which the wetland lies may contribute to local ground-water discharge.

Based strictly on map relationships from the 1965 topographic coverage of the area, the WET65 wetland appears to be at some risk of losing it's main source of surface-water inflow. The unnamed stream flowing through the wetland bifurcates (according to the 1965 mapping) a half mile upstream from WET65. The eastern channel bypasses the wetland site, and according to the 1965 topographic mapping appears to be establishing a lower base level than the channel supporting the wetland. Stream piracy could change water availability at WET65 if this process continues.

Water chemistry. The water sampled at WET65 is dilute, circumneutral in $\mathrm{pH}$ and of calcium-bicarbonate composition. Mineral equilibria indicate approximate saturation with calcite and undersaturation with respect to dolomite. The nitrate 

concentration reported ranks high among Rocky Mountain sites, while orthophosphorous and total organic carbon concentrations rank midrange within the site class. Trace element concentrations analyzed were low, with the exception of zinc, which ranked high in comparison to the site class, and lead (which was detected at the reporting limit.

Chemical history. No other chemical data are known from this site.

Sediments. Extractable arsenic and iron concentrations rank toward the upper end of the ranges shown for Rocky Mountain sites. Copper and zinc concentrations ranked mid-range or lower in comparison to the site class, and most other trace element concentrations were below reporting limits. The arsenic concentration reported exceeded the mean value for soils of the western United States by a factor of 1.4 . 


\section{Telegraph Creek Headwaters}

climatic setting. The net annual precipitation balance for the Telegraph Creek Headwaters (from the MAPS database) is -3 inches, placing the site near the humid end of the range shown by the sample sites, but mid-range for those in the Rocky Mountains. Mean monthly precipitation for the Basin climatic station (at a much different elevation than the site) shows a bimodal distribution, with a primary June maximum and a secondary January peak. The three-year running average of annual precipitation for the Boulder station (also at some distance from WET66) shows values below the long-term average for much of the 1980 s and near or above the longterm average for 1990-93, with precipitation in 1993 (the year of sampling) almost 6 inches above average. [Water supply to the Telegraph Creek headwaters is probably supported mainly by winter snowpack, however, which is not reflected in data from these lowelevation stations.]

Geologic setting. The Telegraph Creek wetland is underlain by deeply weathered glacial till interpreted as early wisconsin in age. Glacial deposits, which are probably very thin, overlie the Cretaceous-aged Elkhorn volcanics and quartz monzonite the Boulder batholith. Hydrothermal mineralization has encouraged extensive prospecting and historic ore production at numerous nearby sites along the Ontario Creek-Telegraph Creek divide.

Hydrologic type. WET66 is a small headwaters site with intermittent(?) surface water outflow and without channelized inflow. Although ground-water relationships are not known, the position of the wetland near a drainage divide suggests recharge from the wetland to ground-water may occur.

Basin characteristics. The Telegraph Creek wetland is a shallow basin with a small, low-gradient catchment and a low catchment to wetland area ratio in comparison to other Rocky Mountain sampling sites. No mines or prospects are known within the immediate catchment, but some level of sulfide mineralization is probably ubiquitous in the area.

Water chemistry. The Telegraph Creek wetland is characterized by dilute, mildly acidic calcium-bicarbonate/sulfate water distinctly different in major-ion chemistry from that of the nearby ontario Creek Headwaters site (WET58). The dissolved solids concentration and $\mathrm{pH}$ are considerably higher at the Telegraph Creek site, and the sulfate concentration proportionately much lower. Ammonium and phosphorous concentrations are also higher at WET66, with the orthophosphate concentration ranking toward the upper end of the range shown by Rocky Mountain sites.

The arsenic, boron, copper, iron and lead concentrations in the WET66 sample were all relatively high, exceeded in the Rocky Mountain sites mainly by sites with known mining and mineral processing impacts. Other trace elements analyzed were below 
reporting limits.

Chemical history. No other chemical data from this site are known.

Sediments. The sediment sample from WET66 exhibited a generally enriched array of trace elements. Arsenic, boron, iron, and vanadium concentrations ranked toward the upper end of ranges shown for Rocky Mountain sites, with the arsenic concentration exceeded only at mine-impacted or hypersaline sites. Only arsenic exceeded the mean values for soils of the western United states (by a factor of 5.5 ). 


\section{Tew Waterfowl Production Area}

climatic setting. The net annual precipitation balance for the Tew WPA (from the MAPS database) is -27 inches, ranking Tew toward the more intensely evaporative end of the range shown by the data set. Mean monthly precipitation for the Broadview climatic station shows a maximum in May; annual totals for the Broadview station are incomplete but show generally below-normal values during the 1980 s. Annual totals after 1990 were not recovered for this station. Regionally, precipitation totals for 1991 through 1993 were above average for many stations.

Geologic setting. WET67 is located on a small structurally controlled(?) basin underlain by the Lebo Shale Member of the early Tertiary Fort Union Formation. Descriptions of the surficial sediments overlying the Fort Union Formation are not available, but they are inferred to consist of relatively thin and locally derived lacustrine or paludal deposits.

Hydrologic type. The WET67 site is a small area of internal drainage lacking discrete surface water inflow or outflow under present hydrologic conditions. Inflow is inferred to be by local runoff and direct precipitation.

Basin characteristics. The small local catchment provides this site with a low catchment to wetland area ratio. At low stages separate water bodies apparently exist within the mapped catchment; during wet conditions the sampled wetland may merge with an adjacent water body outside of the local catchment. Some ground-water outflow may occur, but the basin sediments are probably of low permeability and unlikely to allow very rapid ground-water recharge. The wetland basin has apparently been modified by the construction of the county road adjacent to the WET67 site; this modification may alter the geometry of the water body during high-stage conditions. The water depth of the wetland is unknown but inferred to be shallow.

Water chemistry. At the time of sampling, the Tew wetland contained moderately alkaline, "oligosaline" water lacking a dominant anion or cation. Mineral equilibria indicate oversaturation with carbonate phases. The equivalent concentration of chloride is high compared to most sample sites. The nitrate concentration was below reporting limits and the ammonium concentration was low in comparison to other sites of the plains. Phosphorous concentrations, however, were very high, exceeded only at a few hypersaline or seasonal, closed-basin sample sites. The total organic carbon concentration was among the lowest in the sample set.

Most of the trace elements analyzed occurred in concentrations below reporting limits. The iron concentration ranked near the top of the range shown by plains sites, the arsenic concentration ranked mid-range and the boron concentration was the lowest 

reported for any sample site of the unglaciated plains.

Chemical history. No other chemical data are known for this site. By inference, the salinity of this site probably reaches considerably higher levels than shown by the DHES sample.

Sediments. Extractable concentrations of chromium, manganese, nickel and vanadium rank near or (in the case of chromium) at the high end of the ranges shown for unglaciated plains sample sites. Arsenic, boron, copper, iron and zinc ranked mid-range with respect to the site class. Other trace extractable element concentrations occurred in concentrations below reporting limits. 

Climatic setting. The net annual precipitation balance for Tooley Lake (from the MAPS database) is -14 inches, at the more evaporatively intense extreme of the range shown by Rocky Mountain sites. Mean monthly precipitation at the Eureka Ranger Station climatic station shows a relatively even distribution throughout the year with a maximum in June. Annual totals for the Eureka station show the short-term (3-year) moving average at or above the average for the period of record from 1981 through 1993. In 1993 (the year prior to sampling) the total precipitation exceeded the mean by about 5 inches.

Geologic setting. Tooley Lake occupies a depression of uncertain origin along the margin of a thick sequence of glaciolacustrine sediments deposited during late Pleistocene impoundment of the Kootenai River. The glaciolacustrine sediments are described as predominantly fine sand and silt with only a minor clay fraction. The permeability of these sands and silts appears to be higher than for many lacustrine deposits; ground-water flow is shown by reported behavior during well drilling and by spring discharges from the sediments. Upslope areas within the lake catchment are underlain by drumlinoid till described as bouldery in texture.

Bedrock outcrops within the lake catchment are composed of formations of the mainly argillitic Ravalli Group of the Proterozoic Belt series. Adjacent drainages expose areas of the calcareous and pyritic siyeh Formation of the Belt series.

Hydrologic type. Tooley Lake has intermittent(?) surface water inflow but lacks surface water outflow. Relatively dilute water chemistry in this setting appears to imply significant ground-water outflow from the lake to moderate the accumulation of solutes contributed by lake inflow. Tooley lake is also in a topographic position suggesting the likelihood of ground-water inflow along it's western shore.

Basin characteristics. The catchment to wetland area ratio ranks mid-range with respect to other Rocky Mountain sites. The depth of Tooley Lake is unknown. Ground-water outflow rates may have been altered by the filling of Lake Koocanusa, artificially raising the local hydrologic base level. Road construction along the eastern shore may have altered shoreline characteristics.

Water chemistry. The WET68 sample was moderately dilute, calcium/magnesium-bicarbonate/carbonate in composition, and only slightly basic in the field. Mineral equilibria indicate approximate saturation with calcite and aragonite under field conditions. The $\mathrm{pH}$ measured in the lab, however, was 9.3, indicating that the sample was not in equilibrium with the surface environment. The one other known $\mathrm{pH}$ measurement from Tooley Lake was also above 9. A probable explanation is that ground-water enters the lake along the western shore, increasing in $\mathrm{pH}$ as inflow 

equilibrates with surface $\mathrm{CO} 2$ pressures. This process would allow the precipitation of authigenic carbonate minerals, which is not inconsistent with the relatively high concentration of calcium seen in the Tooley Lake sediment sample.

The ammonium and phosphorous (total and orthophosphate) concentrations reported were high in comparison to the Rocky Mountains sample sites, while the total organic carbon concentration ranked mid-range against the class including WET68. Trace element concentrations were also uniformly low; copper and iron concentrations ranked mid-range or lower, while other trace elements were below reporting limits.

Chemical history. Three previous measurements of specific conductance at uncertain points in Tooley Lake are known, all

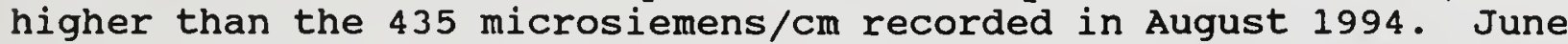
and October, 1968 measurements were 670 and 800 microsiemens $/ \mathrm{cm}$, respectively; in July, 1988 a measurement of $550 \mathrm{microsiemens/cm}$ was recorded. The $\mathrm{pH}$ measurement of 9.3 accompanying the 1988 specific conductance measurement is the only other known chemical measurement from Tooley Lake.

Substantial gradients in $\mathrm{pH}$ and in cation distribution probably exist within Tooley Lake, as apparent ground-water inflow circulates through the lake basin and equilibrates with atmospheric conditions.

Sediments. The relatively high extractable calcium concentration is consistent with some level of authigenic carbonate precipitation from influent ground water. Extractable arsenic and copper concentrations rank toward the lower end of the range shown by Rocky Mountain sites, while boron, selenium and zinc concentrations rank mid-range within the site class. Most other extractable trace element concentrations were below reporting limits. None exceeded the mean concentrations for soils and other surficial materials of the western United States. 

climatic setting. The net annual precipitation balance for the Townsend valley wetland is -28 inches, placing the site at the more intensely evaporative extreme of the range shown by western sampling sites. Mean monthly precipitation for the Townsend climatic station shows a broad summer peak with a June maximum. During most of the 1980s and early 1990s, annual precipitation for the Townsend station was below the average for the period of record. Precipitation in 1993 (the year prior to sampling) exceeded the average by more than 5 inches; regionally, 1994 precipitation was below average at many stations.

Geologic setting. The WET69 site is underlain by Recent alluvium deposited by the Missouri River; tributary alluvium and older Quaternary terrace deposits bound the Recent alluvium, which overlies Tertiary-aged valley fill sediments. Shallow water table depths apparently result in ground-water discharge to depressions such as the WET 69 wetland.

Hydrologic type. The WET69 site occupies a depression of unknown origins lacking apparent surface-water outflow or significant surface-water inflow. Ground-water discharge to the wetland is inferred from shallow local water table depths, chemical characteristics and the lack of a significant surface catchment in an area of net annual evaporation. Ground-water outflow also probably occurs, based on the relatively dilute character of the WET69 sample.

Basin characteristics. The WET69 site has a very small surface catchment substantially modified by human activities. Two transportation corridors (State Highway 12 and an active railroad line) closely bracket the site. Irrigation may contribute to the shallow water table depths supporting the wetland.

Water chemistry. At the time of sampling, water in the WET69 wetland was near-neutral, "oligosaline", and sodium-calciummagnesium/bicarbonate in character. The $\mathrm{pH}$ of the sample was unstable, rising from 7.6 in the field to a lab value of 8.7 . Mineral equilibria indicate approximate saturation with calcium carbonate phases. The proportional chloride concentration ( $>11 \%$ of anion equivalency) is higher than most sample sites of the intermontane valleys. The cation distribution is distinct from most ground-water analyses from the Missouri River alluvial gravels, which tend to have calcium as the proportionately highest cation.

The ammonium and total organic carbon concentrations at this site ranked toward the upper end of the ranges shown by western sample sites. Phosphorous concentrations ranked mid-range or lower. 

The recoverable boron concentration at WET69 ranked near the upper end of the range shown for sites of the intermontane valleys and western sample sites overall. Arsenic, copper, zinc and lead (slightly above the reporting limit) also ranked relatively high in comparison to intermontane valley sites, exceeded mainly at wetlands experiencing known impacts from mining and mineral processing.

Chemical history. No other data from this site are known

Sediments. The relatively high extractable calcium concentration may in part reflect authigenic carbonate precipitation from influent ground water. Extractable concentrations of trace elements are generally high; arsenic, boron, copper, and lead rank near the upper end of the ranges shown for the intermontane valleys and among western are exceeded mainly at those with known impacts from mining and mineral processing. Arsenic, boron, copper, lead and zinc exceed the geometric mean soil concentrations for the western United States by factors of $5.5,3.6,3.9,5.8$ and 2.3 respectively. 



\section{Turtle Lake}

climatic setting. The net annual precipitation balance for Turtle Lake (from the MAPS database) is approximately -11 inches. This places the site toward the less evaporative end of the climatic spectrum for hydrologically similar sample sites, but toward the more evaporative extreme for Rocky Mountain sample sites. Monthly average precipitation for the Fortine climatic station shows relatively even distribution throughout the year, with a moderate peak in May and June. Annual records from the Fortine station show the 3-year running average precipitation has been below the longterm mean during most of the last 30 years. Annual precipitation during the sample year of 1993 exceeded the average for the period of record by approximately 5 inches.

Geologic setting. The Turtle Lake basin is underlain by calcareous till and possibly other glacial sediment types of late(?) Wisconsin age. Bedrock geologic units are of the Proterozoic Belt Series, probably including the calcareous and dolomitic Helena Formation.

Hydrologic type. Turtle Lake is a glacial depression with surface water inflow from an intermittent stream but lacking surface water outflow at current water levels. Groundwater outflow is inferred from the moderate salinity of this topographically closed basin, contrasting with nearby Thirsty Lake, which has high salinity and apparently restricted ground-water outflow.

Basin characteristics. Turtle Lake has a larger surface catchment and considerably larger catchment to wetland area ratio than nearby Alkali Lake. The cluster of lakes in the vicinity display disjunct water quality; Thirsty Lake, nearby and at a lower elevation, exceeds Turtle Lake and Alkali Lake in specific conductance by more than an order of magnitude. Alkali Lake and Turtle Lake display generally similar water chemistry.

Water chemistry. Turtle Lake is proportionately high in magnesium and is nearly depleted in calcium; equilibrium calculations indicate supersaturation with calcium and magnesium carbonate species. Low calcium concentrations appear to be maintained by solubility controls; deposition of authigenic carbonate minerals is inferred from relatively high extractable calcium concentrations in sediment and from observed marl formation in nearby Alkali Lake. High relative magnesium concentrations are typical of hydrologically similar sample sites.

The ammonium and total organic carbon concentrations rank toward the upper end of the ranges shown by Rocky Mountain sites. The orthophosphorous concentration ranks mid-range in comparison to the site class. Trace element concentrations are comparatively low with the exception of selenium, which was reported at the detection Iimit.

Chemical history. A single previous partial chemical analysis from this water body is known. Dating from June of 1987, this partial 

analysis showed specific conductance of about $80 \%$ that measured for the DHES sample, lower $\mathrm{pH}$ and alkalinity, and lower (possibly erroneous) cation concentrations.

Sediments. The comparatively high extractable calcium concentration probably reflects authigenic carbonate formation in Turtle Lake. Most extractable trace element concentrations were below reporting limits. Arsenic, iron and zinc concentrations were comparatively low, while the selenium concentration reported ranked toward the upper end of the range shown by this site class. 

climatic setting. The net annual precipitation balance for Upper Red Rock Lake is -5 inches, at the less evaporative extreme of the range shown by sample sites of the intermontane valleys. Mean monthly precipitation for the Lakeview climatic station shows relatively even seasonal distribution with a maximum in June. Annual precipitation totals for the Lakeview station shows an apparent periodicity, with peaks in the 3-year running average occurring every 5 to 7 years. During the late 1980 s and early 1990s, the station recorded an unusually deep and extended period of precipitation deficit with respect to the average for the period of record. Precipitation during 1993 (the year of sampling) exceeded the average by about 3 inches.

Geologic setting. The WET71 site is underlain by lacustrine deposits of undescribed thickness and character. Alluvial fan deposits shed from the centennial Mountain scarp immediately to the south may interfinger with lacustrine deposits. Bedrock exposed within the Upper Red Rock catchment includes a wide variety of lithologies and ages; Paleozoic and Mesozoic-aged sediments comprise much of the Centennial Mountains, while uplands to the north of the lake expose large areas of Quaternary-aged volcanic rocks.

Major faults underlie the Centennial Valley and exert controls on topography, sedimentation and ground-water flow. Geochemical and thermal evidence indicate the discharge of deeply circulating ground water into shallow aquifers north of the lake and into the northern side of Upper Red Rock Lake itself.

Hydrologic type. Upper Red Rock Lake is a natural structurally controlled(?) basin modified by outlet controls designed to stabilize lake water levels. The lake has surface water inflow and outflow and also receives some ground-water inflow from a deeply circulating geothermal system.

Basin characteristics. Upper Red Rock Lake has a large highelevation catchment and a catchment to wetland area ratio which ranks mid-range among intermontane valley sampling sites. Lake depth and volume are not available. Diversions both for irrigation (in the Alaska Basin upstream) and for fish and wildlife management purposes occur within the catchment.

Water chemistry. Upper Red Rock Lake at the WET7I sampling point contains dilute, moderately alkaline calcium-bicarbonate water. Mineral equilibria indicate slight over-saturation with carbonate phases. Nitrate was reported at a concentration slightly above reporting limits, while ammonium was below reporting limits. The orthophosphate and total organic carbon concentrations ranked toward the lower end of the range shown by sites in this class. 

Most measured trace element concentrations were below reporting limits. Arsenic, copper and iron concentrations ranked mid-range within this site class. Chromium was reported at the detection limit, one of only three western sites with quantifiable concentrations.

Chemical history. No other surface water chemistry is known for this site.

Sediments. Extractable arsenic, iron and copper concentrations rank mid-range or lower with respect to this site class, and most other trace element concentrations were below reporting limits. Extractable chromium and zinc concentrations, by contrast, were exceeded only at sites with known impacts from mining and mineral processing. These relatively elevated concentrations may reflect input to the lake basin from geothermal ground water enriched with trace elements. 
climatic setting. This site is in a high elevation subalpine setting with a high precipitation surplus. The net annual precipitation balance (from the MAPS database) is 44 inches, one of the two highest values for the sample sites. Mean monthly precipitation for the cooke City climatic station shows relatively even distribution throughout the year, with low summer and winter peaks. Total annual precipitation for this station shows comparatively low values throughout the later 1980 s and early 1990s. Precipitation in 1993 (the year prior to sampling) was near the average for the period of record.

Geologic setting. The WET72 site is underlain by Holocene-aged alluvium and Pleistocene glacial deposits of undescribed character. The surficial deposits cover bedrock lithologies including Tertiary-aged volcanic rocks of silicic to intermediate composition and Cambrian-aged limestone and shale. The upper basin of Daisy Creek, tributary to the upper stillwater River above the WET72 site, is characterized by extensive hydrothermal mineralization related to the intrusion of the Henderson Mountain stock and associated dike complex.

Hydrologic type. The Upper Stillwater wetland is a riparian meadow with perennial surface water inflow and outflow during the ice-free season.

Basin characteristics. The alpine and subalpine basin of the Upper Stillwater basin provides a relatively low catchment to wetland area ratio due to the large estimated wetland area. Stream gradients within the wetland are very low. Mine wastes and acid mine drainage (AMD) from the historic McLaren Mine have resulted in severe contamination of upper Daisy Creek, a tributary joining the Stillwater River upstream from the WET72 site. Metal-laden AMD encounters calcareous geologic formations (the Meaghar Limestone) a short distance below the McLaren Mine, depositing a hydroxide precipitate as $\mathrm{pH}$ rises and removing most dissolved metals from solution. High flows scour the hydroxide solids from Daisy Creek and redeposit them in the stream channel and as overbank sediments in the low-gradient wetland area.

Water chemistry. The WET72 water sample exhibited a dilute, mildly alkaline calcium-bicarbonate character. Equilibrium calculations indicate slight undersaturation with carbonate minerals. Phosphorous (total and orthophosphate) and total organic carbon concentrations were low in comparison to most other Rocky Mountain sites. The ammonium concentration was below reporting limits and the nitrate concentration ranked mid-range in comparison to other Rocky Mountain sites.

With the exception of iron (ranking mid-range in comparison to other Rocky Mountain sample sites), trace element concentrations were below reporting limits in the water column. 

Chemical history. Sampling of the WET72 site was carried out in conjunction with a synoptic sampling program on the stillwater River and it's tributaries which incorporated 16 surface water, sediment and biological sampling stations both above and below the WET72 site. For details, refer to work of the Montana Department of State Lands, Hardrock Bureau of the Reclamation Division. Additional environmental sampling near WET72 may have been conducted by the Crown Butte Mining Company.

Sediments. In contrast to the water column data, the sediments from this site display a generally elevated distribution of trace elements. Extractable concentrations of arsenic, boron, chromium, copper, cobalt, iron, nickel, vanadium, and zinc all are near or at the high end of ranges shown for Rocky Mountain sites and (in most cases) for the entire data set. Most are exceeded only at other sites of known contamination by mining or mineral processing wastes. Extractable concentrations exceed the geometric means for soils of the western United states by the following factors: arsenic (4.1), boron (4.7) cobalt (2), nickel (2.7), selenium (1.7) and zinc $(2.8)$. For all but selenium, these factors exceed one geometric deviation above the mean soil values. 

Climatic setting. The net annual precipitation balance for wagner Basin (from the MAPS database) is -6 inches, ranking mid-range among sample sites of the Rocky Mountains. Mean monthly precipitation for the Gibson Reservoir climatic station shows a May-June peak. Total annual precipitation for the Gibson Reservoir station shows apparent periodicity, with the 3-year running average peaking every 4 to 7 years. The 3 -year average remained near or below the long-term average throughout the $1980 \mathrm{~s}$ and was near the long-term average in the early 1990s. In 1993 (the year of the DHES sampling) precipitation exceeded the long-term mean by nearly 5 inches.

Geologic setting. Wagner Basin is underlain by a faulted slice of Paleozoic sedimentary rocks including the Mississippian-aged Madison Group. The wetland is supported by a large spring discharging ground water from the Madison Group(?), or possibly from another carbonate formation in the Paleozoic section. Recharge to the ground-water system probably occurs locally within Wagner Basin. The location of the spring may be controlled by cavernous zones within carbonate aquifer(s) or, possibly, by thrust faults underlying basin. Discharging ground water flows across outwash and terrace gravel sediments fringing the wetland and to the Sun River. Surficial sediments include travertine and tufa deposits precipitated from the discharging ground water.

Hydrologic type. Wagner Basin receives perennial ground-water discharge from a discrete spring source and intermittent(?) surface runoff. Outflow occurs via an outlet stream and probably by seepage into terrace gravels fringing the wetland.

Basin characteristics. The catchment to wetland area ratio for wagner Basin is relatively high compared to most other Rocky Mountain sample sites. Carbonate rocks underlie a large portion of the steep catchment and are inferred to receive ground-water recharge readily.

Water chemistry. Water sampled at the WET73 site was relatively dilute, slightiy alkaline and calcium-sulfate/bicarbonate in composition. The calcium-sulfate character of this site is unusual among the unimpaired sample sites; the few other sites with similar proportions of major ion equivalents are in wetlands impacted by acid mine drainage or underlain by notably gypsiferous colorado Group shales. Wagner Basin's water composition is believed to be influenced by dissolution of calcium sulfate evaporites (gypsum or anhydrite) within the carbonate aquifer(s) drained by the Wagner Basin springs. Mineral equilibria indicate slight over-saturation with carbonate phases and undersaturation with gypsum.

WET73 was among the minority of sites with reportable nitrate; the orthophosphate concentration ranked mid-range in comparison to 

sites within this class, and the ammonium concentration was below reporting limits. The total organic carbon concentration was among the lowest for all sample sites.

Most trace element concentrations analyzed were below reporting limits. The iron concentration was comparatively low, and boron occurred at the reporting limit.

Chemical history. No other chemical data from this site are known.

Sediments. Extractable arsenic and copper concentrations ranked toward the bottom of the ranges shown for Rocky Mountain sites. Boron, iron, chromium, nickel and zinc were all relatively high within the site class, and were exceeded mainly at sample sites with known impacts from mining or mineral processing. The extractable zinc concentration exceeded the mean value for soils of the western United States by a factor of 1.4, and nickel and boron exceeded the regional mean soil concentrations by small factors. 



\section{Warhorse National wildlife Refuge}

climatic setting. The net annual precipitation balance for Warhorse Lake (from the MAPS database) is -28 inches, placing Warhorse in the middle of the narrow range of evaporative intensity shown by sites of the unglaciated plains, and near the evaporative extreme of the range shown by the entire data set. Mean monthly precipitation for the winnett climatic station shows a pronounced summer peak with a June maximum. Annual total precipitation for the winnett station is not available for recent years; regionally, many stations experienced above-average precipitation in 1993 (the year of sampling) and near-average precipitation in 1992.

Geologic setting. Warhorse Lake and it's natural catchment are underlain entirely by fine-grained sedimentary rocks of the Colorado Group. Colorado Group shales in the Warhorse area are described as bearing ubiquitous selenite (gypsum). The Warhorse basin appears to be structurally controlled, lying along the axis of a northwest-trending syncline. No description of surficial sediments in the immediate area is available; based on the underlying geology, surficial sediments are inferred to be mainly fine-grained, of low permeability and gypsiferous.

Hydrologic type. Warhorse Lake occupies a natural, structurally controlled basin augmented by impoundments and formerly supplied by water imports from Fords creek, draining portions of the southern Judith Mountains. Water imports have not occurred for at least 10 years, and water supply to the lake is now derived only from the natural surface catchment. Warhorse Lake has presently unused outflow structure formerly used to control irrigation water supply.

Basin characteristics. The natural catchment of warhorse Lake is relatively small, and the catchment to wetland area ratio is the lowest among sites of the unglaciated plains. Past water imports from the Fords creek drainage (no longer practiced) effectively increased the contributing area many-fold. Information on water depth is not available. Under current management practices, the lake is reported to hold water during the autumn bird migration less than $50 \%$ of the time, and low basin gradients ensure a high degree of shoreline transience.

Water chemistry. At the time of sampling, warhorse Lake contained slightly alkaline, "oligosaline" water of unusual calcium-sulfate composition. [Calcium is the proportionately highest cation but does not dominate the cation field, accounting for $42 \%$ of the cation equivalence.] Equilibrium calculations indicate nearequilibrium with carbonate phases and undersaturation with gypsum. The major-ion chemistry of Warhorse Lake is apparently influenced by the (reportedly) ubiquitous occurrence of selenite (gypsum) in local colorado Group shales and derivative soils. 

Warhorse Lake contained the second-highest nitrate concentration in the sample set, and the highest among sites of the unglaciated plains. The WET74 sample also contained significant ammonium. The orthophosphorous concentration was one of the lowest of the unglaciated plains, exceeding only non-lacustrine sites (Burns Creek and the Lavina DOT site.) The total phosphorous and total organic carbon concentrations also were relatively low in comparison to other sites in this classification. (The total phosphorous analysis was conducted on a different sample collected under different hydrologic conditions.)

Arsenic and boron concentrations were relatively low in comparison to other sites in this class. The chromium concentration reported ranks mid-range among the generally enriched nonglaciated plains sites, but still exceeds all sample sites in other ecoregions. The copper concentration reported is the highest in the sample set, exceeding western sites with impacts from mining and mineral processing.

Chemical history. No other data on the water chemistry of this site are known. The U.S. Fish and wildlife service reports no water quality problems or history of visible salinization during low-water conditions.

sediments. The extractable iron concentration of the wET74 sediment sample was one of the highest in the data set, exceeded only by samples from sites with known impacts from mining and mineral processing. Extractable arsenic, copper, nickel and zinc concentrations were at or near the upper end of the ranges shown for sites in the unglaciated plains. Chromium and vanadium concentrations ranked mid-range or lower within the site class. WET74 was one of the few plains sites without a reportable concentration of extractable boron in the sediment sample.

Extractable arsenic, copper, nickel and zinc concentrations exceed the geometric mean values for soils of the western United states by factors of $1.5,2.1,2.3$ and 1.9 respectively. 



\section{Warm Springs Ducks Unlimited Pond}

Climatic setting. The net annual precipitation balance for the Warm Springs DU pond (from the MAPS database) is -20 inches, placing the site mid-range in evaporative intensity when compared to other sites of the intermontane basins. Mean monthly precipitation for the Anaconda climatic station shows a broad summertime maximum. The 3-year running average of annual precipitation was below the long-term average from 1986 through 1992. In 1993 (the year prior to sampling), precipitation exceeded the long-term average by about 8 inches. Regionally, precipitation totals in 1994 were below average.

Geologic setting. The WET75 site is underlain by alluvial fan sediments deposited by Warm Springs Creek. Fan sediments are relatively thin (a few tens of feet) and are underlain by valleyfill sediments of Tertiary age. Recent surficial sediments in the Warm Springs Creek area are pervasively contaminated with mineral processing wastes. Shallow water table depths and ground-water discharge from shallow flow systems characterize the lower warm Springs Creek fan near the WET75 site. Discharge from a deepcirculating geothermal flow system also occurs nearby, supporting the local hot springs.

Hydrologic type. The Ducks Unlimited pond is a depression of unknown origin in the Warm Springs fan sediments, seasonally(?) intersecting the water table surface. The wetland is augmented by water imports diverted from Warm Springs creek. The water body does not appear to have a surface outlet but is inferred to discharge to the shallow ground-water system under at least some conditions.

Basin characteristics. The DU pond has a minimal natural surface catchment but is believed to receive ground-water recharged over a broad area, as well as diverted warm springs creek water. The depth of the small water body is uncertain and has been subject to modification to meet wildlife habitat objectives.

Water chemistry. The DU pond contains dilute calciumsulfate/bicarbonate water with moderately low alkalinity and basic pH. Mineral equilibria indicate slight oversaturation with carbonate phases. Ammonium, nitrate, and phosphorous concentrations rank mid-range with respect to sample sites in the intermontane valleys. (Phosphorous concentrations are low, however, in comparison to other sites lacking surface water outflow.) The total organic carbon concentration was among the lowest sampled.

Trace element concentrations in the water column were generally low. Iron and arsenic concentrations ranked toward the lower end of the ranges shown for western sites. The copper and aluminum concentrations ranked mid-range within the site class, and most other trace elements analyzed occurred at concentrations below 

reporting limits.

Chemical history. No previous chemical data from this site are known.

Sediments. Extractable concentrations of arsenic, chromium, copper, nickel, vanadium and zinc rank near the upper end of the ranges shown for western sites, reflecting contamination of surficial sediments with mineral processing waste. WET75 was also one of the few sites with a reportable mercury concentration (at the reporting limit).

The extractable arsenic, copper, and zinc concentrations exceed the geometric mean soil concentrations for the western United states by factors of $4,4.8$ and 2.4 respectively. Other trace element concentrations are near or below the regional means. 
climatic setting. The net annual precipitation balance for the Warm Springs ponds (from the MAPS database) is -20 inches, placing these sites mid-range in evaporative intensity when compared to other sites of the intermontane basins. Mean monthly precipitation for the Anaconda climatic station shows a broad summertime maximum. The 3-year running average of annual precipitation was below the long-term average from 1986 through 1992. In 1993 (the year prior to sampling), precipitation exceeded the long-term average by about 8 inches. Regionally, precipitation totals in 1994 were below average.

Geologic setting. The Warm springs Ponds are underlain by mill tailings, heavily contaminated historic stream sediments and chemical precipitates deposited by Silver Bow Creek. The ponds are constructed over earlier alluvial deposits of Silver Bow (and Warm Springs?) Creek in the neighborhood of 20 feet in thickness, which in turn overlie Tertiary-aged sediments up to several hundred feet thick.

Hydrologic type. The Warm springs Ponds are a complex of artificial impoundments constructed and managed for the purpose of capturing tailings and treating contaminated streams (Silver Bow Creek, Mill Creek and Willow Creek) draining the Butte and Anaconda areas. Water inflows, outflows, routing and chemistry are manipulated in order to meet water treatment objectives. The design and operation of the ponds have been altered significantly in the past 5 years (see below).

Basin characteristics. Silver Bow creek and most of the flow of Mill and Willow Creeks carried by the Mill-willow Bypass enters Pond \#3 near the WET78 sample site, where continuous pH adjustment by lime injection occurs. Up to $300 \mathrm{cfs}$ is discharged from Pond \#3 by two outflow structures into Pond \#2; Pond \#3 inflow in excess of 300 cfs is routed back into the Mill-willow Bypass and out of the pond system. Outflow from Pond \#2 discharges to the lowermost channel of the Mill-Willow Bypass and on to the Clark Fork River. No water is intentionally routed to Pond \#1, the oldest cell in the pond complex. Seepage from Pond \#2 to the downgradient Pond \#1 occurs, joining precipitation falling on the pond \#1 surface. Ground-water outflow from Pond \#1 to the alluvium downgradient also occurs.

The operation of Pond \#2 changed during the 5 years prior to the DHES sampling in order to improve effluent water quality. The stage of Pond \#2 has been raised in order to permanently flood areas of tailings which in the past were subject to fluctuating water levels and variable redox conditions. Increased head in Pond \#2 appears to have increased ground-water outflow to Pond \#1. Prior to raising water levels in Pond \#2, the surface was treated with lime to immobilize metals. 

The western portion of Pond \#1 has been treated and capped and the process of establishing vegetation on the capped surface begun. Future water levels in the eastern portion of pond \#1 (including the WET76 site) may be manipulated to retain reducing conditions in wetland sediments.

Water chemistry. At the time of sampling, Pond \#1 contained "oligosaline" calcium-sulfate water of low alkalinity and moderately basic pH. Equilibrium calculations indicate moderate oversaturation with carbonate minerals. Nitrogen concentrations (nitrate and ammonium) were below reporting limits. Phosphorous (total and orthophosphate) and total organic carbon concentrations ranked mid-range among sites of the intermontane valleys.

Water-column concentrations of boron, copper, iron, lead and zinc ranked near the upper end of the ranges shown for intermontane sites. The arsenic concentration ranked mid-range, and most other trace elements occurred in concentrations below reporting limits.

Chemical history. Although DHES documents (see bibliography) identify this as a sampling site, no other water chemistry data were recovered. See discussion above for general history of water chemistry factors.

Sediments. Sediments collected at wET76 show the highest extractable concentrations in the sample set for many trace elements, and in general may reflect the most heavily contaminated conditions of the mining-impacted sites. Extractable concentrations of arsenic, chromium, copper, manganese, selenium, and mercury ranked at the top of the range shown by the data set; boron, iron, lead, vanadium, and zinc concentrations rank near the top also. These elements exceed geometric mean values for soils of the western United states by factors ranging from 1.5 to more than 100 . 


\section{Warm Springs Pond 2}

climatic setting. The net annual precipitation balance for the Warm Springs ponds (from the MAPS database) is -20 inches, placing these sites mid-range in evaporative intensity when compared to other sites of the intermontane basins. Mean monthly precipitation for the Anaconda climatic station shows a broad summertime maximum. The 3-year running average of annual precipitation was below the long-term average from 1986 through 1992. In 1993 (the year prior to sampling), precipitation exceeded the long-term average by about 8 inches. Regionally, precipitation totals in 1994 were below average.

Geologic setting. The Warm springs Ponds are underlain by mill tailings, heavily contaminated historic stream sediments and chemical precipitates deposited by Silver Bow Creek. The ponds are constructed over earlier alluvial deposits of Silver Bow (and Warm Springs?) Creek in the neighborhood of 20 feet in thickness, which in turn overlie Tertiary-aged sediments up to several hundred feet thick.

Hydrologic type. The Warm Springs Ponds are a complex of artificial impoundments constructed and managed for the purpose of capturing tailings and treating contaminated streams (Silver Bow Creek, Mill Creek and Willow Creek) draining the Butte and Anaconda areas. Water inflows, outflows, routing and chemistry are manipulated in order to meet water treatment objectives. The design and operation of the ponds have been altered significantly in the past 5 years (see below).

Basin characteristics. Silver Bow Creek and most of the flow of Mill and Willow Creeks carried by the Mill-willow Bypass enters Pond \#3 near the WET78 sample site, where continuous $\mathrm{pH}$ adjustment by lime injection occurs. Up to 300 cfs is discharged from Pond \#3 by two outflow structures into Pond \#2; Pond \#3 inflow in excess of $300 \mathrm{cfs}$ is routed back into the Mill-Willow Bypass and out of the pond system. Outflow from Pond \#2 discharges to the lowermost channel of the Mill-Willow Bypass and on to the Clark Fork River. No water is intentionally routed to Pond \#1, the oldest cell in the pond complex. Seepage from Pond \#2 to the downgradient Pond \#1 occurs, joining precipitation falling on the Pond \#1 surface. Ground-water outflow from Pond \#1 to the alluvium downgradient also occurs.

The operation of Pond \#2 changed during the 5 years prior to the DHES sampling in order to improve effluent water quality. The stage of Pond \#2 has been raised in order to permanently flood areas of tailings which in the past were subject to fluctuating water levels and variable redox conditions. Increased head in Pond \#2 appears to have increased ground-water outflow to Pond \#1. Prior to raising water levels in Pond \#2, the surface was treated with lime to immobilize metals. 

The western portion of Pond \#1 has been treated and capped and the process of establishing vegetation on the capped surface begun. Future water levels in the eastern portion of Pond \#l may be manipulated to retain reducing conditions in wetland sediments.

Water chemistry. At the time of sampling, the WET77 site exhibited dilute, moderately alkaline calcium-bicarbonate/sulfate water. Dissolved solids, $\mathrm{pH}$ and proportional sulfate concentrations were lower than at WET76. Mineral equilibria indicate slight oversaturation with calcium carbonate phases. In contrast to WET77, nitrate and ammonium concentrations were comparatively high. Phosphorous concentrations (total and orthophosphorous) ranked midrange with respect to sample sites of the intermontane valleys, and the total organic carbon concentration was near the low end of the range for the site class.

Water-column concentrations of arsenic, iron, copper and zinc rank mid-range among sites of the intermontane valieys and are of similar magnitude to WET76 concentrations. Most other trace element concentrations were below reporting limits.

Chemical history. Seasonal time-series water chemistry data are presented in DHES documents referenced in the site bibliography.

Sediments. Extractable calcium concentrations in the WET77 sediment sample are high, reflecting liming of the pond saturation of the water column with calcium carbonate. Extractable concentrations of trace elements are generally much lower than at either WET76 or WET78. Arsenic, copper and zinc concentrations exceed geometric means of soils concentrations in the western United States by factors of $2.7,1.4$ and 1.7 respectively. 

climatic setting. The net annual precipitation balance for the Warm Springs ponds (from the MAPS database) is -20 inches, placing these sites mid-range in evaporative intensity when compared to other sites of the intermontane basins. Mean monthly precipitation for the Anaconda climatic station shows a broad summertime maximum. The 3-year running average of annual precipitation was below the long-term average from 1986 through 1992. In 1993 (the year prior to sampling), precipitation exceeded the long-term average by about 8 inches. Regionally, precipitation totals in 1994 were below average.

Geologic setting. The Warm Springs Ponds are underlain by mill tailings, heavily contaminated historic stream sediments and chemical precipitates deposited by Silver Bow Creek. The ponds are constructed over earlier alluvial deposits of silver Bow (and Warm Springs?) Creek in the neighborhood of 20 feet in thickness, which in turn overlie Tertiary-aged sediments up to several hundred feet thick.

Hydrologic type. The Warm Springs Ponds are a complex of artificial impoundments constructed and managed for the purpose of capturing tailings and treating contaminated streams (silver Bow Creek, Mill Creek and Willow Creek) draining the Butte and Anaconda areas. Water inflows, outflows, routing and chemistry are manipulated in order to meet water treatment objectives. The design and operation of the ponds have been altered significantly in the past 5 years (see below).

Basin characteristics. Silver Bow Creek and most of the flow of Mill and willow Creeks carried by the Mill-willow Bypass enters Pond \#3 near the WET78 sample site, where continuous $\mathrm{pH}$ adjustment by lime injection occurs. Up to 300 cfs is discharged from Pond \#3 by two outflow structures into Pond \#2; Pond \#3 inflow in excess of $300 \mathrm{cfs}$ is routed back into the Mill-willow Bypass and out of the pond system. Outflow from Pond \#2 discharges to the lowermost channel of the Mill-Willow Bypass and on to the Clark Fork River. No water is intentionally routed to Pond \#1, the oldest cell in the pond complex. Seepage from Pond \#2 to the downgradient Pond \#1 occurs, joining precipitation falling on the Pond \#1 surface. Ground-water outflow from Pond \#1 to the alluvium downgradient also occurs.

The operation of Pond \#2 changed during the 5 years prior to the DHES sampling in order to improve effluent water quality. The stage of Pond \#2 has been raised in order to permanently flood areas of tailings which in the past were subject to fluctuating water levels and variable redox conditions. Increased head in Pond \#2 appears to have increased ground-water outflow to Pond \#1. Prior to raising water levels in Pond \#2, the surface was treated with lime to immobilize metals. 
The western portion of Pond \#1 has been treated and capped and the process of establishing vegetation on the capped surface begun. Future water levels in the eastern portion of Pond \#1 may be manipulated to retain reducing conditions in wetland sediments.

Water chemistry. At the time of sampling, Pond \#3 at WET78 exhibited relatively dilute, moderately alkaline calciumbicarbonate chemistry. Mineral equilibria indicate near-saturation with carbonate phases. Nitrogen and phosphorous concentrations rank mid-range in comparison to other sites of the intermontane valleys. The total organic carbon concentration was low in comparison to other sites in this class. Water-column concentrations of arsenic, copper, cadmium, iron and zinc rank at or near the upper end of the ranges shown by intermontane valley sites, and are generally higher than those at the other two warm Springs Ponds sites. Other trace element concentrations were below reporting limits.

Chemical history. No other chemical data from this site are known. Data from a site approximately 1 mile from WET78 include seasonal time-series water quality analyses. See the site bibliography for references.

Sediments. Sediments from WET78 display highly elevated concentrations of trace elements. Extractable concentrations of arsenic, copper, lead, mercury, selenium, and zinc near the top of the ranges shown by sites of the intermontane valleys, and for most elements are exceeded only at other sites contaminated with mining and mineral processing wastes. Extractable concentrations of all of these elements (and boron) exceed the geometric mean values for soils of the western Unites States by up to factors of 50 . 



\section{White Lake}

climatic setting. The net annual precipitation balance for white Lake derived from the MAPS database is -23 inches, toward the less evaporative end for sites in this class. Based on analyses of evaporation pan data, this is a considerable underestimate white Lake's water deficit, and points out the need to view the MAPS estimates only as relative indicators of net site precipitation. Mean monthly precipitation for the Medicine Lake climatic station shows a pronounced June maximum. Annual totals for this station show apparent periodicity with a 5 to 7 year cycle. Throughout the 1980 s, the 3-year running average remained below (often well below) the long-term average, recovering in the early 1990s. In 1993 (the year before sampling) precipitation exceeded the long-term average by more than 1 inch.

Geologic setting. White Lake occupies an ice-block depression (kettle) on the margin of the late Pleistocene outwash sand and gravel forming the clear lake aquifer. Surficial sediments within the lake basin are dominated by authigenic sulfate minerals precipitated from in-flowing ground water and fine-grained glaciolacustrine sediments contrasting with the permeable sand and gravel of the Brush Lake basin. Glacial sediments are underlain at depth by the early Tertiary Fort Union Formation.

Hydrologic type. White Lake is an ephemeral saline playa which receives in-flowing ground water (depleted in calcium through carbonate precipitation in upgradient Brush Lake) and has restricted ground-water outflow. White Lake lacks significant surface water inflow or outflow.

Basin characteristics. The shallow White Lake depression has a minimal surface catchment beyond the playa surface; the lake's water and solute budgets contrast with those of adjacent Brush Lake due to distinct aquifer permeabilities, different lake geometries and different influent water chemistry. The resulting lake water chemistries are markedly different but genetically related as components of a serial system of ground-water supported lakes which responds to variations in aquifer head with changes in lake area, volume and water chemistry.

Water chemistry. White Lake contains highly alkaline "hypersaline" sodium sulfate brine with very high ammonium concentration and total organic carbon concentrations and exceptionally high phosphorous concentration. Due to depletion through carbonate precipitation in Brush Lake, the influent calcium concentration in White Lake is very low and authigenic sedimentation is dominated by mirabilite (Na2SO $4 * 10 \mathrm{H} 2 \mathrm{O})$; mineral equilibria indicate slight undersaturation with respect to mirabilite at the time of the DHES sampling.

The concentrated white Lake brine exhibited the highest arsenic and second-highest boron concentrations of the sample set. The zinc 

and iron concentrations were also high, with most higher concentrations reported from sites of known contamination with mining and mineral processing waste. Most other trace element concentrations were below reporting limits.

Chemical history. Previous chemical data from the white Lake basin were collected on shallow ground-water samples drawn from beneath the playa surface or from peripheral ponds known as East and West White Lakes, which exhibit much more dilute water chemistry. The shallow ground-water samples (collected in 1990 at a time of little or no surface water in the playa) were more concentrated than the WET79 sample; density gradients may maintain salinity contrasts between the shallow ground water brine and surface water during periods of inundation. Generally, white Lake probably exhibits substantial salinity variation but remains hypersaline in character.

Sediments. Authigenic sediments in the white Lake basin are dominated by sodium sulfate salts not represented in the DHES sediment analysis. Relatively high calcium and magnesium concentrations may reflect both detrital sediments and minor authigenic carbonate precipitation.

The extractable arsenic concentration was the highest for any sample site not impacted by mining wastes, and exceeded all other Great Plains sites by a wide margin. The boron concentration reported also ranks relatively high. Extractable iron, vanadium and zinc concentrations were relatively low, and most other trace element concentrations were below reporting limits. Extractable arsenic and boron concentrations exceeded geometric mean soil concentrations for the western United States by factors of 13.9 and 2.4 , respectively. 

Climatic setting. The net annual precipitation balance for WET 80 (from the MAPS database) is -30 inches, placing it at the more intensely evaporative extreme of the data set. Mean monthly precipitation for the Miles City climatic station shows a pronounced June maximum. Annual total precipitation was below the long-term average most years during the 1980s, while precipitation in the 1991-1993 period was at or above the long-term average. water supply to the WET80 wetland is, however, probably tied closely to the stage of the Yellowstone River, which is influenced by precipitation and other climatic conditions throughout the basin.

Geologic setting. The WET80 site occupies an abandoned side channel of the Yellowstone River, developed along the edge of the modern floodplain and just below the edge of the older alluvial terrace underlying most of Miles City. The adjacent and underlying(?) bedrock is the Tullock member of the early Tertiaryaged Fort Union Formation. The alluvium is described as relatively coarse-grained and permeable; water table elevations are shallow, and are apparently intersected by the old channel swale containing the wetland. Geologic structures to the east and west generate pressure head in the Fort Union and underlying Hell Creek aquifers. Flowing wells (and by inference, discharge to the shallow alluvial aquifer system) occur in the vicinity of Miles city.

Hydrologic type. The Yellowstone River "oxbow" (sic) occupies a modified natural channel originating near the confluence of the Yellowstone and Tongue Rivers and passing through Miles City before rejoining the Yellowstone channel. The channel appears to intersect the water table of the alluvial aquifer in places. The wetland receives intermittent surface water inflow and, probably, ground-water discharge from the Yellowstone River alluvium. Outflow occurs via a high-water channel to the Yellowstone River. Rates of flux through the wetland probably depend on the stage of the Yellowstone and Tongue Rivers and on related water levels in the alluvial aquifer underlying the floodplain.

Basin characteristics. WET80 has a small local surface catchment heavily modified by urban activities and structures. Ground water inferred to support the wetland is probably recharged in part by the mainstem Yellowstone River. The depth and volume of the wetland water body and the frequency of surface inflow and outflow are not known.

The WET80 site is the only one of the sample sites where urban land uses dominate the wetland catchment.

Water chemistry. At the time of sampling, the WET80 site displayed near-neutral, "oligosaline" sodium-sulfate/carbonate water with a depressed dissolved oxygen concentration and relatively high total 

alkalinity. Equilibrium calculations indicate moderate oversaturation with respect to carbonate minerals. Depressed dissolved oxygen and apparent non-equilibrium of $\mathrm{pH}$, carbonate and bicarbonate with surface conditions may reflect ground-water discharge to the WET80 site. The high sodium concentration (64\% of the cation load in meq/1) may reflect some input from deeper aquifers to the alluvial gravel aquifer.

The nitrate concentration at WET80 was below the reporting limit; the ammonium concentration was among the highest for sample sites from the unglaciated plains province. Phosphorous concentrations were also relatively high, exceeded in the region mainly by closedbasin sites. The total organic carbon concentration ranked midrange among sites of the plains.

Arsenic, boron, and copper concentrations ranked mid-range or lower in comparison to the site class, while iron and lead concentrations ranked relatively high. Most other trace elements analyzed were below reporting limits.

Chemical history. No previous data from this site are known.

Sediments. Most extractable trace element concentrations are relatively low in comparison to other sites of the unglaciated plains. Extractable lead and zinc concentrations, however, rank relatively high, and in the case of lead are exceeded almost entirely by sites with known impacts from mining or mineral processing. Boron, lead and zinc concentrations exceed geometric mean concentrations for soils of the western United states by factors of $2.3,2.4$ and 1.5 , respectively. Other trace element concentrations reported are below regional geometric mean soil values. 
.

(1)

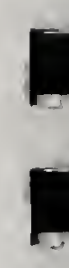

IJ

F

s

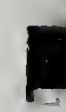

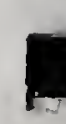

(2)

5

5

D 